\title{
Koalitionsbildungen und Koalitionsstrategien im neuen Fünfparteiensystem der Bundesrepublik Deutschland
}

\section{Kurzfassung}

Koalitionsbildungen werden in der älteren international vergleichenden Koalitionsforschung vorwiegend spieltheoretisch aus dem Interesse der Parteien am Ämtererwerb, an der Durchsetzung politischer Inhalte und an der Stimmenmaximierung erklärt. Eine Überprüfung dieser Theoreme an der empirischen Praxis in Deutschland zeigt, dass sich damit die innere Mechanik der Koalitionsbildungen tatsächlich bis zu einem bestimmten Grad erklären lässt. $\mathrm{Zu}$ diesem Zweck wurden hier erstmals alle 341 Regierungsbildungen, die es in Deutschland auf Bundes- und Landesebene von 1946 bis 2010 gegeben hat, erfasst und einem Koalitionsformat zugeordnet. Dabei zeigt sich, dass Koalitionstheorien im Kontext des jeweiligen Regierungs- und Parteiensystems besonders aussagekräftig sind - eine Tatsache, die auch die Spieltheorie in immer ausgefeilteren Modellen zu berücksichtigen versucht. In Deutschland ging mit der Konsolidierung der bundesdeutschen Kanzlerdemokratie nach dem Zweiten Weltkrieg und der Herausbildung eines zentrierten Dreiparteiensystems die Professionalisierung der Parteien einher, die seit 1961 in der Regel nur noch Koalitionen minimaler Mehrheit und größter ideologischer Verbundenheit geschlossen haben. Diese Gesetzmäßigkeiten der Koalitionsbildung setzten sich im bipolaren Vierparteiensystem von 1990 bis 2005 fort. Selbst im multioptionalen Fünfparteiensystem seit 2005 hat sich bisher wenig an den eingefahrenen Mustern der Koalitionsbildung geändert. Nur das verminderte Auftreten von Einparteiregierungen und eventuell die leichte Zunahme von Minderheitsregierungen deuten den erhöhten Stress im Parteiensystem an. Für ein annähernd vollständiges Verständnis der deutschen Koalitionsbildungen müssen darüber hinaus die Koalitionsstrategien der Parteien im Kontext des deutschen Verbundsföderalismus und deren abgestufte Koalitionsaussagen vor den Wahlen berücksichtigt werden. 


\section{Inhalt}

1. Einleitung 328

2. Koalitionsbildungen in der Theorie 331

3. Koalitionsbildungen in der Bundesrepublik Deutschland:

Historische Muster

a) Koalitionsbildungen im polarisierten Mehrparteiensystem (1946 bis 1961)

b) Koalitionsbildungen im zentrierten Dreiparteiensystem (1961 bis 1990)

c) Koalitionsbildungen im bipolaren Vierparteiensystem (1990 bis 2005)

4. Koalitionsbildungen im multioptionalen Fünfparteiensystem seit 2005355

a) Die Bildung der Großen Koalition nach der Bundestagswahl 2005356

b) Koalitionsbildungen in den Ländern im Schatten der Großen Koalition

c) Koalitionsbildungen in den Ländern im Vorfeld der Bundestagswahl 2009

d) Bundespräsidenten- und Europawahl 2009 als Signale für Schwarz-Gelb

e) Die Bildung der schwarz-gelben Koalition nach der Bundestagswahl 2009

f) Koalitionsbildungen in den Ländern im Schatten der neuen Koalition

g) Koalitionsbildung in Nordrhein-Westfalen und Bundespräsidentenwahl 2010: Comeback von Rot-Grün?

\section{Einleitung}

Was bei den drei Bundestagswahlen zuvor nur befürchtet, aber knapp vermieden worden war, trat 2005 schließlich ein: Keine der beiden Volksparteien Union und SPD war mehr in der Lage, mit nur einem kleinen Partner eine Koalition zu bilden. Das Patt zwischen dem schwarz-gelben und dem abgewählten rot-grünen „Lager“ war auch dem Erstarken der Linken geschuldet, die mit ihren 54 Abgeordneten zur viertstärksten Kraft im Deutschen Bundestag wurde. Gebildet wurde aus der Not heraus die einzig mögliche Zweier-Koalition: 
die Große Koalition. In ihr hatten sich die Wahlverlierer, die zusammen nur etwas mehr als die Hälfte der Wahlberechtigten hinter sich gebracht hatten, in den Worten von Vizekanzler Franz Müntefering zu einer „Lebensabschnittspartnerschaft" (Doemens 2005) vereinigt, deren kurze Lebensdauer von vornherein programmiert war. Bereits in der Mitte der Wahlperiode war der gemeinsame Vorrat an politischen Vorhaben so weit aufgebraucht und hatten die beiden Partner, allen voran die SPD, an der Wahlurne und in den Umfragen derart Federn lassen müssen, dass zumindest öffentlich niemand mehr eine Überführung der Notlösung in den Normalfall anzustreben wagte. Mit den Landtagswahlen seit Januar 2008, der Bundespräsidenten- und der Europawahl bereiteten sich SPD und Union auf den Bundestagswahlkampf 2009 und die Zeit nach der Großen Koalition vor. Den Koalitionsaussagen und den Wahlumfragen zufolge war 2009 (ähnlich wie 2005) überhaupt nur eine einzige Koalitionsbildung realistisch: die schwarz-gelbe. Anders als vier Jahre zuvor folgten die Wähler diesmal dem Angebot von Union und FDP und statteten sie tatsächlich mit dem Auftrag zur Regierungsbildung aus.

Die Bundestagswahl 2009 führte somit doch wieder zu einer Zweier-Koalition mit einem großen (Union) und einem kleinen Partner (FDP). Auf den ersten Blick bestätigte sie scheinbar die Zwei-Lager-Geografie des bipolaren Vierparteiensystems, indem sie dem selbsterklärten „bürgerlichen Lager“ zur Mehrheit verhalf. Schon bald zeigte sich jedoch, dass diesem Lager das Widerlager abhanden gekommen war: Die SPD versammelte nicht einmal mehr ein Viertel der Wählerstimmen auf sich, zusammen kam Rot-Grün auf gerade ein Drittel der Stimmen. Der Schwäche und Zersplitterung der Opposition war es zuzuschreiben, dass der Koalition der gemeinsame Gegner als integrativer Faktor fehlte und sich so schon im Prozess der Koalitionsbildung tiefe Risse zeigten, die auch im ersten halben Jahr des Regierens nicht übertüncht werden konnten. Schwerer aber noch wog der Druck der immensen sachpolitischen Probleme, die eigentlich keinen Aufschub duldeten - den die Koalitionspartner gleichwohl mit Blick auf den befürchteten Verlust der Bundesratsmehrheit bis zur Landtagswahl im Mai 2010 in Nordrhein-Westfalen vereinbarten. Der überraschende Rücktritt von Bundespräsident Horst Köhler am 31. Mai 2010 stellte die Koalition dann vor eine weitere Zerreißprobe, die sie nur mühsam bestand. Der schwere Start der schwarz-gelben Koalition zeigte einmal mehr, wie sehr die alten Lager und die mit ihnen gleichsam naturgegebenen Koalitionen im neuen beweglichen Fünfparteiensystem der Bundesrepublik, in dem sich die gesamtdeutsche Linke auch im Westen etabliert hat, unter Druck stehen (Niedermayer 2007, 2008). 
Dies hatten im Prinzip schon die - oft umkämpften und in sich nicht immer stabilen - Regierungsbildungen in den Ländern seit der Wahl in Hessen im Januar 2008 gezeigt, wo SPD-Spitzenkandidatin Andrea Ypsilanti gleich zweimal mit dem Versuch scheiterte, eine von den Linken tolerierte rot-grüne Koalition zu bilden (Zastrow 2009). Ministerpräsident Roland Koch stand so ein Jahr lang geschäftsführend einer CDU-Minderheitsregierung vor. In Hamburg kam es im Frühjahr 2008 zur ersten schwarz-grünen Koalition auf Landesebene, in Bayern musste die CSU im Herbst desselben Jahres erstmals seit 46 Jahren überhaupt wieder einen Koalitionspartner, die FDP, in die Regierung aufnehmen. Im Anschluss an die sechs Landtagswahlen im Jahre 2009 kam es zwar in drei Fällen zur Bildung gewohnter schwarz-gelber Koalitionen (Hessen, Sachsen, Schleswig-Holstein), in Brandenburg jedoch tauschte Ministerpräsident Matthias Platzeck (SPD) den langjährigen Koalitionspartner CDU gegen die Linke aus. In Thüringen und im Saarland sondierte die SPD ebenfalls in Richtung einer Koalition mit der Linken und den Grünen, konnte oder wollte diesen Linkskoalitionen aber nicht zum Erfolg verhelfen. Im Saarland entschieden sich die Grünen für die erste ,Jamaika“-Koalition in einem Bundesland. Nur acht Monate später, am 14. Juli 2010, wählten die Grünen jedoch in Nordrhein-Westfalen mit Hannelore Kraft wieder eine Sozialdemokratin zur Ministerpräsidentin einer Minderheitsregierung, die sich von der Linken tolerieren ließ. Im November zerbrach dann, drei Monate nach dem Rücktritt von Bürgermeister Ole von Beust, die schwarz-grüne Koalition in Hamburg nach nur 32 Monaten Dauer.

Es ist Ziel dieses Aufsatzes, die innere Mechanik der Koalitionsstrategien und der tatsächlichen Koalitionsbildungen der Parteien in Deutschland zu entschlüsseln. Im folgenden Kapitel sollen zunächst die zentralen theoretischen Befunde der Koalitionsforschung rekapituliert und in Kapitel drei an der empirischen Praxis in der Bundesrepublik Deutschland nach dem Zweiten Weltkrieg überprüft werden. Zu diesem Zweck wurden erstmals alle 341 Regierungsbildungen, die es in Deutschland auf Bundes- und Landesebene von 1946 bis 2010 gegeben hat, erfasst und einem Koalitionsformat zugeordnet (Tabelle A1 im Anhang). Dabei zeigt sich, dass die Erklärungskraft der herkömmlichen office-, policy- und vote-seeking-Theoreme durchaus nicht so gering ist, wie oftmals moniert wurde. ${ }^{1}$ Das gilt zumal dann, wenn die spieltheoretischen Mo-

1 Vgl. die wiederkehrende Kritik an den frühen, allzu schlichten spieltheoretischen Modellen bei Nolte 1988, bei Jun 1994, 2007 bei Kropp 1999, 2001, 2008, bei Kropp/Schüttemeyer/Sturm 2002 oder bei Decker 2009. Alle genannten Autoren sind sich weitgehend einig in ihrem Plädoyer für eine neo-institutionalistisch ausgerichtete Weiterentwicklung der Koalitionstheorie und haben dazu auch bereits erste Hypothesen entwickelt. 
dellannahmen nicht verabsolutiert, sondern in den historischen und institutionellen Kontext eingebettet werden, wie es sich für jede anspruchsvolle geistesund sozialwissenschaftliche Studie gehört. Besonderes Augenmerk richtet die nachfolgende Untersuchung demzufolge auf die historischen Muster der Koalitionsbildungen in Deutschland, die in erster Linie ein Resultat von strategischen Wahlentscheidungen der politischen Akteure sind. Dabei sollte es als Gemeinplatz gelten, dass die Handelnden in ihren Entscheidungen nie so frei sind, wie sie es gerne wären oder sich gelegentlich auch selbst wähnen. Politische Akteure sind bei aller grundsätzlichen Entscheidungsfreiheit in der Koalitionswahl auf vielfältige Weise wahlsoziologisch, institutionell, historisch und kulturell vorgeprägt.

\section{Koalitionsbildungen in der Theorie}

In parlamentarischen Regierungssystemen ist es - noch vor der Gesetzgebung - die vornehmste Aufgabe des gewählten Parlaments, eine Regierung zu bilden und im Amt zu halten (Bagehot 1867/72: 167). In Deutschland und den pluralistischen europäischen Demokratien der Gegenwart sind absolute Mehrheiten einer Partei bei Wahlen nur in Ausnahmefällen möglich - wenn mehrheitsverstärkende Effekte des Wahlrechts oder Besonderheiten der politischen Kultur zur Geltung kommen (Saalfeld 2007: 201-253). Unter den europäischen Einparteiregierungen sind sogar Minderheitskabinette häufiger als solche, die sich auf eine parlamentarische Mehrheit stützen können (Gallagher/Laver/Mair 2006: 401). Wo Minderheitskabinette nicht wie üblicherweise in Deutschland ein Übergangsphänomen im Gefolge des Scheiterns einer Regierungskoalition oder einer Regierungsbildung darstellen, sind sie auf Kooperationen weiterer Parteien angewiesen, wollen sie politische Ziele inhaltlicher Art durchsetzen. Insofern sie nicht selbst schon Koalitionen sind, stellen Minderheitsregierungen Vorstufen zur Koalition dar - eine Art informaler oder parlamentarischer Koalition - und verweisen darauf, dass Wettbewerb und Kooperation von Parteien sich bereits vor (und nach) jeglicher Koalitionsbildung in einem unauflösbaren Spannungsverhältnis zueinander befinden. In der Mehrzahl der Fälle jedoch sind europäische Regierungsbildungen formale Koalitionsbildungen von mindestens zwei Parteien, die mit einer parlamentarischen Mehrheit ausgestattet sind (Müller/Bergman/Strom 2008: 8).

Die Koalitionsforschung hat drei Entwicklungsstadien durchlaufen und in deren Folge auch drei inhaltliche Schwerpunkte ausgebildet: Zunächst fragte sie vor allem danach, warum sich bestimmte (Typen von) Koalitionen bilden 
und andere nicht; danach interessierte sie sich für das Ende, damit auch für die Dauer und Überlebensfähigkeit von Koalitionen, bevor sie sich schließlich auch stärker dem Innenleben von Koalitionen, ihrem Alltagshandeln und Koalitionsmanagement zuwandte (Kropp/Schüttemeyer/Sturm 2002: 7). An dieser Stelle soll es im Kern um die wissenschaftsgeschichtlich ,älteste“ Frage nach der Koalitionsbildung gehen, wobei sich die Fragen nach der Dauer und Stabilität wie auch nach dem Alltagshandeln und Management der so gebildeten Koalitionen davon nicht fein säuberlich trennen lassen. Die Annahme, dass dieses möglich sei, war ein Hauptfehler der älteren ämterbezogenen wie auch noch der policy-orientierten Rational-Choice-Ansätze. Neo-institutionalistische und auch deskriptive Erklärungsansätze, die gegenüber den Präferenzen der politischen Akteure das Gewicht institutioneller Faktoren bei der Koalitionsbildung betonten, hatten von vornherein ein stärker entwickeltes Sensorium für die Tatsache, dass alle drei Phasen im ,demokratischen Lebenszyklus" einer Koalition ineinander übergehen und sich demzufolge auch gegenseitig bedingen (Strom/Müller/Bergman 2008). Der Methodenstreit soll hier jedoch nicht geführt werden; mit Martin und Stevenson (2001) gilt es festzuhalten, dass die Koalitionsforscher ihre Differenzen überbetont und ihre Übereinstimmungen nur allmählich anerkannt haben. Die Herausforderung für die Koalitionsforschung ist es, alle verschiedenen spieltheoretischen, neo-institutionalistischen und politisch-kulturellen Erklärungsansätze ,,in eine einzige kohärente Theorie zu integrieren“ (49) - oder aber sich jeweils eklektisch der geeigneten Methoden für ihre Ziele zu bedienen.

Für unsere Zwecke heißt das, dass in etwa folgendes Hypothesengerüst die Herangehensweise in den nachfolgenden Kapiteln leiten soll: Die bundesdeutschen Parteien und ihre führenden Repräsentanten werden als überwiegend rationale politische Akteure verstanden, die zumeist versuchen, gemäß dem office seeking-Theorem den maximalen Gewinn an Regierungsämtern für sich selbst und ihre Partei herauszuschlagen. Wenn möglich bilden sie demzufolge am liebsten Koalitionen mit kleinstmöglicher Mehrheit (KMK, minimum winning coalitions). Da in der politischen Realität solche Rationalitätskriterien jedoch nicht immer auf die Spitze getrieben werden, begnügen sich die Parteien oftmals mit der Bildung minimaler Mehrheitskoalitionen (MMK, minimal winning coalitions). Auch diese zeichnen sich wie KMK dadurch aus, dass alle Partner für die Mehrheitsbildung unverzichtbar sind; es werden jedoch auch Lösungen zweit- oder drittbester Wahl akzeptiert. Dies lässt sich damit erklären, dass Parteien eben nicht nur nach Ämtergewinn streben, sondern als policy seeker vor allem Politikinhalte verwirklichen wollen. Sie bevorzugen 
deshalb in der Regel Partner, mit denen sie die größte ideologische Nähe verbindet (minimal range oder minimal connected winning coalitions). Als Stimmenmaximierer (vote seeker) gehen sie jedoch nicht jede Koalition und jeden inhaltlichen Kompromiss ein, sondern ziehen gegebenenfalls die Opposition vor, um auch bei den nächsten Wahlen erfolgreich abschneiden zu können (Müller 2004).

Bei Koalitionsbildungen hat sich auch in Deutschland die proportionale Aufteilung der Ministerien auf die Koalitionspartner als kooperative Norm durchgesetzt, wobei die kleineren Parteien - auch aufgrund des lange Zeit in Kraft befindlichen Dreiparteiensystems - überproportional berücksichtigt werden (Linhart/Pappi/Schmitt 2008). Dass die Grünen und die Linke von ihren Seniorpartnern nicht ganz so großzügig behandelt werden wie CSU und FDP, ist vermutlich auf ihre anfängliche Fundamental- bzw. Systemopposition zurückzuführen: Sie mussten den Test der Regierungsfähigkeit und -willigkeit erst bestehen. Auch dass sie insgesamt noch nicht so häufig als Koalitionspartner berücksichtigt wurden, hängt mit ihrer überproportional häufig angezweifelten Regierungsfähigkeit zusammen - aber auch mit ihren eigenen politischen Präferenzen, die generell als stärker policy- denn ämterorientiert bezeichnet werden können (Dumont/Bäck 2006). Schließlich ist zu Recht darauf hin- und empirisch nachgewiesen worden, dass die Parteien nicht nur auf ihren gerechten „Beuteanteil“" aus sind, sondern als policy seeker bestimmte Ministerien höher gewichten als andere: So messen auf Landesebene Union und FDP dem Wirtschaftsministerium, Linke, Grüne und SPD dem Arbeits- und Sozialministerium, die Grünen auch dem Umweltministerium besondere Bedeutung zu. Ihre Wünsche setzen sie jedoch - auch in Abhängigkeit vom Koalitionspartner - in unterschiedlichem Maße durch. Während die Grünen häufig den Umweltminister stellen, besetzen sie nur selten das Arbeits- und Sozialministerium, das Domäne der SPD ist. Die FDP erobert oft das Wirtschaftsministerium, der Union gelingt dies vergleichsweise seltener. Dafür erringt sie vergleichsweise häufig die programmatisch eher nachrangigen Ressorts Landwirtschaft, Kultus und Finanzen (Pappi/Schmitt/Linhart 2008: 332-338).

Die Rationalität politischer Akteure hat jedoch ihre Grenzen - anders formuliert: Sie entfaltet sich innerhalb je spezifischer Grenzen, die ihr von institutionellen und politisch-kulturellen Rahmenbedingungen gesetzt werden. $\mathrm{Zu}$ den institutionellen Bedingungen zählen in erster Linie bestimmte Struktureigenschaften des Regierungs- sowie des Wahl- und des Parteiensystems. Parlamentarische Regierungssysteme wie das deutsche sind in der Regel dadurch gekennzeichnet, dass sie - anders als präsidentielle Regierungssysteme - 
festgefügte exekutive Koalitionen bevorzugen (Decker 2009: 437). In der bundesdeutschen parteienstaatlichen Variante mit „Kanzlerdominanz“ (Steffani 1997b: 120) bedeutet dies, dass die Parteien - faktisch vor allem die Fraktionen (Schüttemeyer 1998, 1999) - autonome Akteure im Koalitionsbildungsprozess sind. Das Staatsoberhaupt nimmt auf die Koalitionsbildung, anders als in Systemen mit Präsidialdominanz oder einem einflussreichen Monarchen, nicht einmal im Falle einer hartnäckigen Regierungskrise Einfluss. In Deutschland hat sich die ungeschriebene Norm etabliert, dass während einer laufenden Wahlperiode die Kanzlerpartei und nach den Wahlen der „Kanzlerkandidat“ der stärksten Partei bzw. der siegreichen Koalition automatisch das erste Zugriffsrecht auf die Koalitionsbildung haben. Nur Gerhard Schröder versuchte nach der Bundestagswahl 2005 diese Norm zu durchbrechen: erfolglos.

Die Partei des Regierungschefs genießt in Deutschland auch dadurch weitere institutionelle Absicherungen, dass der Kanzler nur durch konstruktives Misstrauensvotum gestürzt werden kann und dass er durch eine Investiturabstimmung mit absoluter Mehrheit ins Amt gewählt werden muss. Die vergleichende Koalitionsforschung gebraucht dafür den Begriff des „positiven Parlamentarismus" und ist der Auffassung, dass Minderheitsregierungen so erschwert und Koalitionsverhandlungen im Vergleich zu Ländern mit „,negativem Parlamentarismus" tendenziell verlängert werden (Bergman u. a. 2003: 148-152). Hinzuweisen ist aber darauf, dass Parlamentarismusforscher älterer Schule die Investiturabstimmung nur als Formalität betrachtet haben (von Beyme 1999: 43). Auch ist Investitur nicht gleich Investitur, wie besonders gut an den vielfältigen Regelungen und unterschiedlichen, je nach Wahlgang abgestuften Mehrheitserfordernissen bei der Investitur deutscher Ministerpräsidenten zu studieren ist (Ley 2010).

Verfassungsrechtliche Kontinuitätsregeln sind in ihrer Wirkung ebenfalls umstritten: Sie könnten es einem amtierenden Regierungschef auch über das Ende einer Wahlperiode hinaus erleichtern, im Amt zu verweilen, wenn er seine Mehrheit verloren hat (De Winter/Dumont 2008: 142). In der politischen Praxis bleibt die Regierung jedoch auch in den Ländern, in denen sie mit $\mathrm{Zu}$ sammentritt des neugewählten Parlaments zurücktreten muss, geschäftsführend im Amt, so etwa in Hessen im April 2008 die CDU-Minderheitsregierung von Roland Koch (Ley 2010: 399). Abschließend sei von den zahlreichen verfassungsrechtlichen Bestimmungen, die die Wahlfreiheit der politischen Akteure bei der Koalitionsbildung beeinflussen, noch das Recht zur Parlamentsauflösung genannt: Wo Regierungschefs vollkommen disponibel über dieses Recht verfügen können wie in Großbritannien, Schweden oder Portugal (Berg- 
man u. a. 2003: 186-188), haben ihre Parteien gegenüber aktuellen und potenziellen Koalitionspartnern einen Vorteil im Handeln und Verhandeln. Deutschen Regierungschefs in Bund und Land sind in dieser Hinsicht die Hände stärker gebunden: Sie müssen wie Gerhard Schröder 2005 oder Peter Harry Carstensen $2009 \mathrm{zu}$,unechten Vertrauensfragen“ greifen, um das Parlament auflösen zu können (Horst 2010: 372-376).

Vielleicht noch stärker als verfassungsrechtliche Regelungen wirken die Charakteristika des Wahl- und des Parteiensystems auf die Koalitionsbildungen und Koalitionsstrategien der politischen Akteure ein. Nur Systeme relativer Mehrheitswahl erzeugen mit einiger Verlässlichkeit Zweiparteiensysteme und vermindern damit die Notwendigkeit, überhaupt Koalitionen bilden zu müssen. Wenn doch einmal der Zwang zur Koalitionsbildung entsteht wie 2010 in Großbritannien, so hat die siegreiche der beiden großen Parteien einen koalitionsstrategischen Vorteil, der allerdings weniger aus der Verhandlungssituation als aus Parametern der politischen Kultur - the winner takes it all - zu resultieren scheint (Hough/Fisher 2010: 735-738). Auch Verhältniswahlsysteme können ausgeprägt mehrheitsverstärkende Effekte haben, wenn die Stimmenverrechnung zum Beispiel wie in Spanien auf der Ebene der (unterschiedlich großen) Wahlkreise erfolgt. Vor allem in den kleinen Wahlkreisen kommt es zu einem künstlich erhöhten Sperrklauseleffekt, der die Konzentration im Parteiensystem befördern und so ebenfalls die Notwendigkeit zur Koalitionsbildung reduzieren kann. In Spanien hat das Wahlsystem zu einem Quasi-Zweiparteiensystem geführt, in dem die ursprünglich durchaus zahlreichen Klein- und Regionalparteien auf nationaler Ebene zur Bedeutungslosigkeit verurteilt sind. Alleinregierungen einer Partei, ob mit parlamentarischer Mehrheit oder ohne, sind dort die Norm (Nohlen 2009: 357-364).

Sperrklauseln in Verhältniswahlsystemen bieten ebenso wie Elemente der relativen Mehrheitswahl Anreize zur Parteienkooperation im Vorfeld von Wahlen: Die CDU der Adenauer-Ära hat Wahlabsprachen mit bürgerlichen Kleinparteien getroffen, um deren Abgeordneten die Eroberung eines Direktmandats zu ermöglichen. Die Zweistimmen-Konstruktion des Bundestagswahlrechts ermöglicht den Wählern ein strategisches Wählen über das Stimmen-Splitting und lädt damit die Parteien zur Kooperation im Wahlkampf ein. In Deutschland hat dies dazu geführt, dass die Parteien meistens vor Wahlen ihre Koalitionsabsichten verkünden, um nicht potenzielle Stützstimmen ihres potenziellen Koalitionspartners zu verschenken. Die kleinen Parteien profitieren davon mehr noch als die großen, weil ihnen die für die Mandatsverteilung entscheidende Zweitstimme ,geborgt“ wird, während die großen Parteien von 
den geliehenen Erststimmen nur dann einen zusätzlichen Gewinn haben, wenn sie Überhangmandate erzielen (337-346). Lediglich hingewiesen sei an dieser Stelle auf die Tatsache, dass das Single Transferable Vote-System nach irischem Muster oder das französische absolute Mehrheitswahlsystem mindestens ebenso starke Anreize zur Bildung ,prä-elektoraler Koalitionen“ setzen (Debus 2007, Golder 2006).

Wahl- und Parteiensystem hängen bekanntlich eng zusammen; gelegentlich werden aber die Auswirkungen des Ersteren auf das Letztere überschätzt. Das Parteiensystem eines Landes ist mindestens ebenso sehr das Resultat seiner gesellschaftlichen Konfliktlinien und politischen Kultur wie seines Wahlsystems. Das Parteiensystem setzt folglich auch unabhängig vom Wahlsystem entscheidende Parameter für das Koalitionshandeln der politischen Akteure. Schon das schlichte Format des Parteiensystems - Zwei-, Mehr- oder Vielparteiensystem (Duverger 1959) - ist von nicht zu unterschätzender Bedeutung für die zur Verfügung stehenden Koalitionsoptionen. Bei den Mehr- (drei bis fünf Parteien) und Vielparteiensystemen (mehr als fünf Parteien) ist darüber hinaus das Größenverhältnis der Parteien zueinander, gemessen durch die ,effektive Parteienzahl““ (Laakso/Taagepera 1979), von entscheidender Bedeutung für die Art und Weise, wie der Parteienwettbewerb funktioniert. Um nur ein simples Rechenbeispiel zu geben: In einem System mit vier Parteien macht es einen fundamentalen Unterschied, ob zwei große Parteien mit jeweils 45 Prozent und zwei kleine Parteien mit jeweils fünf Prozent der Mandate die parlamentarische Arena bevölkern (effektive Parteienzahl: 2,4) oder aber vier gleichgroße Parteien mit jeweils 25 Prozent (effektive Parteienzahl: vier). Für Deutschland lässt sich die Bedeutung der Größenrelationen der Parteien an einem diachronen Vergleich exemplifizieren: In der Hochphase des konzentrierten Dreiparteiensystems betrug die effektive Zahl der nach der Bundestagswahl 1972 im Parlament vertretenen Parteien 2,3 (Union 225, SPD 230, FDP 41 Mandate). Im multioptionalen Fünfparteiensystem nach der Bundestagswahl 2009 (Union 239, SPD 146, FDP 93, Grüne 68, Linke 76 Mandate) betrug die effektive Parteienzahl dagegen schon vier. ${ }^{2}$

Zusätzlich zu Zahl und relativer Größe der Parteien spielen auch die ideologischen Distanzen der Parteien zueinander eine maßgebliche Rolle für die

2 Die effektive Parteienzahl berechnet sich nach Laakso/Taagepera (1979), indem man die quadrierten Stimm- bzw. Mandatsanteile aller Parteien summiert und dann den Kehrwert bildet. Am Beispiel der vier Parteien mit Sitzanteilen von jeweils 25 Prozent lautet die Gleichung also: $1: \sum 0,25^{2}+0,25^{2}+0,25^{2}+0,25^{2}=1: \sum 0,0625+0,0625+0,0625$ $+0,0625=1: 0,25=4$. 
Möglichkeiten der Koalitionsbildung (Ware 1996: 147-175). Sartori (1976) unterschied noch relativ intuitiv zwischen moderaten, segmentierten und polarisierten Mehrparteiensystemen, wobei letztere aufgrund der hohen ideologischen Distanz der Parteien und ihres zentrifugalen Wettbewerbs über nur eingeschränkte Koalitionsmöglichkeiten verfügten. Paradebeispiel für den polarisierten Parteienpluralismus war bis in die 1970er Jahre hinein Italien, wo sowohl eine neofaschistische als auch eine - noch dazu sehr starke - kommunistische Partei im Parlament vertreten waren, die beide den Parteien der Mitte als nicht koalitionsfähig galten. Diese Tatsache garantierte den italienischen Christdemokraten in der Ersten Republik (1946-92) die ununterbrochene Teilnahme an der Regierung.

In der Nachfolge Sartoris sind die programmatischen Differenzen der Parteien mit immer aufwendigeren empirischen Methoden erfasst worden, so dass inzwischen für eine große Zahl nationaler Parteiensysteme die Position der Parteien auf der Links-Rechts-Achse und auch deren Veränderung über die Zeit bestimmt werden kann (Budge u. a. 2001, Klingemann u. a. 2006) - und zwar auf verschiedenen Politikfeldern. Dies ermöglicht zum Beispiel die Bestimmung von Medianparteien und sogenannten ,starken“ Parteien in zwei- und mehrdimensionalen Politikräumen. Dem Portfolioallokationsmodell von Laver und Shepsle (1996) zufolge nehmen diese Parteien nicht nur bei der Koalitionsbildung, sondern auch bei der Ministerienverteilung eine zentrale Verhandlungsposition ein: So habe bei der Bildung der christlich-liberalen Koalition 1987 zum Beispiel die CDU das Finanz- und die FDP das Außenministerium erhalten, weil sie auf der betreffenden Politikdimension den Medianabgeordneten in ihren Reihen hatten (Laver/Shepsle 1998: 44, Saalfeld 2006: 496-500).

Mit Blick auf die Koalitionsstrategien und Koalitionsbildungen sind Parteiensysteme in föderalistischen Staaten wie der Bundesrepublik stets auch daraufhin zu untersuchen, in welcher Wechselbeziehung nationale und regionale Ebenen zueinander stehen. In allen Bundesstaaten ist es von Bedeutung, ob nationale und regionale Parteiensysteme sich einander ähneln oder zumindest übereinstimmenden Wettbewerbslogiken folgen - seien diese Logiken nun hegemonial, dualistisch, pluralistisch oder polarisierend. Auch ist es bedeutsam, ob die Parteien eher zentral oder dezentral organisiert sind. Für Deutschland ist im internationalen Vergleich festgestellt worden, dass das Parteiensystem durch eine dualistische Wettbewerbslogik und eine - zumindest bis zur deutschen Vereinigung - relativ große Kongruenz der beiden Ebenen gekennzeichnet ist. Auch sind die deutschen Parteien vergleichsweise zentral organisiert und stark auf die Bundespolitik hin orientiert (Grande 2002: 185-197). 
Dies hängt mit der Tatsache des deutschen „Verbundsföderalismus“ (Steffani 1997a: 64) zusammen, in dem die Regierungen der subnationalen Ebene an der nationalen Gesetzgebung mitwirken. Koalitionsbildungen auf Landesebene haben somit für die Bundesebene eine unmittelbare Bedeutung, weil sie dort die Zusammensetzung der zweiten Parlamentskammer ändern - und zwar kontinuierlich mit jeder neuen Regierungsbildung in den Ländern. Es kann deshalb wenig verwundern, dass die nationalen Parteien bzw. ihre politischen Repräsentanten Einfluss auf die Koalitionsbildungen in den Ländern nehmen, mögen sie solche Einflussnahmen auch weit von sich weisen (Pappi/Becker/Herzog 2005). Die Einflusswirkung muss im Übrigen auch nicht auf direkten Interventionen beruhen, sondern kann gleichsam in vorauseilendem Gehorsam erfolgen, da selbstverständlich auch die Parteien der Landesebene davon profitieren (können), wenn sie ihre Koalitionen kongruent zum Bund bilden.

Die Feststellung, dass von der Struktur des Parteienwettbewerbs im Bund Wirkungen auf die Koalitionsbildungen in den Ländern ausgehen, heißt aber nicht, dass auf Landesebene nicht auch unabhängige Faktoren die Koalitionsentscheidungen beeinflussen: Die Stärke der Parteien auf Landesebene kann ebenso von der Lage im Bund abweichen wie deren programmatische Positionen oder Koalitionsaussagen (Bräuninger/Debus 2008). Es sind also immer komplexe Motivlagen und Einflusswirkungen, die letztlich eine Koalitionsentscheidung im Land herbeiführen. Auch können von Koalitionsbildungen auf Landesebene wiederum Wirkungen auf die Bundesebene ausgehen. Oft kündigen sich Koalitionswechsel im Bund auf Landesebene an oder werden zumindest neue Koalitionsmodelle dort erprobt. Man könnte jede Koalitionsbildung in einem Bundesland - wie auch die Koalitionen und Kooperationen, die sich aus Anlass anderer „,second order elections“ (Reif/Schmitt 1980) wie der Europa- oder Bundespräsidentenwahl bilden - als „externen Schock“ für die regierende Koalition im Bund begreifen, die sie genauso wie andere kritische Ereignisse (Absturz in den Meinungsumfragen, schlechte Wirtschaftsdaten, Terroranschlag, Tod oder Rücktritt des Regierungschefs etc.) erfolgreich bewältigen muss (Saalfeld 2010a: 509-512).

Dies führt uns zu einem letzten, für die folgende Darstellung entscheidenden konzeptionellen Punkt: Koalitionsbildungen werden hier nicht als einmalige, in sich abgeschlossene Ereignisse verstanden, sondern als dynamische Prozesse, die ständig wiederholt und erneuert werden (müssen). Koalitionsbildungen und Koalitionsverhandlungen sind nie abgeschlossen, weil sie fortlaufend auf neue Ereignisse und Umstände - auch auf die Unvollständigkeit der eigenen Entscheidungen und deren Folgewirkungen - reagieren müssen (Lu- 
Koalitionsbildungen und Koalitionsstrategien im neuen Fünfparteiensystem der BRD

pia/Strom 2008). Um die komplexen Ursachenbündel dynamischer Koalitionsbildungen zu entwirren, wäre es deshalb ideal, Methoden teilnehmender Beobachtung und leitfadengestützter Befragung der handelnden Akteure zu wählen, um zu einer „dichten Beschreibung“ (Geertz 1987: 7-43) komplexer Motivlagen und Vorstellungswelten zu gelangen. Da dies hier nicht geleistet werden kann, erscheint es insbesondere für die im vierten Kapitel darzustellenden aktuellen Koalitionsentscheidungen seit der Bundestagswahl 2005 angemessen, sich unter Auswertung der medialen Berichterstattung und der wissenschaftlichen Sekundärliteratur auf die sorgfältige Nachzeichnung der Koalitionsbildungsprozesse zu beschränken.

\section{Koalitionsbildungen in der Bundesrepublik Deutschland: Historische Muster}

Auf Bundesebene war in Deutschland bisher jede der insgesamt 30 Regierungen eine Koalition - mit Ausnahme der knapp anderthalb Jahre dauernden CDU/CSU-Alleinregierung unter Konrad Adenauer (Juli 1960 bis November 1961) und dreier kurzer Minderheitsregierungen nach dem Auszug der FDP aus der Regierung in den Jahren 1962, 1966 und 1982. Sechs der 26 verbleibenden Koalitionen waren übergroß, allein fünf von ihnen wurden von Adenauer in den 1950er Jahren gebildet. Die andere übergroße Koalition aus dem Wiedervereinigungsjahr 1990 währte nur zwei Monate und war der Aufnahme der DSU in die Regierung geschuldet. Die restlichen 20 Koalitionen (zwei Drittel) seit 1949 waren mit minimaler oder kleinster Mehrheit ausgestattet, zwischen 1961 und 2009 waren dies sogar 19 von 23 Koalitionen, knapp 83 Prozent (Tabelle 1). Den Grundannahmen der Koalitionstheorie wurde somit seit der Koalitionsbildung 1961 im Bund immer entsprochen: Selbst die beiden 1966 und 2005 gebildeten Großen Koalitionen waren minimale Mehrheitskoalitionen, die insofern nur in deutscher Wahrnehmung, nicht aber nach den Maßstäben der internationalen Koalitionsforschung einen Sonderfall darstellten (Müller 2008). 
Tabelle 1

Koalitionsformate im Bund 1949 - 2010 (Prozentwerte)

\begin{tabular}{|c|c|c|c|c|c|c|c|}
\hline \multirow[t]{2}{*}{ Zeitraum } & \multicolumn{2}{|c|}{$\begin{array}{c}\text { Einpartei- } \\
\text { regierungen }\end{array}$} & \multicolumn{4}{|c|}{ Koalitionen } & \multirow[t]{2}{*}{ Alle } \\
\hline & MR & ER & MK & MMK & KMK & $\ddot{\mathbf{U} K}$ & \\
\hline 1949 bis $1961(n=7)$ & - & 14.3 & - & 14.3 & - & 71.4 & 100 \\
\hline 1961 bis $1966(n=6)$ & 33.3 & - & - & 66.7 & - & - & 100 \\
\hline 1966 bis $1969(\mathrm{n}=1)$ & - & - & - & 100 & - & - & 100 \\
\hline 1969 bis $1982(n=6)$ & 16.7 & - & - & 33.3 & 50.0 & - & 100 \\
\hline 1982 bis $1990(n=4)$ & - & - & - & 50.0 & 25.0 & 25.0 & 100 \\
\hline 1990 bis $1998(n=2)$ & - & - & - & 50.0 & 50.0 & - & 100 \\
\hline 1998 bis $2005(n=2)$ & - & - & - & 100 & - & - & 100 \\
\hline 2005 bis $2010(n=2)$ & - & - & - & 100 & - & - & 100 \\
\hline 1949 bis $2010(n=30)$ & 10.0 & 3.3 & - & 50.0 & 16.7 & 20.0 & 100 \\
\hline 1961 bis $2010(n=23)$ & 13.0 & - & - & 60.9 & 21.7 & 4.3 & 100 \\
\hline
\end{tabular}

Legende: $\mathrm{MR}=$ Minderheitsregierung, $\mathrm{ER}=$ Einparteiregierung (mit parlamentarischer Mehrheit), $\mathrm{MK}=$ Minderheitskoalition, MMK = Minimale Mehrheitskoalition (minimal winning), $\mathrm{KMK}=$ Kleinste Mehrheitskoalition (minimum winning), ÜK = Übergroße Koalition.

Quellen: Wie in der Tabelle A1 „Regierungen und Regierungskoalitionen in Bund und Ländern 1946 bis 2010“ im Anhang.

In den Bundesländern war die Situation ähnlich: Dort kam es zwar infolge von Hochburgenbildungen in den Ländern häufiger zu Einparteiregierungen, insbesondere in der Blütephase des konzentrierten „Zweieinhalbparteiensystems" in den 1970er und 1980er Jahren, doch auch hier benötigten die siegreichen Parteien meist einen Koalitionspartner. Seit 1961 kam es, den Sätzen der Koalitionsforschung entsprechend, in den Ländern fast nur noch zu Einparteiregierungen sowie zu Koalitionen kleinster oder minimaler Mehrheiten (85 Prozent). Nur in Ausnahmefällen kam es zu Minderheitsregierungen einer Partei bzw. Koalition (zehn Prozent) oder zu übergroßen Koalitionen (fünf Prozent, Tabelle 2). 
Koalitionsbildungen und Koalitionsstrategien im neuen Fünfparteiensystem der BRD

Tabelle 2

Koalitionsformate in den Bundesländern 1946 - 2010 (Prozentwerte)

\begin{tabular}{|c|c|c|c|c|c|c|c|}
\hline \multirow[t]{2}{*}{ Zeitraum } & \multicolumn{2}{|c|}{$\begin{array}{l}\text { Einpartei- } \\
\text { regierungen }\end{array}$} & \multicolumn{4}{|c|}{ Koalitionen } & \multirow[t]{2}{*}{ Alle } \\
\hline & MR & ER & MK & МMK & KMK & ÜK & \\
\hline 1946 bis $1949(n=26)$ & - & 11.5 & - & 11.5 & - & 76.9 & 100 \\
\hline 1949 bis $1961(\mathrm{n}=60)$ & 3.3 & 8.3 & 6.0 & 11.7 & 13.3 & 53.3 & 100 \\
\hline 1946 bis $1961(n=86)$ & 2.3 & 10.5 & 5.8 & 11.6 & 9.3 & 60.5 & 100 \\
\hline 1961 bis $1966(n=20)$ & 5.0 & 20.0 & - & 15.0 & 30.0 & 30.0 & 100 \\
\hline 1966 bis $1969(\mathrm{n}=11)$ & - & - & - & 54.5 & 18.2 & 27.3 & 100 \\
\hline 1969 bis $1982(\mathrm{n}=52)$ & 11.5 & 50.0 & - & - & 34.6 & 3.8 & 100 \\
\hline 1982 bis $1990(\mathrm{n}=41)$ & 12.2 & 46.3 & - & 14.6 & 26.8 & - & 100 \\
\hline 1961 bis $1990(n=124)$ & 9.7 & 39.5 & - & 12.1 & 29.8 & 8.9 & 100 \\
\hline 1990 bis $1998(n=38)$ & 5.3 & 31.6 & 5.3 & 21.1 & 34.2 & 2.6 & 100 \\
\hline 1998 bis $2005(n=36)$ & - & 36.1 & 5.6 & 25.0 & 33.3 & - & 100 \\
\hline 1990 bis $2005(n=74)$ & 2.7 & 33.8 & 5.4 & 23.0 & 33.8 & 1.4 & 100 \\
\hline 2005 bis $2009(n=21)$ & 9.5 & 9.5 & - & 42.9 & 38.1 & - & 100 \\
\hline 2009 bis $2010(\mathrm{n}=6)$ & - & - & 33.3 & 50.0 & 16.7 & - & 100 \\
\hline 2005 bis $2010(n=27)$ & 7.4 & 7.4 & 7.4 & 44.4 & 33.3 & - & 100 \\
\hline 1946 bis $2010(n=311)$ & 5.8 & 27.3 & 3.5 & 17.4 & 25.4 & 20.6 & 100 \\
\hline 1961 bis $2010(n=225)$ & 7.1 & 33.8 & 2.7 & 19.6 & 31.6 & 5.3 & 100 \\
\hline
\end{tabular}

Legende: $\mathrm{MR}=$ Minderheitsregierung, $\mathrm{ER}=$ Einparteiregierung (mit parlamentarischer Mehrheit), $\mathrm{MK}=$ Minderheitskoalition, MMK = Minimale Mehrheitskoalition (minimal winning), $\mathrm{KMK}=$ Kleinste Mehrheitskoalition (minimum winning), ÜK = Übergroße Koalition.

Quellen: Wie in der Tabelle A1 „Regierungen und Regierungskoalitionen in Bund und Ländern 1946 bis 2010“ im Anhang. Das von Oktober 1955 bis Januar 1956 amtierende Fachkabinett im Saarland wurde hier außen vor gelassen, da es nur von Parteilosen gebildet worden war.

\section{a) Koalitionsbildungen im polarisierten Mehrparteiensystem (1946 bis 1961)}

Die ersten Regierungsbildungen der Nachkriegszeit können nur bedingt an den Maßstäben der Koalitionsforschung gemessen werden. Deutschland war noch keine konsolidierte Demokratie; mit Bezug auf die Parteien ist sogar mit Recht von einer „Stunde Null“ gesprochen worden, mussten diese doch nach den zwölf Jahren Nationalsozialismus erst wieder - oder gar wie CDU und CSU gänzlich neu - gegründet werden (Alemann 2000: 43). Anfänglich waren es die Alliierten, die die Zulassung der Parteien und auch die Bildung der ersten Re- 
gierungen in ihren Besatzungszonen kontrollierten. Oftmals waren dies Große, übergroße oder gar All-Parteien-Koalitionen aller maßgeblichen gesellschaftlichen Kräfte, bis zum Beginn des Kalten Krieges und der Blockade Berlins im Juni 1948 durch die Sowjetunion auch unter Einschluss der Kommunisten. Die Bildung der ersten Bundesregierung 1949 durch Bundeskanzler Konrad Adenauer, eine minimale Mehrheitskoalition aus CDU/CSU, FDP und DP, ist somit sogar für die Formierungsphase des deutschen Parteiensystems die erklärungsbedürftige Abweichung von der Regel. Es gab starke Kräfte innerhalb der Union, die auf eine Große Koalition drängten, sich aber nicht gegen den strategisch denkenden und handelnden Adenauer durchsetzen konnten. Adenauer hatte lange vor der Bundestagswahl die Weichen in Richtung einer kleinen Koalition mit der FDP gestellt, die dafür das Bundespräsidentenamt mit Theodor Heuss besetzen konnte (Wengst 1985).

Im polarisierten Mehrparteiensystem der Anfangsjahre - im ersten Bundestag (1949) waren zehn, im zweiten (1953) sechs und im dritten (1957) noch vier Parteien vertreten - gab es viele gute Gründe, übergroße Koalitionen zu bilden. Drei stachen besonders hervor: Erstens sollte der noch unsichere Übergang von der NS-Diktatur zur Demokratie (erst im Mai 1955 wurde das Besatzungsstatut aufgehoben), auch unter dem Eindruck der Frontstellung des geteilten Deutschlands im Ost-West-Konflikt, durch breite parlamentarische Koalitionen abgesichert werden. Zweitens benötigte die Bundesregierung in den Anfangsjahren für bestimmte außen- und verteidigungspolitische Weichenstellungen wie die Westintegration (EVG- und Nato-Beitritt) und die Wiederbewaffnung verfassungsändernde Mehrheiten, weshalb Adenauer in sein zweites Kabinett zusätzlich zu FDP und DP auch noch die Vertriebenenpartei GB/BHE aufnahm. Drittens schließlich erschien Adenauer die Bildung übergroßer Koalitionen auch aus parteistrategischem Kalkül opportun, konnte er so doch während seiner 14 Jahre währenden Kanzlerschaft die CDU zur erfolgreichen interkonfessionellen Sammlungspartei des bürgerlichen Lagers ausbauen, die alle Kleinparteien des rechten politischen Spektrums in sich aufsog (Bösch 2001). Kurzfristige Mandats- und Ämtereinbußen, die die CDU ihren kleinen Koalitionspartnern zuliebe hinnahm, konnte sie in mittel- und langfristiger Sicht mehr als kompensieren. Vor allem durch Wahlkreisabsprachen verhalf die CDU ihren Koalitionspartnern zu direkt gewählten Abgeordneten. Der DP gelang 1957 nur noch in diesem „Huckepack-Verfahren“ der Sprung über die gegenüber 1949 und 1953 erhöhte Sperrklausel (Schindler 1999: 138141, Rudzio 2002: 46). 
Die Koalitionsbildungen in den Bundesländern erfolgten insofern nach ähnlichen Mustern, als auch hier oftmals übergroße Koalitionen gebildet wurden - selbst dann noch, als die Gründe für deren Bildung längst hinfällig waren. Anders als im Bund, wo FDP, DP und GB/BHE (auch mangels Alternativen) fest an der Seite der Union standen, gab es in den Ländern eine größere koalitionspolitische Offenheit. Neben den oftmals fortbestehenden übergroßen und Großen Koalitionen zeigten sich im Grunde alle demokratischen Parteien miteinander koalitionsbereit. So koalierte der GB/BHE zum Beispiel in Niedersachsen und Hessen lange mit der SPD. Die FDP zeigte sich insbesondere in den Stadtstaaten gegenüber den Sozialdemokraten bündniswillig, experimentierte aber auch schon einmal zwischen 1956 und 1958 im bevölkerungsreichsten deutschen Flächenland Nordrhein-Westfalen mit einer sozialliberalen Koalition. Und von Stuttgart aus trug der Altliberale Reinhold Maier (DVP/ FDP), der bis 1953 einer Koalition mit der SPD und dem GB/BHE vorstand, seine Privatfehde mit Bundeskanzler Adenauer aus. Als Präsident des Bundesrats 1952/53 trieb er den Bundeskanzler mit seiner Opposition gegen die EVGVerträge kurzzeitig zur Verzweiflung (Baring 1969: 261-293). Ähnlich wie im Bund setzte sich aber auch in den Ländern in den 1950er Jahren eine Konzentration im Parteiensystem durch, die im wesentlichen Anfang der 1960er Jahre abgeschlossen war und - von wenigen landespolitischen Besonderheiten abgesehen - nur noch drei Parteien in den Parlamenten übrigließ: CDU/CSU, SPD und FDP (Tabelle A1 im Anhang).

\section{b) Koalitionsbildungen im zentrierten Dreiparteiensystem (1961 bis 1990)}

Mit der Bundestagswahl 1961 war eine Zäsur in der Entwicklung des bundesdeutschen Parteiensystems erreicht: Die Adenauer-CDU hatte alle Kleinparteien des rechten politischen Spektrums, zuletzt 1960 die DP, absorbiert - nur die 1956/57 aus der Regierung ausgeschiedene FDP hatte den Umarmungsversuchen der Union erfolgreich widerstanden. Für mehr als zwei Jahrzehnte von 1961 bis 1983 sollte das Parteienspektrum im Deutschen Bundestag nun nur noch drei Parteien umfassen: Christdemokraten, Sozialdemokraten und - als „Zünglein an der Waage“ - die Liberalen. Infolge der Godesberger Programmreform 1959, mit der die SPD erstmals in der Nachkriegszeit offensiv ihren Regierungsanspruch formulierte, sowie der Entfremdung zwischen CDU und FDP erhöhte sich der Wettbewerb zwischen den Parteien ab 1961 wieder: Zunächst machte die FDP Wahlkampf mit dem Versprechen, Bundeskanzler Adenauer abzulösen, dann drängten starke Kräfte in Union (nicht zuletzt 
Adenauer selbst) und SPD (Herbert Wehner) auf die Bildung einer Großen Koalition, die nach mehreren Anläufen und dem Intermezzo der von Ludwig Erhard geführten kleinen Koalition mit der FDP schließlich 1966 auch gebildet wurde.

Drei Jahre später waren dann SPD und FDP so weit, den „Machtwechsel“ (Baring 1982) zu wagen - erst probeweise bei der Wahl Gustav Heinemanns zum Bundespräsidenten im März 1969, ein halbes Jahr später dann auch bei der Regierungsbildung im Anschluss an die Bundestagswahl. Die sozialliberale Koalition unter den Bundeskanzlern Willy Brandt und Helmut Schmidt hielt dreizehn Jahre, ehe sie an innerparteilichen Flügelkämpfen der SPD und der Entfremdung der beiden Koalitionspartner zerbrach. Die FDP scherte schließlich im September 1982 aus der Regierung aus und machte Helmut Kohl zum Kanzler einer christlich-liberalen Koalition, die in den Bundestagswahlen 1983 und 1987 ungefährdet wiedergewählt wurde, ehe sie 1989 in schwere Fahrwasser geriet. Die innerparteiliche Opposition in der CDU gegen ihren Bundeskanzler und Parteivorsitzenden erwies sich jedoch als wenig durchschlagskräftig - und geriet alsbald zur Fußnote in den Geschichtsbüchern, als Helmut Kohl (noch hinter den Kulissen des Bremer Parteitags) den „Mantel der Geschichte“ ergriff und als „Kanzler der Einheit“ seiner Regierung eine Amtszeitverlängerung bis 1998 verschaffte (Bahners 1998).

Die lange Amtsdauer der christlich-liberalen Koalition täuschte jedoch darüber hinweg, dass das Parteiensystem längst in Bewegung geraten war. Bei der Bundestagswahl 1983 war erstmals die neue Partei der Grünen (Raschke 1993, 2001) in den Bundestag gewählt worden - ein Umstand, der die Parteienforscher mit Blick auf die 1980er Jahre von einer "Transformationsphase“ (Alemann 2000: 62) oder „Pluralisierungsphase“ (Niedermayer 2007: 124) sprechen ließ. Da sich die Grünen jedoch in ihren Anfangsjahren langwierigen Selbstverständnisdebatten hingaben, änderte sich zunächst nur wenig an den eingespielten Mechanismen der Koalitionsbildung. In der alten Bundesrepublik galten die Grün-Alternativen den beiden Volksparteien auf Bundesebene ohnehin nicht als koalitionsfähig; aber auch in den Ländern gingen den ersten Regierungsbeteiligungen langwierige politische Diskussions- und Verhandlungsprozesse voraus. In den meisten Ländern, wo es die Grünen seit 1979 in die Landesparlamente geschafft hatten, dominierte der fundamentalistische Flügel und damit das Selbstverständnis einer „Bewegungs“-, einer „Anti-Parteien"- oder einer fundamentaloppositionellen Partei (Horst 2001). Die beiden rot-grünen Landeskoalitionen in Hessen (1985-87) und Berlin (1989-90) waren für alle Beteiligten gewagte Experimente und stellten vor allem auch die Grü- 
nen selbst vor eine Zerreißprobe. Sie hielten beide nur jeweils etwas mehr als ein Jahr. Erst die dritte, von Gerhard Schröder im Juni 1990 gebildete rot-grüne Koalition hielt die gesamte Wahlperiode. Die Regel aber blieb bis 1990, dass überall dort, wo es für eine der beiden großen Parteien nicht zur Mehrheit reichte, Koalitionen mit der FDP gebildet wurden, die insofern in der komfortablen Rolle des Königsmachers verblieb (Dittberner 1987, 2005). Allenfalls bewirkte die parlamentarische Existenz der Grünen, dass Regierungsbildungen insgesamt erschwert wurden. Mancherorts erschienen nun nach Wahlen Koalitionsbildungen nicht mehr möglich, weshalb Regierungen geschäftsführend im Amt verblieben. „Hessische“ (Schroeder 2008) oder „Hamburger Verhältnisse“ (Horst 2002: 44 f.) wurden zum geflügelten Wort und bezeichneten Situationen, in denen die Grünen so stark waren, dass sie den Regierungswechsel zwischen den beiden Großparteien blockierten.

Unter dem Blickwinkel der Koalitionsbildung erscheint es gerechtfertigt, die Phase des stabilen Dreiparteiensystems von 1961 bis 1990 dauern zu lassen, auch wenn sich bereits eine vierte Partei in den Parlamenten etabliert hatte. Regierungsparteien waren in diesen drei Jahrzehnten jedoch mit den drei genannten Ausnahmen ausschließlich Union, SPD und FDP. Bei Koalitionsbildungen kam den Liberalen dort, wo es für Alleinregierungen der beiden großen Parteien nicht reichte, die zentrale Rolle im Verhandlungspoker zu. Mit Ausnahme der Großen Koalition und den drei kurzen Übergangsregierungen ohne Mehrheit 1962, 1966 und 1982 gehörte die FDP jeder Bundesregierung an. In den Ländern war sie Partner in 55 von 64 Koalitionen, die zwischen den Bundestagswahlen 1961 und 1990 gebildet wurden. SPD (43) und Union (28) waren an weniger Koalitionen beteiligt; dafür konnten sie in der Phase des stabilen Dreiparteiensystems so viele Alleinregierungen in den Ländern bilden wie nie zuvor und auch danach nicht mehr: Knapp zwei Drittel aller Alleinregierungen von SPD und Union seit 1961 (vorher gab es sie in den Ländern kaum) wurden in der Blütezeit des "Zweieinhalbparteiensystems“ in den 1970er und 1980er Jahren gebildet (Tabelle 3). Dabei kam es einer Volkspartei in den Bundesländern zugute, wenn sie im Bund in der Opposition war. Nie war die Union in den Ländern so erfolgreich wie zu Zeiten der sozial-liberalen Koalition (1969-82), nie schnitt die SPD bei Landtagswahlen so gut ab wie in den ersten acht Jahren der christlich-liberalen Koalition (Tabelle 3). 
Tabelle 3

Regierungs- und Koalitionsmodelle in den Bundesländern 1961 bis 2010

\begin{tabular}{|l|c|c|c|c|c|c|c|c|c|}
\hline & $\mathbf{6 1 -}$ & $\mathbf{6 6 -}$ & $\mathbf{6 9 -}$ & $\mathbf{8 2 -}$ & $\mathbf{9 0 -}$ & $\mathbf{9 8}-$ & $\mathbf{0 5}-$ & $\mathbf{0 9 -}$ & $\mathbf{6 1 -}$ \\
$\mathbf{6 6}$ & $\mathbf{6 9}$ & $\mathbf{8 2}$ & $\mathbf{9 0}$ & $\mathbf{9 8}$ & $\mathbf{0 5}$ & $\mathbf{0 9}$ & $\mathbf{1 0}$ & $\mathbf{1 0}$ \\
\hline Union & 3 & - & 20 & 11 & 5 & 10 & 3 & 1 & 53 \\
\hline Union, SPD & - & 2 & - & 1 & 4 & 3 & 4 & - & 14 \\
\hline Union, FDP & 6 & 3 & 4 & 10 & 5 & 7 & 5 & 3 & 43 \\
\hline Union, Grüne & - & - & - & - & - & - & 1 & 1 & 2 \\
\hline Union, Schill, FDP & - & - & - & - & - & 1 & - & & 1 \\
\hline Union, FDP, Grüne & - & - & - & - & - & - & 1 & & 1 \\
\hline Unionsgeführt & $\mathbf{9}$ & $\mathbf{5}$ & $\mathbf{2 4}$ & $\mathbf{2 2}$ & $\mathbf{1 4}$ & $\mathbf{2 1}$ & $\mathbf{1 4}$ & $\mathbf{5}$ & $\mathbf{1 1 4}$ \\
\hline SPD & 2 & - & 12 & 13 & 9 & 3 & 1 & - & 40 \\
\hline SPD, CDU & 1 & 1 & - & - & 1 & 5 & 3 & - & 11 \\
\hline SPD, FDP & 7 & 5 & 16 & 2 & 4 & 1 & - & - & 35 \\
\hline SPD, Grüne & - & - & - & 3 & 7 & 4 & 1 & 1 & 16 \\
\hline SPD, Linke & - & - & - & - & 1 & 2 & 2 & - & 5 \\
\hline SPD, GDP/BHE & 1 & - & - & - & - & - & - & - & 1 \\
\hline SPD, GB/BHE, FDP & 1 & - & - & - & - & - & - & - & 1 \\
\hline SPD, Statt & - & - & - & - & 1 & - & - & & 1 \\
\hline SPD, FDP, Grüne & - & - & - & 1 & 1 & - & - & & 2 \\
\hline SPD-geführt & $\mathbf{1 2}$ & $\mathbf{6}$ & $\mathbf{2 8}$ & $\mathbf{1 9}$ & $\mathbf{2 4}$ & $\mathbf{1 5}$ & $\mathbf{7}$ & $\mathbf{1}$ & $\mathbf{1 1 2}$ \\
\hline
\end{tabular}

Alternative Liste (Berlin) und Bündnis 90 (Brandenburg) sind unter Grüne, die PDS unter Linke subsumiert.

Quellen: Wie in der Tabelle A1 „Regierungen und Regierungskoalitionen in Bund und Ländern 1946 bis 2010“ im Anhang.

Da im stabilen Dreiparteiensystem zumeist nur (maximal) drei Parteien in den Parlamenten vertreten waren, jedenfalls nur drei Parteien für die Regierungsbildung in Frage kamen, bildeten sich Koalitionen nahezu zwangsläufig mit minimalen Mehrheiten. Ob diese minimale Mehrheit gemäß den Sätzen der älteren Koalitionstheorie (Gamson 1961, Riker 1962) zusätzlich noch die Bedingung einer kleinsten Mehrheit erfüllte, hing im Wesentlichen vom Größenverhältnis von Union und SPD ab. Im Bund genügten nur die SPD/FDP-Koalitionen - mit Ausnahme des zweiten Kabinetts Brandts und des ersten Kabinetts Schmidts - diesem Kriterium, in den Ländern war die Situation vielfältiger und wechselhafter. Generell bildeten sich hier häufiger Koalitionen kleinster Mehrheit, egal ob Christ- oder Sozialdemokraten Partner der FDP wurden, als im 
Bund (Tabellen 1 und 2). Dies hatte zweifelsohne auch mit dem teilweisen Charakter der Landtagswahlen als „Bundestestwahlen“ zu tun, was der jeweiligen Oppositionspartei im Bund wachsenden Wählerzuspruch in den Ländern verhieß (Völkl u.a. 2008). Der im Bund asymmetrisch zugunsten der Union ausschlagende Parteienwettbewerb war in der Ländergesamtheit ausgeglichener. $\mathrm{Zu}$ betonen ist jedoch, dass nicht das auf Ämter bezogene maximale Gewinninteresse den Ausschlag für die Wahl einer spezifischen Koalition gab, denn dann hätte die FDP im Bund fast immer die SPD der Union als Koalitionspartner vorziehen müssen. Wie die Tabelle 4 verdeutlicht, war der Anteil der FDP an den Kabinettsmitgliedern zwar in allen Koalitionen immer leicht überproportional zu ihrem Anteil an den Mandaten gewesen - in den Koalitionen mit der SPD schnitt die FDP quantitativ aber immer etwas besser ab als in den Koalitionen mit der Union. Qualitativ allerdings machte der Koalitionspartner keinen Unterschied: Seit 1969 stellte die FDP immer den Außenminister, seit 1972 immer den Wirtschaftsminister. Auch besetzte sie seit 1969 in allen Koalitionen ein Verfassungsressort - in der sozialliberalen Koalition das Innen-, in den christlich-liberalen Koalitionen das Justizministerium (Schindler 1999: 1043-1059).

Wichtiger als das rein quantitative Ämterinteresse war folglich das Interesse an der Durchsetzung politischer Inhalte (auch über die Auswahl der jeweiligen Ressorts) und machtstrategischer Kalküle. Im zentrierten Dreiparteiensystem der Jahre 1961 bis 1990 oblag es dabei meist der FDP zu entscheiden, welcher der beiden Volksparteien sie sich politisch näher fühlen wollte. Aufgrund der Mitteposition der FDP im Parteienwettbewerb waren alle Koalitionen dieser Zeit automatisch minimal verbundene Koalitionen im Sinne der Koalitionstheorie. Betonte die FDP politische Inhalte auf der sozio-ökonomischen Konfliktdimension, entschied sie sich für die Union, waren ihr sozio-kulturelle oder außenpolitische Fragen wichtiger, optierte sie für die SPD (Rudzio 2002: 48 f.). Faktisch war es im zentrierten Dreiparteiensystem dieser Jahre die Koalitionsaussage der FDP vor der Wahl (Michel 2005) die über die Koalitionsbildung danach entschied. Generell sind Koalitionsaussagen als ein Maß für die programmatische Selbstverortung der Parteien, als Ausdruck ihrer koalitionspolitischen Selbstbindung und als Prädiktor für Koalitionsbildungen eine politikwissenschaftlich immer noch zu wenig erforschte Variable (Decker 2009). 
Patrick Horst

Tabelle 4

Mandatsanteil der Koalitionsparteien im Bundestag und Portfolio-Anteil an den neu gebildeten Bundeskabinetten 1949 bis 2009, Prozentwerte

\begin{tabular}{|l|c|c|c|c|c|c|c|c|c|c|}
\hline Jahr & \multicolumn{3}{|c|}{ Sitzanteil der Koalitionsparteien } & \multicolumn{3}{|c|}{ Anteil der Kabinettsmitglieder } \\
\hline & CDU & CSU & FDP & DP & $\begin{array}{c}\text { GB/ } \\
\text { BHE }\end{array}$ & CDU & CSU & FDP & DP & $\begin{array}{c}\text { GB/ } \\
\text { BHE }\end{array}$ \\
\hline 1949 & 55.7 & 11.3 & 25.0 & 8.0 & - & 42.9 & 21.4 & 21.4 & 14.3 & - \\
\hline 1953 & 57.4 & 15.1 & 15.4 & 4.3 & 7.8 & 42.1 & 15.8 & 21.1 & 10.5 & 10.5 \\
\hline 1957 & 76.3 & 18.0 & - & 5.8 & - & 66.7 & 22.2 & - & 11.1 & - \\
\hline 1961 & 63.2 & 15.7 & 21.1 & - & - & 57.1 & 19.0 & 23.8 & - & - \\
\hline 1965 & 67.1 & 16.3 & 16.6 & - & - & 59.1 & 22.7 & 18.2 & - & - \\
\hline & CDU & CSU & FDP & SPD & Gr. & CDU & CSU & FDP & SPD & Gr. \\
\hline 1966 & 43.2 & 10.5 & - & 46.4 & - & 42.9 & 14.3 & - & 42.9 & - \\
\hline 1969 & - & - & 11.6 & 88.4 & - & - & - & 18.8 & 81.3 & - \\
\hline 1972 & - & - & 14.8 & 85.2 & - & - & - & 27.8 & 72.2 & - \\
\hline 1974 & - & - & 14.8 & 85.2 & - & - & - & 25.0 & 75.0 & - \\
\hline 1976 & - & - & 15.2 & 84.8 & - & - & - & 25.0 & 75.0 & - \\
\hline 1980 & - & - & 19.1 & 80.9 & - & - & - & 23.5 & 76.5 & - \\
\hline 1982 & 63.6 & 17.9 & 18.6 & - & - & 52.9 & 23.5 & 23.5 & - & - \\
\hline 1983 & 69.7 & 18.3 & 12.1 & - & - & 52.9 & 29.4 & 17.6 & - & - \\
\hline 1987 & 65.6 & 17.4 & 17.0 & - & - & 52.6 & 26.3 & 21.1 & - & - \\
\hline 1990 & 67.3 & 12.8 & 19.9 & - & - & 55.0 & 20.0 & 25.0 & - & - \\
\hline 1994 & 71.6 & 14.7 & 13.8 & - & - & 61.1 & 22.2 & 16.7 & - & - \\
\hline 1998 & - & - & - & 86.4 & 13.6 & - & - & - & 81.3 & 18.8 \\
\hline 2002 & - & - & - & 82.0 & 18.0 & - & - & - & 71.4 & 28.6 \\
\hline 2005 & 40.2 & 10.3 & - & 49.6 & - & 37.5 & 12.5 & - & 50.0 & - \\
\hline 2009 & 58.4 & 13.6 & 28.0 & - & - & 50.0 & 18.8 & 31.3 & - & - \\
\hline
\end{tabular}

Quellen: Schindler 1999: 1143-1145, Feldkamp 2005: 297; für 2005 und 2009 ergänzt nach Kürschners Volkshandbuch Deutscher Bundestag.

\section{c) Koalitionsbildungen im bipolaren Vierparteiensystem (1990 bis 2005)}

Mit der deutschen Wiedervereinigung war das zentrierte Dreiparteiensystem endgültig an sein Ende gekommen, auch wenn die in der alten Bundesrepublik eingespielten Mechanismen der Koalitionsbildung nach den Bundestagswahlen 1990 und 1994 zunächst weiter griffen. Die christlich-liberale Koalition blieb noch bis 1998 an der Regierung, obwohl ihre parlamentarische Mehrheit be- 
reits 1994 nur noch hauchdünn war (Tabelle 5). SPD und Grüne waren nach ihren historischen Niederlagen bei der Bundestagswahl 1990 zunächst in den Bundesländern und dann auch im Bund zur ernsthaften Konkurrenz für das „bürgerliche Lager“" geworden. Im Laufe der 1990er Jahre wurde Bündnis'90/ Die Grünen in immer mehr Bundesländern an der Regierung beteiligt: im Spätherbst 1990 in Brandenburg, 1991 in Hessen und Bremen („Ampel“), 1994 in Sachsen-Anhalt, wo sich Rot-Grün im „Magdeburger Modell“ von der PDS tolerieren ließ, und nach der Bundestagswahl 1994, in der die Grünen die FDP als dritte Kraft abgelöst hatten, erneut in Hessen, in Nordrhein-Westfalen (1995), in Schleswig-Holstein (1996) und in Hamburg (1997). Mitte der 1990er Jahre waren die Grünen nicht nur in deutlich mehr Landesparlamenten als die FDP vertreten (Horst 2001: 842-847), am Vorabend der Bundestagswahl 1998 gehörten sie auch vier Landesregierungen an, die FDP nur noch zweien (in Rheinland-Pfalz und Baden-Württemberg). Der Machtwechsel von 1998 im Bund hatte sich über die Länder angekündigt. Die gesamte Zeit von 1990 bis 1998 und darüber hinaus bis 2005 organisierte sich der Parteienwettbewerb bipolar: Das „,ürgerliche“ stand dem „rot-grünen Lager“ unversöhnlich gegenüber. Dem Versuch der FDP, im Vorfeld der Bundestagswahl 2002 koalitionsstrategisch an Unabhängigkeit zu gewinnen und ohne Koalitionsaussage zugunsten der Union in den Wahlkampf zu gehen, war kein Erfolg beschieden (Vorländer 2004, 2008). Die SPD/FDP-Koalition in Rheinland-Pfalz (1991 bis 2006) blieb ein Solitär. 
Tabelle 5:

Mandate der Parteien im Deutschen Bundestag 1949 bis 2009, Kanzlermehrheit (KM) und Regierungsmehrheit (RM) am Beginn der Wahlperiode

\begin{tabular}{|l|c|c|c|c|c|c|c|c|c|c|}
\hline Jahr & Insg. & Union & SPD & FDP & DP & GB/ & Sonst. & KM & RM & \% \\
\hline 1949 & 402 & $\mathbf{1 3 9}$ & 131 & $\mathbf{5 2}$ & $\mathbf{1 7}$ & - & 63 & 202 & 209 & 52.0 \\
\hline 1953 & 487 & $\mathbf{2 4 4}$ & 151 & $\mathbf{4 8}$ & $\mathbf{1 5}$ & $\mathbf{2 7}$ & 2 & 244 & 334 & 68.6 \\
\hline 1957 & 497 & $\mathbf{2 7 0}$ & 169 & 41 & $\mathbf{1 7}$ & - & - & 249 & 287 & 57.7 \\
\hline 1961 & 499 & $\mathbf{2 4 2}$ & 190 & $\mathbf{6 7}$ & - & - & - & 250 & 309 & 61.9 \\
\hline 1965 & 496 & $\mathbf{2 4 5}$ & 202 & $\mathbf{4 9}$ & - & - & - & 249 & 294 & 59.3 \\
\hline 1969 & 496 & 242 & $\mathbf{2 2 4}$ & $\mathbf{3 0}$ & - & - & - & 249 & 254 & 51.2 \\
\hline 1972 & 496 & 225 & $\mathbf{2 3 0}$ & $\mathbf{4 1}$ & - & - & - & 249 & 271 & 54.6 \\
\hline 1976 & 496 & 243 & $\mathbf{2 1 4}$ & $\mathbf{3 9}$ & $\mathbf{6 r i n e}$ & Linke & - & 249 & 253 & 51.0 \\
\hline 1980 & 497 & 226 & $\mathbf{2 1 8}$ & $\mathbf{5 3}$ & & - & 249 & 271 & 54.5 \\
\hline 1983 & 498 & $\mathbf{2 4 4}$ & 193 & $\mathbf{3 4}$ & 27 & - & - & 250 & 278 & 55.8 \\
\hline 1987 & 497 & $\mathbf{2 2 3}$ & 186 & $\mathbf{4 6}$ & 42 & - & - & 249 & 269 & 54.1 \\
\hline 1990 & 662 & $\mathbf{3 1 9}$ & 239 & $\mathbf{7 9}$ & 8 & 17 & - & 332 & 398 & 60.1 \\
\hline 1994 & 672 & $\mathbf{2 9 4}$ & 252 & $\mathbf{4 7}$ & 49 & 30 & - & 337 & 341 & 50.7 \\
\hline 1998 & 669 & 245 & $\mathbf{2 9 8}$ & 43 & $\mathbf{4 7}$ & 36 & - & 335 & 345 & 51.6 \\
\hline 2002 & 603 & 248 & $\mathbf{2 5 1}$ & 47 & $\mathbf{5 5}$ & 2 & - & 302 & 306 & 50.7 \\
\hline 2005 & 614 & $\mathbf{2 2 6}$ & $\mathbf{2 2 2}$ & 61 & 51 & 54 & - & 308 & 448 & 73.0 \\
\hline 2009 & 622 & $\mathbf{2 3 9}$ & 146 & $\mathbf{9 3}$ & 68 & 76 & - & 312 & 332 & 53.4 \\
\hline
\end{tabular}

* Einschließlich eines CDU-Mitglieds, das über die Landesliste der Zentrumspartei gewählt wurde. Die Regierungsfraktionen sind fett markiert. Quellen: Schindler 1999: 164-172, 1122-1132, Feldkamp 2005: 16-18; für 2005 und 2009 ergänzt nach Kürschners Volkshandbuch Deutscher Bundestag.

Der bipolare Wettbewerb zweier Lager prägte jedoch, um genau zu sein, nur die Parteienkonkurrenz im Bund und im Westen der Republik. Für die neuen Bundesländer galt diese Konstellation nicht. Hier konnten FDP und Bündnis 90/ Grüne trotz ihrer Erfolge bei den ersten freien Landtagswahlen 1990 in den ersten anderthalb Jahrzehnten nach der Vereinigung kaum Fuß fassen (Tabelle 6). Selbst anfängliche Regierungsbeteiligungen - vor allem der FDP, aber auch der Grünen - konnten nicht verhindern, dass beide Parteien schnell wieder aus den Landtagen der neuen Bundesländer hinausflogen. Im Osten bildete sich so ein Dreiparteiensystem heraus, in dem die beiden im Westen etablierten Volksparteien - anfänglich unter weitgehender Ächtung der SED-Nachfolgepartei PDS - um die Vorherrschaft in den neuen Ländern konkurrierten. In Sachsen und 
Thüringen setzte sich die CDU - mit den aus dem Westen importierten, lange Jahre erfolgreich regierenden Ministerpräsidenten Kurt Biedenkopf (19912002) und Bernhard Vogel (1992-2003) - unangefochten als strukturelle Mehrheitspartei durch; in Brandenburg gelang Ministerpräsident Manfred Stolpe (1990-2002) Vergleichbares für die SPD. Nur in Sachsen-Anhalt und Mecklenburg-Vorpommern entwickelte sich ein offener Wettbewerb um die Regierungsführung, der die SPD jedoch in Koalitionsnöte brachte und vor die Frage stellte, wie sie es mit der Abgrenzung zur PDS hielt. Die SPD musste auf das strategische Dilemma eine Antwort finden, dass sie im Osten Deutschlands nur mit politischer Unterstützung der PDS die Regierungsführung übernehmen konnte oder aber als Juniorpartner der CDU regieren musste (Jesse 2009: 246-250). 
Patrick Horst

Tabelle 6

Landtagsmandate der Parteien in den neuen Bundesländern und Berlin 1990-2005

\begin{tabular}{|c|c|c|c|c|c|c|c|}
\hline Wahl & CDU & SPD & $\begin{array}{l}\text { PDS/ } \\
\text { Linke }\end{array}$ & FDP & B90/Gr. ${ }^{1}$ & Rechte $^{2}$ & $\begin{array}{c}\text { Koali- } \\
\text { tion }\end{array}$ \\
\hline \multicolumn{8}{|c|}{ Brandenburg } \\
\hline 1990 & 27 & 36 & 13 & 6 & 6 & - & KMK \\
\hline 1994 & 18 & 52 & 18 & - & - & - & ER \\
\hline 1999 & 25 & 37 & 22 & - & - & 5 & MMK \\
\hline 2004 & 20 & 33 & 29 & - & - & 6 & KMK \\
\hline \multicolumn{8}{|c|}{ Mecklenburg-Vorpommern } \\
\hline 1990 & 29 & 21 & 12 & 4 & - & - & KMK \\
\hline 1994 & 30 & 23 & 18 & - & - & - & MMK \\
\hline 1998 & 24 & 27 & 20 & - & - & - & KMK \\
\hline 2002 & 25 & 33 & 13 & - & - & - & KMK \\
\hline \multicolumn{8}{|c|}{ Sachsen } \\
\hline 1990 & 92 & 32 & 17 & 9 & 10 & - & ER \\
\hline 1994 & 77 & 22 & 21 & - & - & - & ER \\
\hline 1999 & 76 & 14 & 30 & - & - & - & ER \\
\hline 2004 & 55 & 13 & 31 & 7 & 6 & 12 & KMK \\
\hline \multicolumn{8}{|c|}{ Sachsen-Anhalt } \\
\hline 1990 & 48 & 27 & 12 & 14 & 5 & - & MMK \\
\hline 1994 & 37 & 36 & $21^{3}$ & - & 5 & - & $\mathrm{MK}$ \\
\hline 1998 & 28 & 47 & $25^{3}$ & - & - & 16 & MR \\
\hline 2002 & 48 & 25 & 25 & 17 & - & - & KMK \\
\hline \multicolumn{8}{|c|}{ Thüringen } \\
\hline 1990 & 44 & 21 & 9 & 9 & 6 & - & MMK \\
\hline 1994 & 42 & 29 & 17 & - & - & - & MMK \\
\hline 1999 & 49 & 18 & 21 & - & - & - & ER \\
\hline 2004 & 45 & 15 & 28 & - & - & - & ER \\
\hline \multicolumn{8}{|c|}{ Berlin } \\
\hline 1990 & 101 & 76 & 23 & 18 & 23 & - & MMK \\
\hline 1995 & 87 & 55 & 34 & - & 30 & - & MMK \\
\hline 1999 & 76 & 42 & 33 & - & 18 & - & MMK \\
\hline 2001 & 35 & 44 & 33 & 15 & 14 & - & MMK \\
\hline
\end{tabular}

${ }^{1}$ Im Wahljahr 1990 zogen folgende „grüne“ Gruppierungen in die neuen Landesparlamente ein: in Brandenburg Bündnis 90, in Sachsen Neues Forum, in Sachsen-Anhalt Grüne und Neues Forum, in Thüringen Neues Forum, Grüne und Demokratie Jetzt, in Berlin-West Grüne und AL, in BerlinOst Bündnis 90, Grüne und Unabhängiger Frauenverband. ${ }^{2}$ In Brandenburg und Sachsen-Anhalt die DVU, in Sachsen die NPD. ${ }^{3}$ Tolerierungsfraktion. Regierungsfraktionen sind fett markiert. Quelle: Bundeswahlleiter 2009: 96-127. 
Erstmals akut wurde dieses strategische Dilemma nach der Landtagswahl in Sachsen-Anhalt im Juni 1994. Wenige Monate vor der Bundestagswahl entschied sich der SPD-Landesvorsitzende Reinhard Höppner dafür, eine rotgrüne, von der PDS tolerierte Minderheitskoalition zu bilden - das sogenannte „Magdeburger Modell“ (Renzsch/Schieren 1997, Steffani 1998). Diese Aufweichung des ,anti-extremistischen Konsenses“ (Backes/Jesse 2000) in einem Landesverband der SPD trug möglicherweise zur Niederlage der Sozialdemokraten bei der Bundestagswahl bei, weshalb der SPD-Bundesvorstand nach der Wahl die Abgrenzungsstrategie gegenüber der PDS auf Bundes- wie auf Landesebene wieder bekräftigte. Der SPD-Parteivorsitzende Rudolf Scharping setzte sich - anders als die damaligen Ministerpräsidenten Oskar Lafontaine und Gerhard Schröder, die dem Schweriner SPD-Landesvorsitzenden Harald Ringstorff zur Bildung einer von der PDS tolerierten Minderheitsregierung rieten - vehement dafür ein, dass in Mecklenburg-Vorpommern keine Koalition mit der PDS gebildet wurde, auch wenn dies für Ringstorff den Verzicht auf das Ministerpräsidentenamt bedeutete. In Thüringen zog die SPD zur gleichen Zeit ebenfalls die Rolle eines Juniorpartners an der Seite der CDU der Bildung einer von der PDS tolerierten Minderheitsregierung vor (Schmitt 1995: 291293). In der Folgezeit entfalteten jedoch das „Magdeburger Modell“ und der Wechsel im Amt des SPD-Parteivorsitzenden von Scharping zu Lafontaine ihre Wirkung: Höppners Bildung der PDS-tolerierten Minderheitsregierung in Sachsen-Anhalt im Mai 1998 erregte kaum noch Aufsehen. Im Windschatten der Bundestagswahl 1998 kam es dann in Mecklenburg-Vorpommern zum „Schweriner Modell“ und zur ersten förmlichen SPD/PDS-Regierung auf Landesebene. Die SPD hatte damit der PDS im Osten Deutschlands faktisch den Status einer koalitionsfähigen Partei zuerkannt, wie 2001 die Bildung einer SPD/PDS-Koalition in Berlin unter Bürgermeister Klaus Wowereit und ein Jahr später die Fortführung des „Schweriner Modells“ unter Beweis stellten (Jesse 2009: 250-251).

Im Vergleich zu den ersten Koalitionsbildungen der Nachkriegszeit in Westdeutschland, wo zur Bewältigung des demokratischen Übergangs über lange Jahre hinweg oft Allparteien- und übergroße Koalitionen gebildet worden waren, folgten die Koalitionsbildungen im Osten Deutschlands den eingespielten Mechanismen konsolidierter Parteiensysteme ohne Verzögerung. Von den 28 Regierungsbildungen in den neuen Bundesländern (ohne Berlin) im Zeitraum von 1990 bis 2005 waren neun minimale (32,1 Prozent) und acht kleinstmögliche (28,6 Prozent) Mehrheitskoalitionen (zusammen 60,7 Prozent), weitere acht waren Alleinregierungen einer Partei (28,6 Prozent). Nur in 
zwei Fällen, in Brandenburg 1994 und in Sachsen-Anhalt von 1994 bis 1998, suchten die Parteien Zuflucht in einer Minderheitskoalition (7,1 Prozent); nur einmal, in Sachsen-Anhalt von 1998 bis 2002, regierte eine Partei ohne parlamentarische Mehrheit (3,6 Prozent). Eine übergroße Koalition wurde in den 15 Jahren nicht gebildet (Tabelle 6). Im Großen und Ganzen entsprachen die Koalitionsformate im Osten Deutschlands damit dem Durchschnitt aller Bundesländer in diesem Zeitraum (Tabelle 2). Die regionalen Besonderheiten in den neuen Bundesländern schlugen sich auf koalitionspolitischer Ebene allein darin nieder, dass mit der SPD/PDS-Koalition auf Landesebene ein neues Koalitionsmodell eingeführt wurde. Weil dieses anfangs politisch stark umstritten war und die PDS im Osten Deutschlands zur „Regionalpartei mit Volksparteicharakter" (Neu 2009: 224) aufstieg, die um Platz zwei im Konzert der drei großen Parteien kämpfte, wurden auch viele Koalitionen von CDU und SPD gebildet, die im Westen der Republik als untypische „Große Koalitionen“ gelten würden - insgesamt sechs zwischen 1990 und 2005 (mehr als ein Fünftel aller Koalitionen). 2004 waren diese Koalitionen in Brandenburg und Sachsen jedoch nicht nur Koalitionen minimaler Mehrheit, was sie per definitionem sind, sondern auch diejenigen mit der kleinstmöglichen Mehrheit (Tabelle 6).

Obwohl sich mit der PDS eine fünfte Partei in den Landesparlamenten Ostdeutschlands und Berlins etabliert hatte, ist es mit Blick auf den Parteienwettbewerb im Bund (und in Westdeutschland) dennoch gerechtfertigt, von einem bipolaren, sich in zwei Lager gruppierenden Vierparteiensystem zu sprechen: Zwar war die PDS von 1990 bis 1998 mit Gruppenstatus, von 1998 bis 2002 gar mit Fraktionsstatus im Deutschen Bundestag vertreten, ehe sie bei der Bundestagswahl 2002 an der Grundmandateklausel im Wahlgesetz scheiterte und nur noch zwei direkt gewählte Abgeordnete in den Bundestag entsendete (Tabelle 5), doch blieb sie bis 2005 ostdeutsche Regionalpartei, die zudem im Bund koalitionspolitisch ausgegrenzt wurde und in den westdeutschen Ländern parlamentarisch überhaupt nicht existierte. Schwarz-Gelb (1990-98) versus Rot-Grün (1998-2005) lautete deshalb die Frontstellung im Bund wie in den alten Bundesländern - mit der erwähnten Ausnahme der SPD/FDP-Koalition in Rheinland-Pfalz. Nur in den Ländern kam es hie und da überhaupt zu Abweichungen von den beiden vorherrschenden Koalitionsmodellen. Zumeist wurde in Notfällen zur erprobten Variante der lagerübergreifenden Großen Koalition gegriffen, so 1992 bis 1996 in Baden-Württemberg oder 1990 bis 2001 in Berlin. Die Große Koalition in Bremen (1995-2007) repräsentierte gar den untypischen Fall eines von beiden Partnern aus freien Stücken gesuchten Bündnisses. Jedenfalls hätte Bürgermeister Henning Scherf jederzeit auch eine 
rot-grüne Koalition bilden können, entschied sich nach dem Scheitern der Bremer „Ampel“ (1991-95) aber für die CDU. Noch fortbestehende koalitionspolitische Reserven gegenüber den Grünen bewogen auch seinen hanseatischen Bürgermeisterkollegen Henning Voscherau dazu, 1993 in Hamburg die StattPartei als Koalitionspartner zu bevorzugen. 2001 war es dann eine andere kurzzeitig „schillernde“ bürgerliche Protestpartei in Hamburg, die diesmal ein CDU-Bürgermeister mit in die Regierung aufnahm, um Rot-Grün abzulösen (Horst 2002). In Berlin kam es nur wenig später zur ersten SPD/PDS-Koalition unter Bürgermeister Klaus Wowereit in einem zumindest teilweise westlichen Bundesland (Tabelle A1 im Anhang). All dies waren jedoch Rand- oder Sonderphänomene im bundesdeutschen Parteienwettbewerb bis 2005, die sich zudem vornehmlich unter den stark kommunalpolitisch geprägten Gegebenheiten der Stadtstaaten abspielten.

\section{Koalitionsbildungen im multioptionalen Fünfparteiensystem seit 2005}

Die Bundestagswahl 2005 markierte dann jedoch eine merkliche Zäsur für den bundesdeutschen Parteienwettbewerb, weil mit der Wahlkooperation von PDS (Ost) und WASG (West) erstmals eine gesamtdeutsche Linke entstanden war, die mit einem Wahlergebnis von 8,7 Prozent der Stimmen die Grünen überflügelte und zur vierten Kraft im Deutschen Bundestag wurde. Die Linke galt zwar den anderen Parteien noch bis nach der Bundestagswahl 2009 im Bund als nicht koalitionsfähig, dennoch hatte ihre schlichte parlamentarische Existenz direkte Auswirkungen auf die Koalitionsbildung nach der Wahl. Mit ihren 54 Mandaten hielt die Linksfraktion im Deutschen Bundestag die Balance zwischen schwarz-gelbem (287 Sitze) und rot-grünem Lager (273 Mandate) und verunmöglichte jede kleine Koalitionslösung nach traditionellem Muster (Tabelle 5). Die Linke hatte somit zwar kein eigenes Koalitionspotenzial, sie erfüllte aber das nach Sartori (1976) zweite Kriterium für eine „relevante“ Partei: sie hatte „Erpressungspotenzial“, indem sie die Koalitionsmöglichkeiten der anderen Parteien einschränkte. Denen blieb als „Notlösung“ nur die Bildung einer im Grunde nicht gewollten Großen Koalition. Die Linke blieb auch während der gesamten 16. Wahlperiode das Gespenst, das die Koalitionsstrategien der anderen Parteien im Bund und in den Ländern maßgeblich beeinflusste (Ware 1996: 148-149). 


\section{a) Die Bildung der Großen Koalition nach der Bundestagswahl 2005}

Die Bildung der Großen Koalition im Jahre 2005 war gleich in mehrfacher Hinsicht eine der interessantesten Regierungsbildungen in der Geschichte der Bundesrepublik: Zunächst einmal war es bis dahin noch nie vorgekommen, dass keine der von den Parteien vor der Bundestagswahl in Aussicht genommenen Koalitionen - in diesem Fall Schwarz-Gelb und Rot-Grün - nach der Wahl realisiert werden konnte. Da die Linkspartei nicht als koalitionsfähig galt, kamen als Koalitionen möglichst kleiner Mehrheiten nur Dreier-Bündnisse in Betracht: die Ampel oder die Jamaika-Koalition (Tabelle 7). Erstere wurde jedoch von der FDP ausgeschlossen, letztere von den Grünen. Angesichts dieser festgefahrenen Situation musste es verwundern, dass Bundeskanzler Gerhard Schröder in der „Elefantenrunde“ am Wahlabend zunächst behauptete, nur er sei in der Lage, eine stabile Koalition zu bilden (Thaysen 2006a: 591). Noch wundersamer gestaltete sich dann die Fortsetzung des „Koalitionspokers“ im Stile eines „,chicken games“ (Sturm 2006: 324) in den Folgewochen: Gerhard Schröder hielt den Anspruch auf die Kanzlerschaft noch zwei Wochen lang aufrecht, obwohl dies jeder machtpolitischen Grundlage entbehrte und auch allen parlamentarischen Gepflogenheiten widersprach. Einmalig in der Geschichte der Bundesrepublik war, dass die Wähler noch 14 Tage nach der Bundestagswahl darüber im Unklaren gelassen wurden, wer die kommende Regierung führen sollte. Erst einen Monat nach der Wahl begannen die Verhandlungen zur Bildung der Großen Koalition unter Führung der designierten Bundeskanzlerin Angela Merkel. Mit 65 Tagen wurde es die zweitlängste Regierungsbildung in der bundesdeutschen Geschichte, nur die Bildung des zweiten Kabinetts von Helmut Schmidt im Jahre 1976 hatte noch neun Tage länger gedauert (Thaysen 2006b: 473-474).

Tabelle 7

Arithmetisch und politisch mögliche Koalitionen nach der Bundestagswahl 2005

\begin{tabular}{|l|c|c|}
\hline Koalition & Surplus-Mandate & $\begin{array}{c}\text { Rang kleinster } \\
\text { Mehrheit }\end{array}$ \\
\hline Ampel (rot-gelb-grün) & 26 & 1. \\
\hline Jamaika (schwarz-gelb-grün) & 30 & 2. \\
\hline Große Koalition (schwarz-rot) & 140 & 3. \\
\hline
\end{tabular}

Quelle: Sturm 2006: 325. 
Die Große Koalition war im Sinne der älteren Koalitionstheorie nur die drittbeste Lösung (Tabelle 7). Allerdings sind in spieltheoretischer Logik auch alle Dreier-Konstellationen aufgrund der mit ihnen verbundenen Transaktionskosten mit Mängeln behaftet. So irrational war die Bildung der Großen Koalition also trotz der mit ihr verbundenen Ämterverzichte für die beteiligten Parteien nicht. Die SPD schmerzte zweifelsohne der Verlust der Kanzlerschaft, aber sie ließ ihn sich mit einem gegenüber der Union gleichrangigen Kabinettsanteil angemessen entschädigen. Viel mehr als die acht Ministerposten - darunter mit dem Außen-, dem Finanz- und dem Justizministerium drei herausgehobene - hätte die SPD in einer hypothetischen Ampel-Koalition unter ihrer Führung, die sich die FDP teuer hätte abkaufen lassen, auch nicht erhalten. Auch die Union hätte in einer möglichen Jamaika-Koalition allenfalls zwei Ministerposten mehr herausschlagen können. Die Entscheidung für die Große Koalition ließ sich also durchaus mit dem Ämtererwerbsinteresse der Parteien vereinbaren. Sie war darüber hinaus eine eindrucksvolle Bestätigung für neuere neo-institutionalistisch orientierte Koalitionstheorien, denen die Policy-Präferenzen und die machtstrategischen Kalküle von Spitzenpolitikern der Parteien, faktisch der Fraktionen, für die Prozesse der Koalitionsbildung erklärungskräftiger sind als inhaltsleere Interessen der Parteien am Ämtererwerb (Sturm 2006: 326). Im Koalitionsbildungsprozess des Jahres 2005 wurde deshalb auch „ein politisches Meisterstück des Franz Müntefering“ (Thaysen 2006a: 592) wie von Angela Merkel gesehen. Vor allem Angela Merkel holte - unter tatkräftiger, wenn auch kaum beabsichtigter Mithilfe sowohl des scheidenden Kanzlers wie des ehemaligen CSU-Kanzlerkandidaten Edmund Stoiber - das Optimum für sich und ihre Partei heraus. Bereits vor den Landtagswahlen im Frühjahr 2006 prophezeiten kundige Kenner des parlamentarischen Betriebes in Berlin der Kanzlerin Merkel eine zweite Amtszeit 2009 (593-610).

Allerdings war Anfang 2006 noch lange nicht ausgemacht, wohin die Kanzlerin das Land führen wollte, wohin die Reise ins „Merkelland“ (Meng 2006) ging. Das war vielleicht die größte Hypothek der neuen Koalition: dass niemand wusste, wozu diese Zwangsehe eigentlich geschlossen worden war. Neu in der Geschichte der Bundesrepublik war auch, dass nach der Wahl zwei Partner zusammenfanden, die sich kurz zuvor im Wahlkampf noch auf das Heftigste befehdet hatten. Anders als gemeinhin üblich ging in diesem Fall der „Rosenkrieg“ (Lohse/Wehner 2009) der Eheschließung voraus und begleitete sie, anstatt dass er auf das Scheitern der Ehe folgte. Das hieß aber vor allem, dass dieser Koalition eine vorausgegangene machtpolitische Willensbildung fehlte (Murswieck 2008: 200). Anders als allen anderen Koalitionen vor ihr, 
die immer, selbst 1966 im Falle der ersten Großen Koalition, politisch gewollt waren, fehlte den Partnern dieser Koalition eine gemeinsame politische Vision, eine Raison d'être. Diese musste erst im Zuge der Koalitionsverhandlungen und der gemeinsamen Arbeit der kommenden Monate von Grund auf neu erarbeitet werden - oder die Große Koalition würde ein Übergangsphänomen und Sprungbrett sein, von dem aus die beiden Hauptakteure den Sprung in eine andere politische Konstellation wagen würden (Sturm 2006).

\section{b) Koalitionsbildungen in den Ländern im Schatten der Großen Koalition}

Die besonderen Umstände der Bundestagswahl 2005 und der anschließenden Regierungsbildung blieben nicht ohne Konsequenzen für den Parteienwettbewerb nach der Bundestagswahl. Heiner Geißler (2008: 23) beklagte zu Recht, dass „ein lang andauernder politischer Attentismus“ die ersten Monate der Großen Koalition prägte. Dafür gab es mehrere Gründe - der wichtigste bestand im Wählerauftrag an die Parteien, „die im Wahlkampf vorgetragenen Programme nicht zu realisieren“ (25). Die besondere Ironie des Wahlergebnisses erblickte Uwe Thaysen (2006a: 587) darin, dass die Wähler sich ausgerechnet des Vertrauensschutzes der beiden abgestraften Volksparteien versicherten, um eine weitestgehende Sicherung deutscher Wohlfahrtsstaatlichkeit zu gewährleisten. Besonders von der Union wurde verlangt, nach der Wahl das Gegenteil von dem zu tun, was sie vor der Wahl auf ihrem Leipziger Reformparteitag in Aussicht gestellt hatte. Die abrupte Kehrtwendung der Angela Merkel, die von ihr in dieser Zeit eingeleitete „Sozialdemokratisierung“ der Union, galt vielen innerhalb und außerhalb der Partei zwar als ,politische Todsünde“; sie konnte jedoch überzeugender noch als ,politische[n] Tugend“ interpretiert werden, weil sie vom Wähler erzwungen worden war (Geißler 2008: 26). Für die im März 2006 anstehenden ersten drei Landtagswahlkämpfe hatte der „,selbst verordnete ,Waffenstillstand' der beiden Volksparteien“ (Tenscher 2008: 107) zur Folge, dass sie als „Bundestestwahlen“ (Hough/Jeffery 2003) weitestgehend ausfielen und landespolitische Besonderheiten in den Vordergrund rückten. Im Prinzip reichte der Schatten der Großen Koalition zeitlich gesehen bis zur Bürgerschaftswahl im Mai 2007 in Bremen. Erst die Landtagswahlen in Niedersachsen und Hessen im Januar 2008 (Tabelle 8) orientierten sich dann schon auf die kommende Bundestagswahl hin. 
Koalitionsbildungen und Koalitionsstrategien im neuen Fünfparteiensystem der BRD

Tabelle 8

Mandate der Parteien nach den Landtags- und Europawahlen 2006 bis 2010

\begin{tabular}{|l|c|c|c|c|c|c|c|}
\hline Wahl und Wahltermin & Union & SPD & FDP & Grüne & Linke $^{\mathbf{1}}$ & Andere $^{2}$ & Koal. \\
\hline Baden-Württemb. 03/06 & $\mathbf{6 9}$ & 38 & $\mathbf{1 5}$ & 17 & - & - & KMK \\
\hline Rheinland-Pfalz 03/06 & 38 & $\mathbf{5 3}$ & 10 & - & - & - & ER \\
\hline Sachsen-Anhalt 03/06 & $\mathbf{4 0}$ & $\mathbf{2 4}$ & 7 & - & 26 & - & KMK \\
\hline Meckl.-Vorpomm. 09/06 & $\mathbf{2 2}$ & $\mathbf{2 3}$ & 7 & - & 13 & 6 & MMK \\
\hline Berlin 09/06 & 37 & $\mathbf{5 3}$ & 13 & 23 & $\mathbf{2 3}$ & - & KMK \\
\hline Bremen 05/07 & 23 & $\mathbf{3 2}$ & 5 & $\mathbf{1 4}$ & 7 & 2 & MMK \\
\hline Niedersachsen 01/08 & $\mathbf{6 8}$ & 48 & $\mathbf{1 3}$ & 12 & 11 & - & MMK \\
\hline Hessen 01/08 & $\mathbf{4 2}$ & 42 & 11 & 9 & 6 & - & MR \\
\hline Hamburg 02/08 & $\mathbf{5 6}$ & 45 & - & $\mathbf{1 2}$ & 8 & - & MMK \\
\hline Bayern 09/08 & $\mathbf{9 2}$ & 39 & $\mathbf{1 6}$ & 19 & - & 21 & KMK \\
\hline Hessen 01/09 & $\mathbf{4 6}$ & 29 & $\mathbf{2 0}$ & 17 & 6 & - & MMK \\
\hline Europa 06/09 & 42 & 23 & 12 & 14 & 8 & - & - \\
\hline Saarland 08/09 & $\mathbf{1 9}$ & 13 & $\mathbf{5}$ & $\mathbf{3}$ & 11 & - & KMK \\
\hline Sachsen 08/09 & $\mathbf{5 8}$ & 14 & $\mathbf{1 4}$ & 9 & 29 & 8 & MMK \\
\hline Thüringen 08/09 & $\mathbf{3 0}$ & $\mathbf{1 8}$ & 7 & 6 & 27 & - & KMK \\
\hline Brandenburg 09/09 & 19 & $\mathbf{3 1}$ & 7 & 5 & $\mathbf{2 6}$ & - & MMK \\
\hline Schleswig-Holst. 09/09 & $\mathbf{3 4}$ & 25 & $\mathbf{1 4}$ & 12 & 6 & 4 & KMK \\
\hline Nordrhein-Westf. 05/10 & 67 & $\mathbf{6 7}$ & 13 & $\mathbf{2 3}$ & 11 & - & MK \\
\hline
\end{tabular}

${ }^{1}$ Vor Gründung der Linkspartei im Juni 2007 PDS bzw. Linkspartei.PDS. ${ }^{2}$ Mecklenburg-Vorpommern und Sachsen: NPD, Bremen: DVU (1) und Bürger in Wut (1), Bayern: Freie Wähler, Schleswig-Holstein: SSW. Regierungsfraktionen sind fett markiert. Quellen: Bundes- und Landeswahlleiter.

Allen Landtagswahlen bis zum Mai 2007 war gemeinsam, dass sie die jeweils im Lande führende Regierungspartei bestätigten (Hilmer 2008). Besonders für die SPD war dies ein wichtiger Befund, weil sie damit die fast ununterbrochene Niederlagenserie aus der vorangegangenen Wahlperiode durchbrechen konnte. In Rheinland-Pfalz gelang ihr gar mit Ministerpräsident Kurt Beck der Gewinn der absoluten Mehrheit im Landesparlament. Ähnlich unangefochten regierte im angrenzenden Baden-Württemberg Günther Oettinger zusammen mit der FDP. Oettinger sondierte nach der Wahl zwar kurz mit den Grünen, hatte aber keinen Grund, die - auch in den Augen der Wähler - erfolgreiche Koalition mit den Liberalen aufzukündigen (Gabriel/Völkl 2007: 30-31). Die Sondierungsgespräche mit den Grünen waren deshalb wohl mehr 
als ein, auch von der Bundeskanzlerin gern gesehenes, koalitionspolitisches Signal für kommende Zeiten zu verstehen. In Sachsen-Anhalt bildete Ministerpräsident Wolfgang Böhmer nach der Wahl eine Koalition mit der SPD. Dies war jedoch keinem Druck der Bundesparteien, sondern allein der Tatsache geschuldet, dass es zur Fortsetzung der schwarz-gelben Koalition nach dem Ausscheiden der Liberalen aus dem Landtag nicht mehr reichte. Indirekt entfaltete die Große Koalition jedoch durchaus eine Wirkung auf die Koalitionsbildung: Indem sie den Parteienwettbewerb mäßigte, erleichterte sie es der SPD, die in der Vergangenheit durch die Tolerierungsbündnisse mit der PDS (1994-2002) erheblichen Zerreißproben ausgesetzt gewesen war, zur Geschlossenheit zurück zu finden. Eine mögliche Koalition mit der PDS war diesmal weder vor noch nach der Wahl ein Thema; das Zusammengehen mit der CDU wurde durch den wenig kontroversen Wahlkampf erleichtert (Holtmann 2007).

Wie in Sachsen-Anhalt setzte sich auch in Mecklenburg-Vorpommern im September 2006 das Format der Großen Koalition im Bund durch. Auch hier führten dazu nicht bewusste Koalitionsstrategien der handelnden Akteure oder Einflussnahmen seitens der Bundesparteien, sondern indirekte Konsequenzen aus dem auch hier deutlich entschärften Wahlkampf und den Möglichkeiten, die das Wahlergebnis den Spitzenpolitikern ließ. Ministerpräsident Harald Ringstorff hätte zwar die Koalition mit der PDS fortsetzen können - jedoch nur mit der knappsten aller Mehrheiten. Dies erschien ihm angesichts einer umtriebigen „,antikapitalistischen Linken“ im Schweriner Landesverband und einer Ansprüche stellenden PDS-Sozialministerin zu riskant (Werz/Schoon 2007: 81). Obwohl die acht Jahre währende Koalition mit der PDS eigentlich gut funktioniert und den Koalitionspartner an der Wahlurne eingedämmt hatte, entschied sich Ringstorff für die Koalition mit der CDU, die über neun Surplus-Mandate und auch die geringeren programmatischen Distanzen zwischen den Partnern verfügte. In Berlin führte das strategische Machtkalkül Bürgermeister Klaus Wowereit dagegen zu einer anders gerichteten Entscheidung: Obwohl er die Wahl zwischen einer - jeweils nur mit einem Surplus-Mandat ausgestatteten - Koalition mit den Grünen oder der PDS hatte (Tabelle 8), entschied er sich für das Bündnis mit der PDS. Eine Koalition mit der Berliner CDU hatte Wowereit von vornherein ausgeschlossen; den Ausschlag für die Linke gab deren angeblich höhere Verlässlichkeit. Für den Vorsitzenden der Bundes-SPD Kurt Beck symbolisierte dies eine „kluge Entscheidung“ Wowereits, der seinerseits betonte, dass Rot-Rot in Berlin kein Modell für den Bund sei (Adler 2006). Zukünftige politische Entwicklungen der Bundespolitik sollten jedoch zeigen, dass Wowereit sich mit seiner Berliner Koalitionsent- 
scheidung durchaus auch bundespolitisch als Repräsentant eines Linkskurses in Stellung gebracht hatte. Für Jens Böhrnsens Entscheidung in Bremen, von der Großen in eine rot-grüne Koalition zu wechseln, dürften solche bundespolitischen Ambitionen keine Rolle gespielt haben. Dennoch zeichnete sich im Mai 2007 schon ab, dass die Bundestagswahl 2009 näher rückte. Aufmerksam wurde registriert, dass sich in Bremen erstmals nach den Wahlniederlagen in Schleswig-Holstein und Nordrhein-Westfalen im Jahre 2005, die das Ende von Rot-Grün im Bund eingeleitet hatten, wieder SPD und Grüne in einer Koalition zusammenfanden. Für die Grünen ging damit eine zwei Jahre dauernde Durststrecke ohne Regierungsbeteiligung in den Ländern zu Ende.

Die Große Koalition nutzte den fast zwei Jahre währenden Schonraum bis zum Sommer 2007 durchaus zur Herausarbeitung eines spezifischen politischen Profils, das mehr als eine „Politik des kleinsten gemeinsamen Nenners“ darstellte (Egle 2009: 131-133). Ihre größten gesetzgeberischen Erfolge erzielte sie früh in der Legislaturperiode: die schrittweise Anhebung des Renteneintrittsalters auf 67 Jahre bis zum Jahre 2030, die Verlängerung des Arbeitslosengeldes (ALG I) für ältere Arbeitnehmer, die Konsolidierung des Haushalts vor der Finanzkrise - auch durch die umstrittene Mehrwertsteuererhöhung um drei Punkte („Merkelsteuer") -, die Einführung des Elterngeldes zum 1. Januar 2007, die avisierte Schaffung von zusätzlich 500.000 Krippenplätzen bis 2013, die im Sommer 2006 verabschiedete erste Stufe der Föderalismusreform und der im November 2006 verabschiedete Hochschulpakt zwischen Bund und Ländern, der bis 2010 neunzigtausend neue Studienplätze finanzieren wollte, stachen hierbei besonders hervor. Die Maßnahmen zur Gesundheits- und Pflegereform sowie die arbeitsmarktpolitischen Beschlüsse zum Niedriglohnsektor spiegelten dagegen schon die sachliche Kompromissunfähigkeit der beiden Partner auf diesen Gebieten wider (Batt 2008). Im Sommer 2007 schloss sich das "Gelegenheitsfenster“ zur Verabschiedung politischer Reformen dann weitgehend, weil der Vorrat an politischen Gemeinsamkeiten erschöpft war und das Profilierungsbedürfnis der beiden Koalitionsparteien mit Blick auf die Bundestagswahl 2009 an Oberhand gewann. Die SPD störte sich deshalb auch nicht groß daran, dass mit der Bildung der rot-grünen Koalition in Bremen die seit September 2006 bestehende Zweidrittelmehrheit im Bundesrat wieder verlorenging (Tabelle 9). Einflussnahmen zugunsten einer dem Bund konformen Koalitionsbildung, die möglich gewesen wäre, gab es keine (Hoecker 2008: 279) Die Möglichkeiten der parteipolitischen Umfunktionierung des Bundesrates zum Blockadeinstrument werden ohnehin meist überschätzt (Lehmbruch 2000). Die Große Koalition hatte noch bis zur Regierungsbildung in Hessen 
nach den Landtagswahlen im Januar 2009 die Mehrheit im Bundesrat, war aber zu großen Reformsprüngen schon längst nicht mehr in der Lage. Die kleine rot-grüne Koalition, die ab Mai 2002 ,gegen“ eine Mehrheit oppositionsnaher Länder im Bundesrat regieren musste, verwirklichte ihre großen Reformen in der Arbeitsmarktpolitik dagegen ausgerechnet zwischen März 2003 und März 2005 (Klös/Scharnagel 2009).

Tabelle 9

„Mehrheitswechsel“ im Bundesrat zwischen 1990 und 2010

\begin{tabular}{|l|c|c|c|}
\hline $\begin{array}{l}\text { Termin Wahlen / } \\
\text { Regierungsbildung }\end{array}$ & Regierungsnahe & Oppositionsnahe & Neutrale Länder \\
\hline $12 / 1990$ & 35 & 22 & 11 \\
\hline $01 / 1991$ & 31 & 26 & 11 \\
\hline $02 / 1995$ & 10 & 37 & 21 \\
\hline $05 / 1995$ & 10 & 34 & 24 \\
\hline $01 / 1996^{*}$ & 10 & 35 & 24 \\
\hline $09 / 1998^{* *}$ & 35 & 16 & 18 \\
\hline $02 / 1999$ & 30 & 21 & 18 \\
\hline $04 / 2002$ & 16 & 35 & 18 \\
\hline $05 / 2005^{* * *}$ & 0 & 47 & 22 \\
\hline $09 / 2005^{* *}$ & 36 & 0 & 33 \\
\hline $09 / 2006^{* * *}$ & 47 & 0 & 22 \\
\hline $05 / 2007$ & 44 & 0 & 25 \\
\hline $01 / 2009$ & 30 & 0 & 39 \\
\hline $09 / 2009 * *$ & 37 & 15 & 17 \\
\hline $05 / 2010$ & 31 & 21 & 17 \\
\hline
\end{tabular}

Legende: * Hessen erhält ab Januar 1996 aufgrund seines Bevölkerungszuwachses fünf statt bisher vier Stimmen. ** Regierungswechsel im Bund. *** Oppositionsnah oder regierungsnah regierte Bundesländer erreichen Zweidrittelmehrheit.

Regierungsnahe Länder $=$ Koalition wie im Bund oder Alleinregierung einer im Bund mitregierenden Partei. Oppositionsnahe Länder $=$ Alleinregierung oder Koalition von im Bund opponierenden Parteien. Neutrale Länder $=$ Koalition von zwei oder mehr Parteien, die im Bund sowohl mitregieren als auch opponieren. Regierungsparteien in den Ländern, die im Bundestag nicht repräsentiert sind, werden hier zur Opposition im Bund gerechnet. Transparente Fläche - Regierungsnahe Länder haben die Mehrheit im Bundesrat. Leicht schattierte Fläche - Regierungsnahe Länder haben die Mehrheit verloren. Stark schattierte Fläche - Oppositionsnahe Länder haben die Mehrheit.

Quellen: Wie Tabelle A1 im Anhang. Anhand der dort dokumentierten Regierungsbildungen können die hier erfolgten Zuordnungen überprüft werden. Eine solche Überprüfung ist leider bei den nicht konsistent erscheinenden Zahlen von Benz (2009: 106) aufgrund fehlender Definition der Kategorien und fehlender Quellenangaben nicht möglich. 
Koalitionsbildungen und Koalitionsstrategien im neuen Fünfparteiensystem der BRD

\section{c) Koalitionsbildungen in den Ländern im Vorfeld der Bundestagswahl 2009}

In Bremen war die Wahlkooperation von PDS und WASG, die beide einen Monat nach der Bürgerschaftswahl im Bund zur neuen Linken fusionierten (Neugebauer/Stöss 2008), erstmals in ein westdeutsches Landesparlament eingezogen (Tabelle 8). Da es sich dabei jedoch um einen Stadtstaat handelte und der Linken 23.296 Wähler reichten, um ihr beeindruckendes Ergebnis von 8,4 Prozent der Stimmen zu erzielen, war das Urteil über die Etablierung der Linken im Westen noch nicht gefällt. Die beiden Landtagswahlen im Januar 2008 sollten nun erste Hinweise auf die Frage geben, die alle etablierten Parteien umtrieb: Wie würde es um die gesamtdeutsche Zukunft der Linken bestellt sein? In Hessen hatte sich SPD-Spitzenkandidatin Andrea Ypsilanti mit ihrem „Projekt der sozialen Moderne“ ein ausgesprochen linkes Profil gegeben, zugleich aber eine Koalition mit der Linkspartei - wie auch mit der CDU von Ministerpräsident Roland Koch - vor der Wahl ausdrücklich ausgeschlossen. Da die Linke in Hessen den Einzug in das Parlament knapp schaffte, wäre nach der Wahl eine Ablösung der Koch-Regierung nur mit ihrer Hilfe möglich gewesen. Einer „Ampel“ widersetzten sich die Liberalen, einer Jamaika-Koalition die Grünen. Ypsilanti vollzog daraufhin eine Kehrtwende und versuchte mit Unterstützung der Linken ein rot-grünes Bündnis zu schmieden - ein Versuch, mit dem sie gleich zweimal, im März und im November 2008, spektakulär an Widerständen in ihrer eigenen Partei scheiterte (Zastrow 2009). Roland Koch harrte unterdessen geschäftsführend im Amt aus und konnte nach dem erwarteten Wahlsieg bei der Neuwahl im Januar 2009 eine Koalition mit der FDP bilden (Schmitt-Beck/Faas 2009a, b).

In Niedersachsen hatte die Linke mit einem besseren Ergebnis von 7,1 Prozent der Stimmen - absolut waren dies 243.361 Wähler - zwar auch den Einzug in das Landesparlament geschafft, konnte im dortigen Fünfparteiensystem jedoch nicht die Rolle eines „Züngleins an der Waage“ einnehmen, weil die niedersächsische SPD nicht die Zugkraft wie in Hessen entfaltet hatte. Die Neuauflage der von Ministerpräsident Christian Wulff geführten schwarz-gelben Koalition war deshalb Formsache (Tils/Saretzki 2008). Einen Monat später kam es in Hamburg zum ersten schwarz-grünen Bündnis auf Landesebene. Um die Schwäche der FDP in Hamburg wissend, die wieder einmal an der Sperrklausel scheiterte, hatte Bürgermeister Ole von Beust Schwarz-Grün im Wahlkampf ein Hintertürchen geöffnet und es nach einer CDU-Alleinregierung und Schwarz-Gelb zur dritten Priorität erklärt. Die Grünen hatten widersprüchliche 
Signale zur Koalition mit der CDU gesendet, sie zunächst nicht ausgeschlossen, dann doch, die SPD aber immer zu ihrem Wunschpartner erklärt. SPDSpitzenkandidat Michael Naumann geriet jedoch auf der Zielgeraden seines couragierten Wahlkampfes zwischen die Mühlsteine der Bundespolitik, als der SPD-Vorsitzende Kurt Beck in einem Hamburger Hintergrundgespräch sechs Tage vor der Wahl die Bemerkung fallen ließ, Andrea Ypsilanti wolle sich in Wiesbaden mit den Stimmen der Linken zur Ministerpräsidentin wählen lassen. Naumanns Abgrenzungsstrategie gegenüber der Linken in Hamburg hatte damit an Glaubwürdigkeit eingebüßt, die SPD jede Chance auf einen Wahlsieg verspielt. Auf die der CDU angebotene Große Koalition ließ sich Bürgermeister von Beust nicht ein - trotz größerer programmatischer Differenzen zur GAL bevorzugte er die kleine Koalitionslösung. Ein Modell für den Bund wollten die beiden Partner in ihrer Koalition nicht sehen, wohl aber ein wegweisendes Politikmodell: eine „Ergänzungskoalition“ statt einer „Schnittmengen“- bzw. „Verhinderungskoalition“ üblichen Zuschnitts (Horst 2008: 517519, 524-528).

In welche Turbulenzen das bundesdeutsche Parteiensystem zwischenzeitlich geraten war, zeigte sich im Herbst 2008 auch bei der Landtagswahl in Bayern - nur hatte dies im Freistaat ausnahmsweise nichts mit der Linken zu tun, die hier erst- und einmalig seit ihrer Gründung im Juni 2007 an der Fünfprozenthürde scheiterte (Tabelle 8). In Bayern gärte es seit dem vorauseilenden Rückzug Edmund Stoibers aus dem Bundeskabinett am 1. November 2005 in der CSU - nicht zuletzt weil der bayerische Ministerpräsident damit die Karrierepläne Günther Becksteins und Erwin Hubers zunichte gemacht hatte. Es war schließlich CSU-Landrätin Gabriele Pauli vorbehalten, Stoibers Sturz im Januar 2007 durch die CSU-Landtagsfraktion auszulösen, wenn sie sicherlich auch kaum dessen Verursacherin war (Oberreuter 2008). Beckstein (als Ministerpräsident) und Huber (als Parteivorsitzender) machten daraufhin im September 2007 doch noch den erhofften Karrieresprung, konnten das Wahldebakel der CSU aber nicht mehr abwenden, die nicht nur ihre Zweidrittelmehrheit, sondern erstmals seit 46 Jahren auch die absolute Mehrheit der Mandate im Landtag verlor und somit auf einen Koalitionspartner angewiesen war. Horst Seehofer nutzte die Wahlniederlage, um sowohl Beckstein als auch Huber in ihren Ämtern abzulösen. Für die Koalitionsbildung boten sich dem neuen Ministerpräsidenten im ,,bürgerlichen Lager“ FDP und Freie Wähler an. Obwohl aus landespolitischen Gründen manches für die Freien Wähler gesprochen hätte (Strohmeier 2009: 158), entschied sich Seehofer für die kleinstmögliche Koalition mit der FDP. Neben der größeren programmatischen Schnittmenge gaben 
auch Gründe der erwarteten Koalitionsstabilität und möglicherweise bundespolitische Zukunftspläne den Ausschlag für die FDP. Ein Jahr vor der Bundestagswahl konnte somit immerhin ein Signal für Schwarz-Gelb gegeben werden, das wenig später erwartungsgemäß auch durch die Koalitionsbildung in Hessen bekräftigt wurde. Die FDP hatte von der Beendigung der „hessischen Verhältnisse" kräftig profitiert und ermöglichte Koch das Weiterregieren (Schmitt-Beck/Faas 2009b). Durch die schwarz-gelbe Koalitionsbildung in Hessen, wo die Linke übrigens wieder in den Landtag einzog, verlor die Große Koalition die Mehrheit im Bundesrat (Tabelle 9).

\section{d) Bundespräsidenten- und Europawahl 2009 als Signale für Schwarz- Gelb}

Die Landtagswahlen in Bayern und Hessen sendeten nicht nur selbst ein schwarz-gelbes Signal, sie veränderten auch die Zusammensetzung der Bundesversammlung und beeinflussten dadurch indirekt die Tatsache, ob von der Bundespräsidentenwahl im Mai 2009 erneut ein Zeichen für Schwarz-Gelb gesetzt würde. Dass die Wahl des Staatsoberhauptes ein weiteres Mal in der Geschichte der Bundesrepublik zu einer koalitionspolitischen Richtungsentscheidung uminterpretiert werden konnte, hatte die SPD bewirkt, indem sie im Mai 2008 die Politologin Gesine Schwan als Herausforderin von Horst Köhler nominierte. Der Bundespräsident wurde zwar von den politischen Eliten in Berlin wenig positiv beurteilt, war aber im Volk beliebt. SPD-Parteichef Kurt Beck, sein Stellvertreter Frank-Walter Steinmeier und Fraktionschef Peter Struck befürworteten deshalb, auch mit Blick auf eine schwarz-rote Option nach der Bundestagswahl, eine Unterstützung Köhlers. Sie unterlagen aber innerparteilich einer Gruppe von „Netzwerkern“ und Linken, die sich mit dem Vorschlag durchsetzte, Schwan erneut zu nominieren (Sturm 2009: 378-382). Da diese in der Folgezeit ankündigte, auch mit der Linken sprechen zu wollen und zudem relativierende Bemerkungen zum „Unrechtsstaat DDR“ abgab, den sie nicht mehr pauschal als solchen verstanden wissen wollte (Schwan 2009), drohte in der Wahl des Bundespräsidenten das Menetekel eines Machtwechsels mit den Stimmen der Linken. Die Chance war zwar schon im Mai 2008 eher gering, zumal Schwan den Linken-Vorsitzenden Oskar Lafontaine einen „Demagogen" geziehen (zitiert nach Medick 2009) und die Linkspartei daraufhin Schauspieler Peter Sodann nominiert hatte. Mit den Landtagswahlen in Bayern und Hessen sanken die Chancen von Schwan weiter, weil die Freien Wähler sich auf die Wahl Köhlers festlegten und das Stimmenpotenzial für Schwan 
sich mit dem Wahlergebnis in Hessen weiter verringerte. Horst Köhler, der bereits 2004 von Angela Merkel und Guido Westerwelle als Signalgeber für Schwarz-Gelb präsentiert worden war, konnte so im 1. Wahlgang mit der absoluten Mehrheit von 613 Stimmen für eine zweite Amtszeit gewählt werden.

Nur zwei Wochen später stand mit der Europawahl eine weitere nationale „Nebenwahl“" (Reif/Schmitt 1980) an, von der sich alle Parteien ein positives Signal für die im Herbst anstehende Bundestagswahl erhofften. Wie in der Vergangenheit nutzten die Wähler, sofern sie überhaupt zur Wahl gingen, die Europawahl auch diesmal wieder als Stimmungstest für den Bund. Sie reagierten damit auch auf die Wahlkampfstrategien der Parteien, die den Europawahlkampf als Testlauf für die Bundestagswahl nutzten. Vor allem die SPD machte mit ihrem aggressiven Angriffswahlkampf gegen Union (,Dumpinglöhne würden CDU wählen“), FDP („Finanzhaie würden FDP wählen“) und Linke („,Heiße Luft würde DIE LINKE wählen") deutlich, wie die Fronten in ihrem Bundestagswahlkampf verlaufen würden. Das Wahlergebnis der SPD von 20,8 Prozent, mit dem sie gegenüber der „Hartz-Strafzettelwahl“ von 2004 noch einmal knapp und gegenüber der Bundestagswahl 2005 13,4 Prozentpunkte einbüßte, war ein Debakel und verhieß für den September nichts Gutes. Die Union, die unter dem staatstragenden Motto „Wir in Europa“ und mit dem strahlenden Konterfei der Bundeskanzlerin Wahlkampf gemacht hatte, erzielte dagegen 37,9 Prozent der Stimmen. Gegenüber 2004 hatte sie damit zwar 6,6 Prozentpunkte verloren, im Vergleich zur letzten nationalen Hauptwahl 2005 aber 2,7 Punkte zugelegt. Zusammen mit den elf Prozent der FDP, die mit Spitzenkandidatin Silvana Koch-Mehrin unter dem Wahlslogan „Für Deutschland in Europa“" ihre Nähe zur Union demonstrierte, kam Schwarz-Gelb auf eine absolute Mehrheit von 54 der 99 deutschen Mandate im Europaparlament (Tabelle 8). Auch die CSU, die einen eigenständigen Wahlkampf gemacht hatte, fasste mit ihrem Ergebnis von 48,1 Prozent wieder Tritt und übersprang mit bundesweit 7,2 Prozent die Sperrklausel (Niedermayer 2009).

Bevor der Bundestagswahlkampf nach der Sommerpause mit den drei Landtagswahlen im Saarland, in Sachsen und in Thüringen in seine heiße Phase eintreten würde, waren somit alle Weichen auf Schwarz-Gelb gestellt: Seit Januar 2008 hatten sich in drei Ländern (Niedersachsen, Bayern und Hessen) schwarz-gelbe Koalitionen etabliert, war die Bundespräsidenten- und die Europawahl im Sinne des „bürgerlichen Lagers“ verlaufen. Die drei Landtagswahlen am 30. August stellten dann zwar einen Dämpfer für die schwarz-gelben Aspirationen dar, weil die regierende CDU in allen drei Bundesländern an Zuspruch, im Saarland und in Thüringen gar die absolute Mehrheit im Landtag 
einbüßte. Sowohl im Saarland als auch in Thüringen war die CDU zwar stärkste Partei geblieben, die Koalitionsbildung war aber nicht mehr allein in ihrer Hand. Im Saarland wäre eine Dreierkoalition aus SPD, Linken und Grünen möglich gewesen, in Thüringen hätte eine Linkskoalition auch ohne die Grünen regieren können - jedoch ohne Surplus-Mandat. In beiden Bundesländern zögerten die beteiligten Parteien aufgrund diverser Fallstricke die Koalitionssondierungen bis nach der Bundestagswahl hinaus. Nur in Sachsen, wo Schwarz-Gelb eine eindeutige Mehrheit im Parlament erzielt hatte, wollten Ministerpräsident Stanislaw Tillich (CDU) und FDP-Vorsitzender Holger Zastrow mit einer zügigen Regierungsbildung ihren Parteifreunden in Berlin „Rückenwind“" geben. Bereits zwei Wochen nach der Wahl hatten sie sich auf einen Koalitionsvertrag geeinigt, um die Wahl des Ministerpräsidenten noch in der Woche vor der Bundestagswahl vornehmen zu können (Tabelle A2 im Anhang). Dem verweigerte sich jedoch die linke Alterspräsidentin des Sächsischen Landtages, die die konstituierende Sitzung im Einklang mit der Sächsischen Verfassung erst auf den 29. September einberief. Dennoch nahm der sächsische Wechsel von der CDU/SPD- zur schwarz-gelben Koalition eine „Vorreiterrolle für den Bund“ ein (Jesse 2010).

\section{e) Die Bildung der schwarz-gelben Koalition nach der Bundestagswahl 2009}

Das Ergebnis der Bundestagswahl am 27. September 2009 war nach allen Wahlumfragen der vorausgegangenen Monate und den hier dargestellten bundespolitischen Signalen keine Überraschung mehr - gemessen an der Mechanik eines Fünfparteiensystems und am Bundestagswahlergebnis 2005 war es jedoch schon eine kleine Sensation, dass diesmal wieder eine kleine ZweierKoalition aus Union und FDP möglich wurde (Pappi 2009). Ermöglicht wurde dies vor allem durch das katastrophale Abschneiden der SPD, die mit ihrem Ergebnis von 23 Prozent der Wählerstimmen den Status einer Volkspartei vorerst einbüßte. Auch die Union unterschritt mit 33,8 Prozent im Grunde die kritische Schwelle zur Volkspartei, die Peter Lösche (2009: 7) bei 35 Prozent ansetzt, durfte aber als Kanzlerpartei mit vielfältigen Machtoptionen darauf hoffen, ihrem bereits verkündeten Abgesang als Volkspartei zu widerstehen (Walter 2009). Die Koalitionsverhandlungen in Berlin waren noch nicht abgeschlossen, als manche politische Auguren der FDP bereits prophezeiten, von Bundeskanzlerin Merkel genauso „herunterregiert“ zu werden wie die SPD (Schwennicke 2009). 
Der Ablauf der Koalitionsverhandlungen und das Machttableau, das ihm entsprang, gaben für solche pessimistische Prognosen in der Tat einige Anhaltspunkte. So schnitt die FDP zwar, wie bei Koalitionsbildungen in Deutschland üblich, als kleinerer Koalitionspartner bei der Ämterverteilung im Verhältnis zu ihrem Mandatsanteil leicht überdurchschnittlich ab (Tabelle A3 im Anhang) und stellte fortan fünf Minister. Die Ämterverteilung barg für die FDP jedoch Risiken, obwohl sie mit dem Außen-, dem Wirtschafts- und dem Justizministerium drei Ressorts für sich eroberte, die traditionell den liberalen Markenkern verkörpern. An der Eignung ihres Parteivorsitzenden für das Amt des Außenministers zweifelten auch Parteifreunde; zudem sah sich Westerwelle nicht nur wie jeder seiner Vorgänger mit dem außenpolitischen Primat des Kanzlers in der „Kanzlerdemokratie“ (Niclauß 2004) konfrontiert, sondern auch mit einem außenpolitisch ambitionierten Verteidigungsminister der CSU. Der bisherige Wirtschaftsminister Karl-Theodor zu Guttenberg konnte sich sein Amt aussuchen; er entschied sich für das traditionell schwer zu führende Verteidigungsministerium, in dem schon so manche bundespolitische Karriere vorzeitig beendet - manche aber auch befördert wurde.

Wirtschaftsminister Rainer Brüderle sah sich der Gefahr ausgesetzt, gegenüber Finanzminister Wolfgang Schäuble macht- und sachpolitisch am kürzeren Hebel zu sitzen. Nicht Schäuble, sondern er würde Rechenschaft darüber geben müssen, dass das zentrale Wahlversprechen der FDP, die Steuern zu senken und zu vereinfachen, zwar Eingang in den Koalitionsvertrag (2009: 11-13) gefunden hatte, aber wie ,alle Maßnahmen“" unter Finanzierungsvorbehalt stand (20). Gesundheitsminister Philipp Rösler übernahm ein noch schwierigeres Amt. Er wurde damit beauftragt, die Krankenversicherung „langfristig ... in eine Ordnung mit ... einkommensunabhängigen Arbeitnehmerbeiträgen [zu überführen], die sozial ausgeglichen werden“" (86). Diese hier nicht so genannte Kopfpauschale sollte „,weitgehend“ von den Lohnzusatzkosten entkoppelt werden, der Arbeitgeberanteil festbleiben (86). Weil dies, zumal unter dem generellen Finanzierungsvorbehalt, weithin interpretationsbedürftig war, wurden die konkreten Entscheidungen einer Regierungskommission überantwortet. Diese Kommission, die das halbe Kabinett umfasste, nahm am 14. Februar 2010 ihre Arbeit auf. Landwirtschaftsministerin Ilse Aigner (CSU) fiel darin die Aufgabe zu, die bayerischen Interessen zu wahren und die gesundheitspolitischen Vorstellungen ihres Parteivorsitzenden einfließen zu lassen. Mit Dirk Niebel übernahm schließlich der ehemalige FDP-Generalsekretär ein Amt, das seine Partei im Wahlkampf noch abschaffen wollte (Saalfeld 2010b). 
Gab die Bundeskanzlerin somit einerseits ihrem Koalitionspartner schwer zu lösende Aufgaben mit auf den Weg, so glückten ihr andererseits mit Blick auf die Beherrschung des Kabinetts und ihrer Partei einige vorzügliche Kunstgriffe. Die Entscheidung, Wolfgang Schäuble, ihren ehemaligen Konkurrenten im Kampf um den Parteivorsitz, als Finanzminister ins Kabinett zu holen, brachte ihr Respekt von allen Seiten ein: Er war aufgrund seiner unbestrittenen politischen Statur für dieses wichtige Amt in Zeiten der Finanz- und Wirtschaftskrise schlichtweg die beste Wahl. Weil er im Alter von 67 Jahren kein Konkurrent für Merkel mehr um die politische Führung war, erschien die Wahl doppelt gut. Verteidigungsminister Guttenberg galt - unbeschadet der KundusAffäre - als der zweite männliche „Star“ dieses Kabinetts. Die Attraktion, die er auf die journalistische Zunft ausübte, würde ihn wohl auch den Untersuchungsausschuss überleben lassen. Als Angebot an die Medien wie an neue Wählerschichten war auch die kleine Personalrochade in den Ressorts für Soziales und Familie ein geschickter Schachzug. Ursula von der Leyen als Sozialministerin und Kristina Schröder als Familienministerin sollten die Union moderner, attraktiver und jugendlicher machen. Zusammen mit dem neuen Umweltminister Norbert Röttgen, der am Ausstieg an der Atomenergie, wie ihn Rot-Grün vereinbart hatte, festhalten wollte, stellten sie ein interessantes Angebot an einen potenziellen grünen Koalitionspartner in der Zukunft dar. Ronald Pofalla, der neue Minister im Bundeskanzleramt, hatte als Generalsekretär der CDU schon an solchen Zukunftsperspektiven gefeilt.

$\mathrm{Zu}$ guter Letzt wurde aufmerksam registriert, dass es keinen der angeblichen „Kronprinzen“ aus der Ministerpräsidentenriege der CDU nach Berlin ins Kabinett zog und auch keiner gerufen wurde. Angela Merkel, von manchen männlichen Politikbeobachtern gern als „Sphinx“ (Langguth 2009: 394 f.) oder „schwarze Witwe“ (Schwennicke 2009) charakterisiert, schien auch bei der Koalitionsbildung 2009 die Weichen im Hinblick auf ihre politische Zukunftssicherung mit Bedacht gestellt zu haben. Unzufriedenheit konservativer Abgeordneter, die das mangelnde Profil der Union beklagten, oder ostdeutscher Landesverbände, die ihre fehlende Repräsentanz im Kabinett monierten, gab es zwar - sie blieb jedoch folgenlos. Über die neun fehlenden Stimmen bei ihrer Wahl am 28. Oktober konnte die Bundeskanzlerin angesichts der 20 SurplusMandate ihrer Koalition großzügig hinwegsehen (Tabelle A3 im Anhang). Mit ihren insgesamt 31 Tagen gehörte die Koalitionsbildung 2009 zu den zügigeren der bisher 17 Regierungsbildungen nach Wahlen und dauerte exakt genauso lang wie die letzte Regierungsbildung Kohls und die beiden Regierungsbildungen Schröders (Thaysen 2006b: 473-474). Merkel gelang mit ihrer zweiten 
Koalitionsbildung, was bisher kein Bundeskanzler geschafft geschweige denn in Angriff genommen hätte: Sie bewältigte den Wechsel von einem Koalitionsformat (Schwarz-Rot) in ein anderes (Schwarz-Gelb). Nichts außer der Unberechenbarkeit der Zukunft sprach im Oktober 2009 dagegen, dass sie das Land und ihre Partei nicht auch noch in andere Koalitionsformate führen könnte.

\section{f) Koalitionsbildungen in den Ländern im Schatten der neuen Koalition}

Die Koalitionen, die sich in den Bundesländern parallel zur neuen Koalition im Bund und in deren Gefolge bildeten, gaben eine Ahnung von den vielfältigen Herausforderungen und Chancen, die sich im multioptionalen Fünfparteiensystem der Bundesrepublik Deutschland eröffneten. Eine Option bestand darin, dass sich auch im neuen Fünfparteiensystem die alten Lager wieder stärkten: Nach Niedersachsen, Hessen, Bayern und Sachsen gelang es Union und FDP auch in Schleswig-Holstein, eine hauchdünne Mehrheit der Mandate zu erzielen und im dortigen Sechsparteiensystem eine schwarz-gelbe Koalition zu bilden. Das Kalkül des politisch angeschlagenen Ministerpräsidenten Peter Harry Carstensen, die Landtagswahl auf den Termin der Bundestagswahl vorzuziehen und so mit Hilfe des Rückenwinds aus Berlin den Sprung von der Großen in die kleine Koalition zu schaffen, ging dank des guten Ergebnisses der FDP auf. Die schleswig-holsteinische FDP war sich ihres Beitrags zur Machtsicherung des Ministerpräsidenten bewusst und ließ sich angemessen in Ämtern und inhaltlichen Konzessionen „bezahlen“ (Horst 2010, Tabelle A3 im Anhang).

Für den Politikwissenschaftler interessanter, weil der alten Lagerlogik widersprechend, waren demgegenüber die „verschleppten“ Koalitionsbildungen im Saarland und in Thüringen sowie diejenige in Brandenburg, die sich ebenfalls im Schatten der Berliner Koalitionsbildung ereignete. In der saarländischen Konstellation waren rein rechnerisch fünf Koalitionen möglich; durch die Koalitionsaussagen im Wahlkampf waren davon drei politisch nicht ausgeschlossen: die Große Koalition als einziges mögliches Zweierbündnis, die Linkskoalition aus SPD, Linken und Grünen sowie die „Jamaika“-Koalition aus CDU, FDP und Grünen (Tabelle A2 im Anhang). Heiko Maas, der SPDSpitzenkandidat, erklärte zwar noch am Wahlabend, dass auch eine Große Koalition für ihn denkbar sei; gleichzeitig ließ er sich jedoch als Wahlsieger feiern und setzte auf den „Politikwechsel“ mit Linken und Grünen. Dies erwies sich als mutig für den Spitzenkandidaten einer Partei, die nur 24,5 Prozent der Stimmen (minus 6,3 Prozentpunkte gegenüber 2004) erzielt hatte und damit kaum stärker als Oskar Lafontaines Linkspartei war, die aus dem Stand auf 
21,3 Prozent gesprungen war. Es war zudem voreilig, weil es die Grünen wie selbstverständlich vereinnahmte. Deren Landesvorsitzender Hubert Ulrich war aber ein durchaus unabhängiger Kopf, der insbesondere gegenüber zwei Abgeordneten der Linken, Parteiwechsler von den Grünen, starke Vorbehalte hegte. Auch hatte er nicht vergessen, dass Oskar Lafontaine Wahlkampf mit dem Ziel geführt hatte, die Grünen aus dem Landtag zu ,kegeln“. Ulrich, der mit seinen Grünen in der Rolle des „Königsmachers“ war (Tabelle 8), arbeitete deshalb auf ein „Jamaika“-Bündnis hin und setzte auf einen langen Sondierungsprozess, der erst nach der Bundestagswahl abgeschlossen sein sollte.

Die Sondierungsgespräche in beide Richtungen begannen zwei Wochen nach der Landtagswahl und dauerten gut vier Wochen, bevor sich die Grünen nach drei Regionalkonferenzen auf ihrem Landesparteitag am 11. Oktober für eine der beiden Optionen entscheiden wollten. Die zwei Tage zuvor in Saarbrücken einschlagende Meldung, dass Oskar Lafontaine den Fraktionsvorsitz im Bundestag aufgeben und sich auf die Führung der Landtagsfraktion konzentrieren wolle (Georgi 2009a), spielte der Strategie Ulrichs in die Hände. Der grüne Parteivorsitzende warnte vor einem „Neben-Ministerpräsidenten“ Lafontaine, dem er nicht vertrauen könne, und überzeugte so eine Mehrheit des Parteitages, für die „Jamaika“-Option zu stimmen (FAZ.net 2009a). Bis der fertige Koalitionsvertrag der Öffentlichkeit am 5. November präsentiert werden konnte, vergingen noch einmal knapp vier Wochen. Nachdem die drei Parteien dem Verhandlungsergebnis zugestimmt hatten, konnte Peter Müller (CDU) schließlich am 10. November zum Ministerpräsidenten gewählt werden. Die Bildung der ersten „Jamaika“-Koalition auf Landesebene hatte 72 Tage in Anspruch genommen. Unter Gesichtspunkten des Ämtererwerbs und der Durchsetzung politischer Inhalte (vor allem in der Bildungspolitik) waren die Grünen der große Gewinner dieser kleinstmöglichen Koalitionsvariante (Tabelle A2 im Anhang). Weder Ämter noch policies gaben jedoch im konkreten Fall den Ausschlag bei der Koalitionswahl, denn auch SPD und Linke hatten dem zentralen Spieler im Koalitionspoker genauso weitreichende Angebote gemacht. Entscheidender Faktor war die vom grünen Spitzenpersonal als größer eingeschätzte Vertrauenswürdigkeit der schwarz-gelben Akteure, allen voran von Peter Müller, der damit nach seiner dramatischen Wahlniederlage im August eine bemerkenswerte politische Wiedergeburt feierte (Georgi 2009b).

Keine solch überraschende Wiederkehr erlebte Thüringens Ministerpräsident Dieter Althaus, der am Wahlabend des 30. August ebenfalls die absolute Mehrheit und ein Drittel der Mandate im Landtag verloren hatte - wohl aber seine Partei. Wie im Saarland lag auch hier das Gesetz des Handelns zunächst 
bei der SPD: Würde sie sich für die im Wahlkampf propagierte Ablösung des „Systems Althaus“ und den „Politikwechsel“ an der Seite der Linken und der Grünen entscheiden, dann wäre die Union raus aus dem Koalitionspoker gewesen. Zunächst deutete auch vieles auf die Linkskoalition hin, zumal sich Ministerpräsident Althaus noch einige Tage an sein Amt klammerte. Es war auch der Intervention der Bundeskanzlerin zuzuschreiben, die natürlich erklärte, „keinerlei Druck“ ausgeübt zu haben, dass Althaus vier Tage nach der Wahl dann doch den Rückzug von allen Ämtern antrat (FAZ.net 2009b). Damit war der Weg frei für den SPD-Spitzenkandidaten Christoph Matschie, ,ergebnisoffen" in beide Richtungen zu sondieren. Die Präferenz Matschies für die Koalition mit der CDU war schon zuvor offenkundig geworden, als er die im Wahlkampf aufgestellte Forderung, keinen Ministerpräsidenten der Linkspartei zu wählen, auch nach der Wahl aufrechterhielt. Über diese mit Absicht hoch gestellte Hürde sollte die PDS-Nachfolgepartei am Ende auch stolpern. Als Spitzenkandidat der nach der CDU zweitstärksten Partei im Thüringer Landtag (Tabelle 8) verwahrte sich Bodo Ramelow lange dagegen, den Anspruch auf das Ministerpräsidentenamt aufzugeben. Als er dann einlenkte und mit der grünen Bundestagsvizepräsidentin Katrin Göring-Eckardt und der unterlegenen SPD-Kandidatin für das Bundespräsidentenamt Gesine Schwan zwei Kompromisskandidatinnen ins Gespräch brachte, wurde ihm sein „drolliges Politikverständnis“ (Küpper 2009) zum Verhängnis. Mit seinem Nachgeben zog er sich nicht nur den Unmut seiner Parteiführung in Berlin, sondern auch von führenden Genossen in Erfurt zu. Matschie begründete seine Entscheidung für die Aufnahme von Koalitionsverhandlungen mit der CDU neben der inhaltlichen Kompromissunfähigkeit der Linken vor allem mit diesem „Vertrauensbruch" Ramelows in der Ministerpräsidentenfrage. Seine Partei folgte ihm in dieser Einschätzung, wenn auch eine starke innerparteiliche Opposition für eine Koalition mit der Linken optierte und die Partei vor eine Zerreißprobe stellte (Müller 2009).

Auch in Thüringen zogen die Beteiligten die Koalitionssondierungen bis nach der Bundestagswahl hin: Die Entscheidung für die Aufnahme der Koalitionsverhandlungen mit der CDU fällte die SPD erst am 1. Oktober. Die Verhandlungen selbst konnten dann zügig geführt werden und fanden ihren Abschluss am 21. Oktober in der öffentlichen Präsentation des Koalitionsvertrags. Nachdem die Landesparteitage von CDU und SPD dem Koalitionsvertrag am 25. Oktober zugestimmt hatten - die CDU einstimmig, die SPD mit 44 Gegenstimmen bei 148 Ja-Stimmen und sieben Enthaltungen -, stand der Regierungsbildung eigentlich nichts mehr im Wege (FAZ.net 2009c). Dass jedoch 
auch die Verhandlungsführer mit Unwägbarkeiten rechneten, zeigte sich darin, dass die Mitglieder des Kabinetts noch nicht nominiert waren. Die Namen der kommenden SPD-Minister waren zwar schon im Umlauf, die designierte Ministerpräsidentin Christine Lieberknecht behielt sich jedoch, weil sie die Unzufriedenheit von Vertrauten des „Althaus-Flügels“ fürchtete, die Ernennung der Kabinettsmitglieder ihrer Partei bis nach der Wahl zur Ministerpräsidentin vor. Nicht ohne Grund: Lieberknecht wurde am 30. Oktober erst im 3. Wahlgang gewählt, nachdem sie in den beiden Wahlgängen zuvor nur 44 von 48 möglichen Stimmen erzielt hatte. Die Regierungsbildung in Thüringen hatte damit 61 Tage gedauert (Tabelle A2 im Anhang), vollständig abgeschlossen war sie im Grunde erst fünf Tage später mit der Vereidigung des Kabinetts. Das CDUTablau löste „Murren“ in der Fraktion aus, weil Lieberknecht zwei AlthausVertraute nicht mehr mit Kabinettsposten bedachte und zwei Westimporte ins Kabinett holte (FAZ.net 2009d).

Lieberknecht und Matschie, die sich in ihrer Partei unter schwierigsten Bedingungen durchsetzten, waren die eindeutigen Gewinner dieser schwierigen Koalitionsbildung in Thüringen. Sowohl hinsichtlich der politischen Inhalte als auch bei der Ämterverteilung kamen sie sich großzügig und „,auf Augenhöhe“ entgegen. Beide Parteien erhielten vier Fachministerien, die CDU, die auch die Ministerpräsidentin stellte, zusätzlich das Amt des Staatskanzleichefs im Kabinettsrang. Das gute persönliche Verhältnis der beiden Pfarrerskinder Lieberknecht und Matschie, das seit ihrem jeweils untadeligen politischen Verhalten während und nach der friedlichen Revolution 1989/90 trägt, war das wohl stärkste politische Pfund im erfolgreichen Koalitionsbildungsprozess. Bemerkenswert war der im Dienste politischer Grundüberzeugungen geübte Verzicht Matschies auf das Ministerpräsidentenamt, das er in einer Linkskoalition hätte erreichen können.

In Brandenburg hatte die SPD ebenfalls die Wahl zwischen einer Koalition mit der CDU oder der Linken, allerdings waren hier die Voraussetzungen andere als in Thüringen: Die SPD hatte bereits zehn Jahre mit der CDU regiert, sieben davon unter Ministerpräsident Matthias Platzeck; die CDU war deutlich schwächer als in Thüringen und auch stärker in sich zerstritten; die Linke war in der Opposition bis 2004 zur zweitstärksten Kraft herangewachsen und schickte sich 2009 an, der seit 1990 unangefochten regierenden SPD die Führungsrolle im Land streitig zu machen. In der Bundestagswahl hatte sie die SPD wie in jedem östlichen Bundesland übertroffen (Tabelle 10); in der zeitgleich abgehaltenen Landtagswahl hatten es die Sozialdemokraten nur der Popularität Platzecks und ihrer - schon seit Stolpe (Wyssuwa 2009) - als erfolg- 
reich wahrgenommenen Regierungspolitik in Brandenburg zu verdanken, dass sie die Linke entgegen dem Bundestrend knapp in die Schranken weisen konnten. Es waren deshalb vor allem strategische Erwägungen landespolitischer Art - die größere inhaltliche Schnittmenge mit der Linken, ihre angeblich größere politische Verlässlichkeit im Vergleich zur ,tiefe(n) Zerstrittenheit“ der CDU, die (öffentlich allerdings nicht geäußerte) Möglichkeit zur Entzauberung der Linken in der Regierung -, die Platzeck (2009: 72) schon früh für eine Linkskoalition optieren ließ. Nach zweiwöchigen Sondierungen entschied sich die SPD für die Aufnahme von Koalitionsverhandlungen mit der Linken, die in weiteren zwei Wochen mit der Präsentation des Koalitionsvertrages am 27. Oktober abgeschlossen werden konnten (Tabelle A3 im Anhang).

Tabelle 10

Bundestagswahl 2009 - Ergebnisse der SPD und der Linken in Ostdeutschland (Zweitstimmenanteil, Sitze insgesamt, Direktmandate)

\begin{tabular}{|l|c|c|c|c|c|c|}
\hline & \multicolumn{3}{|l}{ SPD } & \multicolumn{2}{l|}{ Linke } \\
\hline & $\%$ & Sitze & Direkt & $\%$ & Sitze & Direkt \\
\hline Mecklenburg-Vorpommern & 16,6 & 2 & - & 29,0 & 4 & 1 \\
\hline Brandenburg & 25,1 & 5 & 5 & 28,5 & 6 & 4 \\
\hline Sachsen-Anhalt & 16,9 & 3 & - & 32,4 & 6 & 5 \\
\hline Berlin & 20,2 & 5 & 2 & 20,2 & 5 & 4 \\
\hline Sachsen & 14,6 & 5 & - & 24,5 & 8 & - \\
\hline Thüringen & 17,6 & 3 & - & 28,8 & 5 & 2 \\
\hline $\begin{array}{l}\text { Neue Bundesländer mit } \\
\text { Berlin-Ost }\end{array}$ & 17,9 & & & 28,5 & & \\
\hline $\begin{array}{l}\text { Neue Bundesländer ohne } \\
\text { Berlin-Ost }\end{array}$ & 17,9 & & & 28,0 & & \\
\hline $\begin{array}{l}\text { Neue Bundesländer mit } \\
\text { Berlin }\end{array}$ & & 23 & 7 & & 34 & 16 \\
\hline
\end{tabular}

Quelle: Der Bundeswahlleiter, http://www.bundeswahlleiter.de (Stand: 15.01.2011).

Mit der Vertrauenswürdigkeit des Personals der Linken war es jedoch nicht allzu weit her, wie sich schnell erweisen sollte. Zunächst war es der Intervention von Oskar Lafontaine vorbehalten, den innerparteilichen Diskussionsprozess über den Koalitionsvertrag noch einmal zu verlängern. Auf vier Regionalkonferenzen erhielt die Parteibasis Anfang November die Gelegenheit, den Vertrag einer gründlichen Kritik zu unterziehen. Am 4. November stimmte der 
Parteitag der Linken dann zwar genauso wie derjenige der SPD zu - bis zuletzt aber versuchte Lafontaine aufgrund des geplanten Personalabbaus im öffentlichen Dienst die Koalition zu verhindern (FAZ.net 2009e). Noch katastrophaler für die Glaubwürdigkeit der Linken und der Koalition insgesamt entwickelte sich die von Platzeck angestoßene „Versöhnungsdebatte“ gegenüber den SED-Erben, in deren Verlauf vier weitere Linken-Abgeordnete einräumen mussten, der Staatssicherheit der DDR gedient zu haben - drei hatten es vor der Wahl öffentlich gemacht. Die Zahl der stasibelasteten Mitglieder der Linksfraktion erhöhte sich damit auf sieben, was mehr als einem Viertel der ursprünglich 26-köpfigen Fraktion entsprach. Eine Vizepräsidentin des Landtags trat zurück, eine Abgeordnete legte ihr Mandat nieder, ein anderer trat aus der Fraktion aus (Bullion/Heyer 2009). Ministerpräsident Platzeck musste in einer zweiten Regierungserklärung einen „eklatante(n) Vertrauensbruch“ einzelner Abgeordneter der Linken einräumen, der auch dadurch ermöglicht worden war, dass es in Brandenburg seit 1990 nie eine systematische Stasiüberprüfung der Abgeordneten gegeben hatte (PIPr 5/5 vom 4.12.09: 153). Das von Ministerpräsident Stolpe begründete und von Platzeck fortgeführte „Kartell des Schweigens" (Birthler 2010) bildete insofern eine denkbar ungünstige Voraussetzung für die moralische Überhöhung der Brandenburger Linkskoalition zur „Versöhnungskoalition“" (Schröder 2009: 32). Platzeck wollte damit wohl überspielen, dass es ihm um pragmatischere Dinge ging: zunächst um die strategische Macht- und Zukunftssicherung seiner Partei und seiner Person in Brandenburg - das zeigte auch die für die SPD günstige Ämterverteilung in einer Koalition zweier fast gleichstarker Partner (Tabelle A3 im Anhang) -, sodann mit Blick auf den Bund um eine strategische Umorientierung der SPD nach links. Dass diese nun medial nicht mehr im Schatten der neuen Koalition und ihrer Querelen vonstatten ging, hatte sich Platzeck selbst zuzuschreiben.

\section{g) Koalitionsbildung in Nordrhein-Westfalen und Bundespräsidenten- wahl 2010: Comeback von Rot-Grün?}

Die Landtagswahl im bevölkerungsstärksten Bundesland Nordrhein-Westfalen sorgte dafür, dass die Debatte um zukünftige Koalitionsoptionen mit der Bundestagswahl 2009 und den ihr folgenden Koalitionsbildungen kein Ende fand. In Nordrhein-Westfalen, wo seit dem Sommer 2005 Ministerpräsident Jürgen Rüttgers an der Spitze einer schwarz-gelben Koalition regierte, musste sich die neugebildete Regierungskoalition im Bund am 9. Mai 2010 ihrem ersten politischen Test unterziehen. Weil die knappe schwarz-gelbe Mehrheit in der Län- 
derkammer zur Disposition stand (Tabelle 9), hatte die Berliner Koalition vereinbart, schwierige politische Entscheidungen (Haushaltssanierung, Gesundheitsreform, Verlängerung der AKW-Laufzeiten, Hartz-IV-Reform, Euro-Rettungsaktion) bis nach der Wahl zu vertagen, um die Siegchancen der Koalition nicht zu gefährden (Feist/Hoffmann 2010: 767). Hatten noch Anfang des Jahres alle Anzeichen auf eine Bestätigung Rüttgers' im Amt gedeutet - sei es an der Spitze einer schwarz-gelben, einer schwarz-grünen oder einer Großen Koalition -, so führten eine Reihe bundes- wie landespolitischer Faktoren ab Februar zur Kehrtwende in den Meinungsumfragen: Der nicht enden wollende Streit der Berliner Koalitionäre über die Auslegung des ,höchstunvollständige(n) Koalitionsvertrag(s)" (Saalfeld 2010b) und die scharfe mediale Kritik an der auf Betreiben der FDP (und CSU) erfolgten Reduzierung des Mehrwertsteuersatzes für Hotelübernachtungen führte im bundespolitischen Sog zum Absturz der FDP in den Wahlumfragen. Als dann am 20. Februar auch noch die CDUSponsoringaffäre medial skandalisiert wurde, war es bald auch um den Popularitätsvorsprung des Ministerpräsidenten geschehen, der sich bis dato im sozialdemokratischen Stammland Nordrhein-Westfalen eigentlich recht erfolgreich als „Arbeiterführer“ in Szene gesetzt hatte (Feist/Hoffmann 2010: 767-773).

Die demoskopische Ausgangslage war somit im März 2010 wieder offen. Vor diesem Hintergrund kam den Wahlkampf- und Koalitionsstrategien der Parteien auf Landes- wie auf Bundesebene eine besondere Bedeutung zu: In der Union hatte sich nach der Bundestagswahl eine Kritik konservativer Landespolitiker am mangelnden Profil der Partei in der Großen Koalition und an der „Wahlkampftaktik der weichen Botschaften“ artikuliert. Gewarnt wurde vor einer „strategischen Positionierung der CDU als neuer SPD“, die nur die FDP und den rechten Rand stärken würde. Der Kanzlerin wurde ihr ,,präsidiale(r) Stil" vorgehalten und dass ihre hohe Beliebtheit zu keinem Kanzlerbonus für die Partei geführt habe. Die Koalition mit der FDP bot aus dieser Warte nun die - bisher vertane - ,große Chance zur Durchsetzung eigener Inhalte“ und „zur stärkeren Profilierung“ (Ludwig u. a. 2010). Führende Unionspolitiker im Bund sprangen der Kanzlerin bei und verteidigten ihren, so Verteidigungsminister Guttenberg, ,exzellenten“ Führungsstil (Faz.net 2010a). Am 15. Januar verabschiedete der Bundesvorstand der CDU eine „Berliner Erklärung“, die den Modernisierungskurs Merkels stützte. Darin hieß es, dass es der CDU als „Volkspartei der Mitte“ darauf ankomme, Stammwähler zu binden, aber vor allem „neue Wähler hinzuzugewinnen“. Grundlage für die Mehrheitsfähigkeit der Partei sei ihre Identität als „Partei der Sozialen Marktwirtschaft“, für die „wirtschaftliche Vernunft und soziale Gerechtigkeit“ zusammengehörten. Be- 
sonders hervorgehoben wurden der soziale Zusammenhalt der Gesellschaft, eine ,den veränderten gesellschaftlichen Realitäten Rechnung“ tragende Familienpolitik, eine „konsequente Umwelt- und Klimaschutzpolitik“ sowie eine moderne Integrationspolitik. Die Wähler, die man hinzugewinnen wollte, waren bisherige Wähler der SPD, der Grünen und jüngere Wähler (CDU-Bundesvorstand 2010). Die „Berliner Erklärung“ war passgenau auf die Bedürfnisse von Rüttgers (2009) zugeschnitten, der schon länger auf enttäuschte SPDWähler, die sogenannten „Johannes-Rau-Wähler“, zielte und die CDU als „Schutzmacht der kleinen Leute“ aufzubauen suchte (Burger 2010b). Die nordrhein-westfälische CDU betonte zwar wiederholt - und die Bundeskanzlerin unterstützte sie darin, dass sie auf eine Fortsetzung der Koalition mit der FDP aus sei, sie hatte sich mit ihrer strategischen Positionierung jedoch auch für Schwarz-Grün und, als Notlösung, selbst für eine Große Koalition gewappnet (CDU Nordrhein-Westfalen 2010).

Die Grünen hatten ihrerseits eine ausgeklügelte Strategie in der Koalitionsfrage entwickelt: Weil sie den „Politikwechsel für Mensch und Natur“ propagierten, erklärten sie, ,als Mehrheitsbeschaffer für eine abgewählte Regierung von CDU und FDP" nicht zur Verfügung zu stehen (Grüne Nordrhein-Westfalen 2010: 3-4). Eine „Jamaika“-Koalition wurde also ausgeschlossen, eine schwarz-grüne Koalition explizit nicht. Als erste Präferenz wurde jedoch nach wie vor die Koalition mit der SPD ausgegeben, mit der die Grünen die größte programmatische Schnittmenge verband. Zur Frage einer möglichen Koalitionsbeteiligung der Linken äußerten sich die Grünen nicht eindeutig, stellten aber einige inhaltliche Kautelen auf, an denen sich die Regierungsfähigkeit der Linken messen lassen müsse. Jedweden Tolerierungsbündnissen erteilten die Grünen eine Absage: „Ein großes Industrieland wie NRW lässt sich verantwortlich nur in einer stabilen Koalition mit einem klaren Arbeitsprogramm und einem gemeinsamen Kabinett regieren" (4).

Die Frage nach der Regierungsfähigkeit der Linken stellte sich für SPDSpitzenkandidatin Hannelore Kraft noch einmal stärker als für die Grünen, weil die Linkskoalition mit den Grünen und der Linken (jedenfalls bis zum Ausbruch der Parteisponsoring-Affäre der CDU, die auch Rot-Grün wieder in Reichweite brachte) die einzig realistische Machtoption für die SPD war. Die SPD hatte sich ähnlich wie die Grünen aus ihrem Dilemma beholfen, indem sie salomonisch erklärte, in einem Fünfparteiensystem könne kein Bündnis prinzipiell ausgeschlossen werden. Die nordrhein-westfälische Linkspartei sei aber „derzeit weder regierungswillig noch regierungs- oder koalitionsfähig.“ Die SPD suchte deshalb „die Auseinandersetzung und nicht die Zusammenarbeit 
mit der Linkspartei“ (SPD Nordrhein-Westfalen 2010). Es war dem SPDBundesvorsitzenden Sigmar Gabriel, machtstrategisch eigentlich ein Befürworter von Linkskoalitionen (2008: 362), vorbehalten, schwerere Geschütze in Stellung zu bringen und darauf hinzuweisen, dass die Linkspartei in Nordrhein-Westfalen ,,völlig regierungsunfähig“ sei. Die Sozialdemokraten sollten nicht „,auch nur den Eindruck erwecken“, mit diesem „sehr chaotischen Haufen“ regieren zu wollen (Burger 2010a). Mit dem am 23. Januar 2010 angekündigten Rückzug von Oskar Lafontaine vom Amt des Parteivorsitzenden für den Mai schien jedoch der Weg frei für ein Bündnis mit der Linkspartei. Nur einen Tag später traten junge Bundestagsabgeordnete von SPD, Grünen und Linken mit einem Papier unter dem Titel „Das Leben ist bunter!“ an die Öffentlichkeit. Darin wurde zur Debatte darüber aufgerufen, ,wie es zu gesellschaftlichen und perspektivisch auch zu parlamentarischen Mehrheiten jenseits von CDU/CSU und FDP kommen kann“ (Wehner 2010). Die nordrhein-westfälische SPD vermied es bis zuletzt, sich in der Frage einer etwaigen Regierungsbeteiligung der Linken festzulegen.

Auch die Linke ihrerseits ließ die Koalitionsfrage offen. In NordrheinWestfalen lag der Landesverband ganz auf der strategischen Linie des scheidenden Vorsitzenden Lafontaine (2010), die dieser seiner Partei im Januar als Vermächtnis mit auf den Weg gegeben hatte und auch in den im März vorgestellten Entwurf für ein Grundsatzprogramm der Linken hineinschreiben ließ: Die Linke werde sich ,,an keiner Regierung beteiligen, die Privatisierungen vornimmt, Sozial- oder Arbeitsplatzabbau betreibt“ und nicht die „Lebensbedingungen der Menschen“"verbessere (Linke-Bundesvorstand 2010: 24). Dieser Satz stand wortgleich im Wahlprogramm der nordrhein-westfälischen Linken (Linke Nordrhein-Westfalen 2009: 62), die zudem ihren Anspruch in den Vordergrund rückte, ,die gesellschaftlichen Verhältnisse in NRW ändern zu wollen“. Als gesellschaftliche Alternative schwebte ihr dabei der ,demokratische Sozialismus“ vor, „eine Gesellschaft, welche die Ausbeutung von Mensch und Natur überwindet". Dazu propagierte sie unter anderem ,eine völlig neue Richtung bei der Vermögensverteilung“ (3). Systemveränderung sei aber durch parlamentarische Arbeit alleine nicht zu leisten, sondern nur im „Zusammenspiel mit außerparlamentarischen Kräften“ (62) möglich: „Deshalb ist der wichtigste Programmpunkt: Mehr werden - in der Partei, aber auch bei Protesten auf der Straße und bei Streiks in den Betrieben und Verwaltungen“ (8). Eine Partei, die in der Tradition ihrer politischen Ahnherrin Rosa Luxemburg den politischen Generalstreik wiederbeleben wollte, konnte von den ande- 
ren demokratischen Parteien eigentlich nicht als koalitionsfähig betrachtet werden.

Der FDP war die Regierungsunfähigkeit der Linken wohl von allen Parteien in Nordrhein-Westfalen am klarsten. Für die Liberalen kamen auch SPD und Grüne angesichts ihres Flirts mit einer Linkskoalition als Koalitionspartner nicht infrage. Die FDP in Nordrhein-Westfalen richtete ihre Wahlkampfstrategie folglich ganz auf ihren Koalitionspartner CDU aus. Sie behauptete, „den jahrelangen Abwärtstrend unter Rot-Grün" gestoppt und Nordrhein-Westfalen zum „Aufsteigerland“ gemacht zu haben (FDP Nordrhein-Westfalen 2010: 3). Sie reagierte damit wie schon bei der vorangegangenen Bundestagswahl auf die koalitionsstrategischen Dilemmata, die das neue Fünfparteiensystem für sie mitbrachte, indem sie diese schlichtweg ignorierte. Die „Einmannpartei im bürgerlichen Lager" (Dittberner 2009) tat so, als ob sie weiterhin in einem bipolaren Zweilagersystem agierte und setzte ganz auf die Mehrheit für SchwarzGelb.

Der Wahlausgang am 9. Mai - ein Patt zwischen CDU und SPD mit jeweils knapp 35 Prozent der Stimmen und 67 Sitzen im Landtag - reduzierte dann die den Parteien zur Verfügung stehenden Optionen deutlich: Schwarz-gelb hatte die Mehrheit verloren, Schwarz-Grün verfehlte sie um eine Stimme und stand aufgrund des Patts von CDU und SPD für die Grünen ohnehin nicht mehr zur Disposition - so blieben nur noch vier Mehrheitsbildungen für eine Regierungskoalition übrig: die Große, die Jamaika-, die Ampel- und die Links-Koalition. Weil die Dreier-Bündnisse immer von mindestens einem der potenziellen Koalitionspartner im Wahlkampf wie auch nach der Wahl ausgeschlossen worden waren und Sondierungsgespräche für ein Linksbündnis zunächst scheiterten, fokussierte sich die Aufmerksamkeit auf die Große Koalition (FAZ.net 2010b). Die Sondierungsgespräche zwischen CDU und SPD scheiterten jedoch, weil die CDU an einem Ministerpräsidenten Rüttgers festhielt, Kraft ihren Anspruch auf das Amt der Regierungschefin jedoch nicht fallenlassen wollte (FAZ.net 2010c). So kam es überraschend doch noch zu Sondierungen von SPD und Grünen mit der FDP über eine Ampel-Koalition (Burger 2010c), denen jedoch aufgrund unversöhnlicher Gegensätze der beiden kleinen Parteien auch kein Erfolg beschieden war. Damit lag der Spielball wieder bei SPDSpitzenkandidatin Kraft, die jedoch am Tag nach dem Scheitern der AmpelSondierungen (11. Juni) überraschend den Verzicht auf jegliche aktive Regierungsbildung ankündigte: Weder strebe sie die von der CDU angebotene Große noch die von den Grünen gesuchte rot-grüne Minderheitskoalition an. Auch Neuwahlen schloss sie aus, stattdessen wollte sie eine geschäftsführende 
Regierung Rüttgers aus dem Parlament heraus vor sich her treiben (Burger 2010d).

Die Ereignisse, die dann innerhalb einer Woche zur Entscheidungsumkehr Krafts und zur Bildung einer rot-grünen Minderheitskoalition führten, waren ein Lehrstück im Hinblick auf die Komplexität und Interdependenz der landeswie bundespolitischen Koalitionsstrategien im deutschen „Parteienbundesstaat" (Decker 2006): Krafts Verzicht auf die Regierungsbildung bildete die Interessen (oder auch nur Besorgnisse) der Landes-SPD, deren Vorstand sich einstimmig hinter Kraft gestellt und dabei vielleicht das Schicksal der hessischen Ypsilanti-SPD vor Augen gehabt hatte, zwar gut ab. Weniger gut nahm der Beschluss jedoch die strategischen Interessen der Bundespartei auf, die mit Blick auf die Mehrheitsverhältnisse im Bundesrat, aber auch auf generelle bundespolitische Machtperspektiven die Regierungsübernahme in NordrheinWestfalen bevorzugte. SPD-Parteichef Gabriel war daran gelegen, die Grünen nicht zu verprellen, die im Land wie im Bund energisch für die Bildung einer rot-grünen Minderheitsregierung eintraten. Auch verfolgte Gabriel zusammen mit Fraktionschef Steinmeier mit Blick auf die Bundestagswahl 2013 die Ampeloption, wozu regelmäßige Gespräche mit der FDP geführt werden sollten. Eine rot-grüne Minderheitsregierung in Düsseldorf, die sich ihre Mehrheiten im Parlament suchen müsste, konnte diesen Prozess nur befördern. Schließlich nahm zumindest Gabriel nicht unerfreut wahr, dass führende Bundespolitiker der Linkspartei kaum weniger energisch als die Grünen auf die Bildung einer Minderheitsregierung drängten (Burger/Sattar 2010a, b).

Diese allgemeine politische Strategie verfolgte der SPD-Parteivorsitzende auch bei seinem - gemeinsam mit den Grünen eingebrachten - Kandidatenvorschlag zur Bundespräsidentenwahl, die mit dem überraschenden Rücktritt von Horst Köhler am 31. Mai des Jahres fällig geworden war: Die Nominierung des DDR-Bürgerrechtlers und ehemaligen Chefs der Stasi-Unterlagenbehörde Joachim Gauck zielte erkennbar darauf, einen Keil zwischen die Partner der schwarz-gelben Regierungskoalition in Berlin zu treiben. Durchaus mit Erfolg, wie die im Juni immer lauter werdende Kritik aus einigen Landesverbänden der FDP an ihrem Bundesvorsitzenden zeigte. Guido Westerwelle hatte bei der Auswahl des gemeinsamen Kandidaten von Union und FDP, des niedersächsischen Ministerpräsidenten Christian Wulff, erkennbar keine Rolle gespielt (Carstens 2010). Weil die FDP sich auch in zentralen Sachentscheidungen der Berliner Koalition, allen voran in der Frage der Steuersenkungen und der Gesundheitsreform, nicht gegen die Union durchsetzen konnte, stürzte mit Vizekanzler Westerwelle die gesamte Koalition in die Krise. Selbst die auswärtige 
Presse registrierte erstaunt, dass ein Sturz der Regierung Merkel, sollte sie mit ihrem Vorschlag in der Bundespräsidentenwahl scheitern, nicht mehr ausgeschlossen sei (Kulish 2010). Die Berliner Koalition konnte dieses kritische Ereignis am Ende bewältigen - aber nicht ohne vorher noch ihren Kandidaten für das Bundespräsidentenamt trotz absoluter Mehrheit in der Bundesversammlung in den ersten beiden Wahlgängen scheitern zu lassen. Dies zeigte an, dass die Krise der Koalition noch lange nicht beendet war, und wurde von der rot-grünen Opposition verständlicherweise als ein Sieg in der Niederlage bewertet (FAZ.net 2010d).

In der Zusammenschau mit der Wahl Krafts zur Ministerpräsidentin einer rot-grünen Minderheitsregierung in Nordrhein-Westfalen zwei Wochen später war nur ein halbes Jahr nach dem Amtsantritt der schwarz-gelben Koalition und der historischen Niederlage der SPD ein bemerkenswertes Ergebnis zu konstatieren: Rot-Grün war wieder im Gespräch - und sollte es mit Blick auf das Superwahljahr 2011 auch bleiben, wie der Rückzug der Grünen aus der schwarz-grünen Koalition in Hamburg im November 2010 zeigte (Tabelle A1 im Anhang), der erkennbar unter dem Eindruck rot-grüner Mehrheiten in den Wahlumfragen erfolgte.

\section{Fazit: Koalitionsbildungen im deutschen Parteienbundesstaat}

Koalitionsbildungen und Koalitionsstrategien in Deutschland lassen sich mit den herkömmlichen office-, policy- und vote-seeking-Theoremen bis zu einem gewissen Grad erklären; besser verständlich werden sie jedoch, wie die vorstehenden Analysen demonstriert haben sollten, unter Einbeziehung institutioneller und politisch-kultureller Kontexte: Mit der erfolgreichen Stabilisierung der westdeutschen Demokratie und der Herausbildung eines zentrierten Dreiparteiensystem Anfang der 1960er Jahre ging auch die Professionalisierung der Parteien in dem Sinne einher, dass sie keine übergroßen Koalitionen mehr bildeten. Koalitionsbildungen minimaler oder kleinster Mehrheiten wurden nun zur Regel, weil sie maximalen Gewinn mit Blick auf den Ämtererwerb versprachen. Weit wichtiger als der Ämtererwerb war den deutschen Parteien jedoch immer die Durchsetzung von Politikinhalten und die Sicherung strategischer Machtpositionen im deutschen Bundesstaat, weshalb sich diejenigen Parteien zur Koalition zusammenfanden, welche die größten inhaltlichen Schnittmengen und eine erfolgversprechende Zukunftsperspektive miteinander verband. Das konnte wie 1966 auch eine Große Koalition sein, die in Deutschland zwar den politischen Akteuren unter demokratiepolitischen Ge- 
sichtspunkten als Ausnahmefall gilt, aber in spieltheoretischer Hinsicht dem Kriterium einer minimalen Mehrheit genügt. Faktisch deuteten sich in Deutschland die späteren Koalitionsbildungen schon im Wahlkampf an; Koalitionssignale und Koalitionsaussagen vor der Wahl determinierten die Koalitionsbildung nach der Wahl weitestgehend. Mit der deutschen Wiedervereinigung änderte sich im Wesentlichen nichts an diesen eingespielten Mechanismen. Auch im bipolaren Vierparteiensystem bildeten sich Koalitionen minimaler Mehrheiten mit den größten inhaltlichen Schnittmengen nach (zumeist) vorher ausgesendeten Koalitionssignalen. In den ostdeutschen Bundesländern kam es zur Herausbildung eines stärker polarisierten Dreiparteiensystems und - angesichts der Stärke der koalitionspolitisch ausgegrenzten Linkspartei - auch des Öfteren zur Bildung von Koalitionen der beiden West-Volksparteien CDU und SPD. Sie waren hier jedoch nicht demokratiepolitisch umstritten, sondern oft die kleinstmögliche Koalitionsvariante.

Selbst im neuen Fünfparteiensystem der Bundesrepublik Deutschland, das sich seit der Bundestagswahl 2005 mit der Etablierung der gesamtdeutschen Linken im Bund und in bisher 13 der 16 Bundesländer durchsetzte, änderte sich an den eingespielten Mustern der Koalitionsbildung nur wenig. Die Notwendigkeit, sich auf neue lagerübergreifende Koalitionsvarianten und Dreierkoalitionen einzustellen, existierte bisher mehr in der Theorie als in der Praxis. In Hamburg gab es zweieinhalb Jahre lang eine schwarz-grüne Koalition, im Saarland formierte sich im November 2009 eine Jamaika-Koalition. Der Versuch, eine Linkskoalition aus drei Partnern zu bilden, scheiterte in Hessen, im Saarland und in Thüringen; in Nordrhein-Westfalen ließ sich die rot-grüne Minderheitskoalition im Juli 2010 jedoch mit Unterstützung der Linken ins Amt heben. Der erhöhten Stress im Parteiensystem bildete sich so bisher vornehmlich darin ab, dass weniger Einparteiregierungen, die sich auf eine parlamentarische Mehrheit stützen konnten, gebildet wurden. Hier setzte sich ein Trend fort, der auch schon im bipolaren Vierparteiensystem nach 1990 zu beobachten war. Schließlich könnte es auch sein, dass Minderheitsregierungen ein häufigeres Phänomen werden als bisher in Deutschland üblich. Um hier einen Trend ablesen zu können, ist es jedoch noch zu früh. So hat die Ausdifferenzierung des Parteiensystems einstweilen bedeutsame Konsequenzen mehr auf der Ebene der Koalitionsstrategien als der tatsächlichen Koalitionsbildungen. Sie äußern sich, wie zuletzt in Nordrhein-Westfalen, in den immer feiner ziselierten, abgestuften Koalitionsaussagen. Parteien treffen inzwischen nicht mehr nur Aussagen darüber, mit wem sie koalieren wollen und mit wem nicht - sie äußern regelmäßig auch Präferenzen erster, zweiter oder gar dritter Wahl. Und 
diese Präferenzen sind im Parteienbundesstaat Deutschland immer mit Blick auf die jeweils andere staatsrechtliche Ebene zu formulieren und gegebenenfalls zu revidieren.

Für die Weiterentwicklung der Koalitionstheorie lässt sich aus den hier angestellten Untersuchungen schlussfolgern, dass zwar die Struktur des Parteiensystems und die inhaltlichen Dimensionen des Parteienwettbewerbs ohne Frage die zentralen Einflussgrößen für die Koalitionsstrategien der Parteien sind, dass aber die Beharrungskräfte politisch-kultureller Verhaltensmuster sehr ausgeprägt sind. Dies gilt besonders stark im deutschen Verbundföderalismus, der zwar auch Raum für neue Koalitionsexperimente bietet, aber durch seinen Zwang zum Dauerwahlkampf die Parteien immer wieder in altbewährte Strategien zurückfallen lässt. So scheint sich derzeit trotz der eigentlich größeren Optionspalette im Fünfparteiensystem eine Rückkehr zum bipolaren Wettbewerb zweier politischer Lager anzudeuten, was darauf hinweist, dass der Bund ungeachtet mancher regionalen Eigenwilligkeiten die Handlungsspielräume auf Landesebene weitgehend absteckt. Es ist also derzeit mehr als ungewiss, ob es tatsächlich zu Verhaltensänderungen der politischen Akteure kommt, zu denen sie die Struktur des Parteiensystems einlädt. Für die weitere Forschung erscheint es deshalb vor allem vielversprechend, sich dieser bemerkenswerten Persistenz politisch-kultureller Verhaltensmuster zuzuwenden. Weiterführende Hypothesen ließen sich derzeit am ehesten über intensive Einzelfallstudien von Koalitionsbildungsprozessen generieren, in denen die Motive und strategischen Erwägungen der politischen Akteure sowie ihre wechselseitigen Einflussnahmen auf Bundes- wie Landesebene erfahrungsnah mit geradezu ethnologischem Blick erforscht würden (Geertz 1987: 289-309). Auch in der überwiegend modellartig, mit verschiedenen Variablensets arbeitenden internationalen Koalitionsforschung ist diese Einsicht angelangt. Lieven De Winter und Patrick Dumont (2008: 154) können in ihrem Wunsch nur nachdrücklich unterstützt werden. ,[C]oalition research could benefit from more researchers abandoning for a while their computer screens, hitting the road and getting their tape recorders running. The ultimate aim of such an inductive approach should not be to write a roman fleuvre of 'formation dramatics', but to feed information gathered by thick descriptions back into theory formulation." 


\section{Literatur}

Adler, Lucas, 2006: Berlin: SPD und Linkspartei wollen Koalition fortsetzen, World Socialist Web Site.org, 10.10.06, http://www.wsws.org/de/2006/ okt2006/berl-o10.shtml (Stand. 16.12.10).

Alemann, Ulrich von, 2000: Das Parteiensystem der Bundesrepublik Deutschland, Bonn.

Backes, Uwe/Jesse, Eckhard, 2000: Antiextremistischer Konsens - Prinzipien und Praxis, in: dies. (Hrsg.), Jahrbuch Extremismus und Demokratie 12, Baden-Baden, 13-30.

Bagehot, Walter, 1915: The English Constitution, in: ders., The Works and Life, Band 5, London (Zuerst 1867/72).

Bahners, Patrick, 1998: Im Mantel der Geschichte. Helmut Kohl oder Die Unersetzlichkeit, Berlin.

Baring, Arnulf, 1969: Außenpolitik in Adenauers Kanzlerdemokratie. Bonns Beitrag zur Europäischen Verteidigungsgemeinschaft, München.

Baring, Arnulf, 1982: Machtwechsel. Die Ära Brandt-Scheel, Stuttgart.

Batt, Helge, 2008: Weder stark noch schwach - aber nicht groß: Die Große Koalition und ihre Reformpolitik, in: Jens Tenscher/Helge Batt (Hrsg.), 100 Tage Schonfrist, Wiesbaden, 215-246.

Benz, Arthur, 2009: Politik in Mehrebenensystemen, Wiesbaden.

Bergman, Torbjörn/Müller, Wolfgang C./Strom Kaare/Blomgren, Magnus, 2003: Democratic Delegation and Accountability: Cross-national Patterns, in: Kaare Strom/Wolfgang C. Müller/Torbjörn Bergman (Hrsg.), Delegation and Accountability in Parliamentary Democracies, Oxford, 109-220.

Beyme, Klaus von, 1999: Die parlamentarische Demokratie. Entstehung und Funktionsweise 1789-1999, Opladen (3. Aufl.).

Birthler, Marianne, 2010: „Kartell des Schweigens“, in: Der Spiegel, 04.01.10, 40-41.

Bösch, Frank, 2001: Die Adenauer-CDU. Gründung, Aufstieg und Krise einer Erfolgspartei 1945-1969, Stuttgart.

Bräuninger, Thomas/Debus, Marc, 2008: Der Einfluss von Koalitionsaussagen, programmatischen Standpunkten und der Bundespolitik auf die Regierungsbildung in den deutschen Ländern, in: PVS 49 (2), 309-338.

Budge, Ian/Klingemann, Hans-Dieter/Volkens, Andrea/Bara, Judith/Tanenbaum, Eric, 2001: Mapping Policy Preferences. Estimates for Parties, Electors, and Governments 1945-1998, Oxford. 
Koalitionsbildungen und Koalitionsstrategien im neuen Fünfparteiensystem der BRD

Bullion, Constanze von/Heyer, Julia Amalia, 2009: Brandenburg: Stasi-Enthüllungen - Da waren es schon sieben, Süddeutsche Zeitung.de, 03.12.09, http:// www.sueddeutsche.de/politik/74/496380/text/print.html (Stand: 27.01.11).

Bundeswahlleiter, 2009: Wahl zum 17. Deutschen Bundestag am 27. September 2009. Heft 1: Ergebnisse und Vergleichszahlen früherer Bundestags-, Europa- und Landtagswahlen sowie Strukturdaten für die Bundestagswahlkreise, Wiesbaden.

Burger, Rainer, 2010a: Gabriel lehnt Koalition mit Linkspartei ab, FAZ.net, 21.01.10, http://www.faz.net, (Stand: 16.12.10).

Burger, Rainer, 2010b: Wer hat ein Recht auf Rau?, FAZ.net, 30.01.10, http:// www.faz.net, (Stand: 16.12.10).

Burger, Rainer, 2010c: Wieder zurück im Spiel, FAZ.net, 01.06.10, http://www. faz.net, (Stand: 16.12.10).

Burger, Rainer, 2010d: Rüttgers hofft auf Verfassungsspielräume, FAZ.net, 13.06.10, http://www.faz.net, (Stand: 16.12.10).

Burger, Rainer/Sattar, Majid, 2010a: Planlos in Düsseldorf, FAZ.net, 17.06.10, http://www.faz.net, (Stand: 16.12.10).

Burger, Rainer/Sattar, Majid, 2010b: Nichts wie raus aus dem Labyrinth, FAZ. net, 18.06.10, http://www.faz.net, (Stand: 16.12.10).

Carstens, Peter, 2010: Westerwelle in der Abseitsfalle, FAZ.net, 07.06.10, http://www.faz.net, (Stand: 16.12.10).

CDU-Bundesvorstand, 2010: Berliner Erklärung. Unsere Perspektiven 2010 2013, Berlin, 15.1.10.

CDU Nordrhein-Westfalen, 2010: CDU gibt die Rüttgers-Garantie, Düsseldorf, 25.3.10.

Debus, Marc, 2007: Pre-Electoral Alliances, Coalition Rejections, and Multiparty Governments, Baden-Baden.

Decker, Frank, 2006: Direkte Demokratie im deutschen „Parteienbundesstaat“, in: APuZ, B 10, 3-10.

Decker, Frank, 2009: Koalitionsaussagen der Parteien vor Wahlen. Eine Forschungsskizze im Kontext des deutschen Regierungssystems, in: ZParl 40 (2), 431-453.

De Winter, Lieven/Dumont, Patrick, 2008: Uncertainty and Complexity in Cabinet Formation, in: Kaare Strom/Wolfgang C. Müller/Torbjörn Bergman (Hrsg.), Cabinets and Coalition Bargaining, Oxford, 123-157.

Dittberner, Jürgen, 1987: FDP - Partei der zweiten Wahl. Ein Beitrag zur Geschichte der liberalen Partei und ihrer Funktionen im Parteiensystem der Bundesrepublik, Opladen. 
Dittberner, Jürgen, 2005: Die FDP. Geschichte, Personen, Organisation, Perspektiven. Eine Einführung, Wiesbaden.

Dittberner, Jürgen, 2009: FDP - Einmannpartei im bürgerlichen Lager, in: Matthias Machnig/Joachim Raschke (Hrsg.), Wohin steuert Deutschland?, Hamburg, 250-257.

Doemens, Karl, 2005: Der Lebensabschnittsgefährte des Zeitgeists, Handelsblatt.com, 24.12.05, http://www.handelsblatt.com (Stand: 16.12.10).

Dumont, Patrick/Bäck, Hanna, 2006: Why so few, and why so late? Green parties and the question of governmental participation, in: European Journal of Political Research 45, (issue supplement 1), 35-67.

Duverger, Maurice, 1959: Die politischen Parteien, Tübingen.

Egle, Christoph, 2009: Weder Reform- noch Blockadekoalition. Die Bilanz der Großen Koalition, in: vorgänge 48 (3), 129-139.

FAZ.net, 2009a: Klare Mehrheit für „Jamaika“"Koalition, FAZ.net, 11.10.09, http://www.faz.net, (Stand: 16.12.10).

FAZ.net, 2009b: Merkel: „SPD hat keine Ausreden mehr“, FAZ.net, 03.09.09, http://www.faz.net, (Stand: 16.12.10).

FAZ.net, 2009c: SPD und CDU ebnen Weg für Koalition, FAZ.net, 25.10.09, http://www.faz.net, (Stand: 16.12.10).

FAZ.net, 2009d: Lieberknecht beendet mit neuem Kabinett die Ära Althaus, FAZ.net, 03.11.09, http://www.faz.net, (Stand: 16.12.10).

FAZ.net, 2009e: Lafontaine wollte Rot-Rot verhindern, FAZ.net, 07.11.09, http://www.faz.net, (Stand: 16.12.10).

FAZ.net, 2010a: „Moderne Führung“ statt „Gockel-Gehabe“, FAZ.net, 11.01.10, http://www.faz.net, (Stand: 16.12.10).

FAZ.net, 2010b: Ohne Drohgebärden - aber mit Rüttgers?, FAZ.net, 27.05.10, http://www.faz.net, (Stand: 16.12.10).

FAZ.net, 2010c: Große Koalition wenig wahrscheinlich - SPD enttäuscht, FAZ. net 02.06.10, http://www.faz.net, (Stand: 16.12.10).

FAZ.net, 2010d: „Ein guter Tag für die Demokratie“, FAZ.net 01.07.10, http:// www.faz.net, (Stand: 16.12.10).

Feist, Ursula/Hoffmann, Hans-Jürgen, 2010: Die nordrhein-westfälische Landtagswahl vom 9. Mai 2010: Vom Abwarten zur Kehrtwende, in: ZParl 41 (4), 766-787.

Feldkamp, Michael F., 2005: Datenhandbuch zur Geschichte des Deutschen Bundestages 1994 bis 2003, Baden-Baden.

FDP Nordrhein-Westfalen, 2010: Aufsteigerland NRW. Das Programm zur nordrhein-westfälischen Landtagswahl 2010, beschlossen in Siegen am 14.03.10. 
Koalitionsbildungen und Koalitionsstrategien im neuen Fünfparteiensystem der BRD

Gabriel, Oscar W./Völkl, Kerstin, 2007: Die baden-württembergische Landtagswahl vom 26. März 2006: Schwarzes Land mit bunten Tupfern, in: ZParl 38 (1), 16-33.

Gabriel, Sigmar, 2008: Links neu denken. Politik für die Mehrheit, München.

Gallagher, Michael/Laver, Michael/Mair, Peter, 2006: Representative Government in Modern Europe. Institutions, Parties, and Governments, Boston, Mass. (4. Aufl.)

Gamson, William A., 1961: A Theory of Coalition Formation, in: American Sociological Review 26 (3), 373-382.

Geertz, Clifford, 1987: Dichte Beschreibung. Beiträge zum Verstehen kultureller Systeme, Frankfurt am Main.

Geißler, Heiner, 2008: Zur Schonung gezwungen? Politischer Attentismus nach der Bundestagswahl 2005, in: Jens Tenscher/Helge Batt (Hrsg.), 100 Tage Schonfrist, Wiesbaden, 23-26.

Georgi, Oliver, 2009a: Lafontaine verzichtet auf Fraktionsvorsitz, FAZ.net, 09.10.09, http://www.faz.net, (Stand: 16.12.10).

Georgi, Oliver, 2009b: Peter Müller - Der Wiederkehrer, FAZ.net, 27.10.09, http://www.faz.net, (Stand: 16.12.10).

Golder, Sona Nadenichek, 2006: The Logic of Pre-Electoral Coalition Formation, Columbus, Ohio.

Grande, Edgar, 2002: Parteiensystem und Föderalismus. Institutionelle Strukturmuster und politische Dynamiken im internationalen Vergleich, in: Arthur Benz/Gerhard Lehmbruch (Hrsg.), Föderalismus. Analysen in entwicklungsgeschichtlicher und vergleichender Perspektive (PVS-Sonderheft 32/2001), Wiesbaden, 179-212.

Grüne Nordrhein-Westfalen, 2010: „9. Mai 2010: Zeit zum Wechsel!“ Leitantrag des Landesvorstands zur ordentlichen Landesdelegiertenkonferenz Essen am 6./7. Februar 2010 in Essen.

Hilmer, Richard, 2008: Landtagswahlen 2006 im Zeichen der Großen Koalition: Eine vergleichende Betrachtung, in: Jens Tenscher/Helge Batt (Hrsg.), 100 Tage Schonfrist, Wiesbaden, 93-106.

Hoecker, Beate, 2008: Die Bremer Bürgerschaftswahl vom 13. Mai 2007: Neustart für Rot-Grün und Fünf- statt Dreiparteiensystem, in: ZParl 39 (2), 270-282.

Holtmann, Everhard, 2007: Die sachsen-anhaltische Landtagswahl vom 26. März 2006: Magdeburg übernimmt das Berliner Format des „halben Machtwechsels“, in: ZParl 38 (1), 51-67. 
Horst, Patrick, 2001: Totgesagte leben häufig länger, manchmal lange. Zu den Überlebenschancen der Grünen vor dem koalitionspolitischen Erfahrungshintergrund der FDP, in: ZParl 32 (4), 841-860.

Horst, Patrick, 2002: Die Hamburger Bürgerschaftswahl vom 23. September 2001: Schillerndem „Bürger-Block“ gelingt der Machtwechsel, in: ZParl 33 (1), 43-63.

Horst, Patrick, 2008: Die Wahl zur Hamburger Bürgerschaft vom 24. Februar 2008: Wahlsieger Ole von Beust bildet die erste schwarz-grüne Koalition auf Landesebene, in: ZParl 39 (3), 509-528.

Horst, Patrick, 2010: Die schleswig-holsteinische Landtagswahl vom 27. September 2009: Ministerpräsident auf Abruf kann nach vorgezogener Neuwahl schwarz-gelbe Wunschkoalition bilden, in: ZParl 41 (2), 372-389.

Hough, Dan/Fisher, Justin, 2010: Wird alles anders? Oder viel Lärm um nichts? Die britischen Parlamentswahlen vom 6. Mai 2010, in: ZParl 41 (4), 725-739.

Hough, Daniel/Jeffery, Charlie, 2003: Landtagswahlen: Bundestestwahlen oder Regionalwahlen?, in: ZParl 34 (1), 79-94.

Jesse, Eckhard, 2009: Die koalitionspolitische Haltung der SPD gegenüber der SED, der PDS, der Linkspartei und der LINKEN, in: Antonius Liedhegener/Torsten Oppelland (Hrsg.), Parteiendemokratie in der Bewährung, Baden-Baden, 243-256.

Jesse, Eckhard, 2010: Die sächsische Landtagswahl vom 30. August 2009: Sachsens Vorreiterrolle für den Bund, in: ZParl 41 (1), 91-101.

Jun, Uwe, 1994: Koalitionsbildung in den deutschen Bundesländern. Theoretische Betrachtungen, Dokumentation und Analyse der Koalitionsbildungen auf Länderebene seit 1949, Opladen.

Jun, Uwe, 2007: Parteiensystem und Koalitionskonstellationen vor und nach der Bundestagswahl 2005, in: Frank Brettschneider/Oskar Niedermayer/ Bernhard Wessels (Hrsg.), Die Bundestagswahl 2005, Wiesbaden, 491-515. Jun, Uwe/Haas, Melanie/Niedermayer, Oskar (Hrsg.), 2008: Parteien und Parteiensysteme in den deutschen Ländern, Wiesbaden.

Koalitionsvertrag, 2009: Wachstum. Bildung. Zusammenhalt. Der Koalitionsvertrag zwischen CDU, CSU und FDP für die 17. Legislaturperiode, Berlin, 26.10.09.

Klingemann, Hans-Dieter/Volkens, Andrea/Bara, Judith L./ Budge, Ian/ McDonald, Michael D., 2001: Mapping Policy Preferences II. Estimates for Parties, Electors, and Governments in Eastern Europe, European Union, and OECD 1990-2003, Oxford. 
Koalitionsbildungen und Koalitionsstrategien im neuen Fünfparteiensystem der BRD

Klös, Hans-Peter/Scharnagel, Benjamin, 2009: Arbeitsmarktpolitik seit 2003: Reformbilanz und Handlungsbedarf, in: APuZ, B 27, 21-27.

Koalitionsvertrag zwischen CDU, CSU und FDP, 2009, http://www.cdu.de/ doc/pdfc/091026-koalitionsvertrag-cducsu-fdp.pdf (Stand 16.12.10).

Kropp, Sabine, 1999: Strategisches Koalitionshandeln und Koalitionstheorien. Konzeptionelle Überlegungen zur Untersuchung von Konflikt und Konsensbildung in Koalitionen, in: Roland Sturm/Sabine Kropp (Hrsg.), Hinter den Kulissen von Regierungsbündnissen, Baden-Baden, 44-80.

Kropp, Sabine, 2001: Regieren in Koalitionen. Handlungsmuster und Entscheidungsbildung in deutschen Länderregierungen, Wiesbaden.

Kropp, Sabine, 2008: Koalitionsregierungen, in: Oscar W. Gabriel/Sabine Kropp (Hrsg.), Die EU-Staaten im Vergleich, Wiesbaden (3. Aufl.), 514-549.

Kropp, Sabine/Schüttemeyer, Suzanne S./Sturm, Roland, 2002: Koalitionen in West- und Osteuropa. Theoretische Überlegungen und Systematisierungen des Vergleichs, in: dies. (Hrsg.), Koalitionen in West- und Osteuropa, Opladen, 7-41.

Küpper, Mechthild, 2009: Stark, klug, Frau, FAZ.net, 26.09.09, http://www.faz. net, (Stand 16.12.10).

Kulish, Nicholas, 2010: Merkel's Coalition Under Pressure in Germany, New York Times, 14.06.10, http://www.nytimes.com/2010/06/15/world/ europe/15germany.html (Stand 16.12.10).

Laakso, Markku/Taagepera, Rein, 1979: The „Effective“ Number of Parties. A Measure with Application to West Europe, in: Comparative Political Studies 12 (1), 3-27.

Lafontaine, Oskar, 2010: Zur Strategie der Partei DIE LINKE. nach der Bundestagswahl 2009, in: Neues Deutschland, 20.01.10, 7.

Langguth, Gerd, 2009: Kohl, Schröder, Merkel - Machtmenschen, München.

Laver, Michael/Shepsle, Kenneth A., 1996: Making and Braking Governments. Cabinets and Legislatures in Parliamentary Democracies, Cambridge.

Laver, Michael/Shepsle, Kenneth A., 1998: Events, Equilibra, and Government Survival, in: American Journal of Political Science 42 (1), 28-54.

Lehmbruch, Gerhard, 2000: Parteienwettbewerb im Bundesstaat, Wiesbaden (3. Aufl.).

Ley, Richard, 2010: Die Wahl der Ministerpräsidenten in den Bundesländern. Rechtslage und Staatspraxis, in: ZParl 41 (2), 390-420.

Linhart, Eric/Pappi, Franz U./Schmitt, Ralf, 2008: Die proportionale Ministerienverteilung in deutschen Koalitionsregierungen: Akzeptierte Norm oder das Ausnutzen strategischer Vorteile?, in: PVS 69 (1), 46-67. 
Linke-Bundesvorstand, 2010: Entwurf der Programmkommission für ein Programm der Partei DIE LINKE, Berlin, 21.03.10.

Linke Nordrhein-Westfalen, 2009: Original sozial - konsequent solidarisch.

Das Landeswahlprogramm 2010, beschlossen in Hamm am 08.11.09.

Lösche, Peter, 2009: Ende der Volksparteien, in: APuZ, B 51, 6-12.

Lohse, Eckart/Wehner, Markus, 2009: Rosenkrieg. Die große Koalition 2005 - 2009, Köln.

Ludwig, Saskia/Wagner, Christean/Flath, Steffen/Mohring, Mike, 2010: Mehr Profil wagen!, FAZ.net, 10.01.10, http://www.faz.net, (Stand 16.12.10).

Lupia, Arthur/Strom, Kaare, 2008: Bargaining, Transaction Costs, and Coalition Governance, in: Kaare Strom/Wolfgang C. Müller/Torbjörn Bergman (Hrsg.), Cabinets and Coalition Bargaining, Oxford, 51-83.

Martin, Lanny W./Stevenson, Randolph T., 2001: Government Formation in Parliamentary Democracies, in: American Journal of Political Science 45 (1), 33-50.

Medick, Veit, 2009: Kandidatur der Missverständnisse, Spiegel online, 22.05.09 http://www.spiegel.de/politik/deutschland/0,1518,626073,00.html (Stand 16.12.10).

Meng, Richard, 2006: Merkelland. Wohin führt die Kanzlerin?, Köln.

Michel, Marco, 2005: Die Bundestagswahlkämpfe der FDP 1949 - 2002, Wiesbaden.

Müller, Claus Peter, 2009: SPD-Vorstand entscheidet sich für CDU, FAZ.net, 01.10.09, http://www.faz.net, (Stand 16.12.10).

Müller, Wolfgang C., 2004: Koalitionstheorien, in: Ludger Helms/Uwe Jun (Hrsg.), Politische Theorie und Regierungslehre, Frankfurt a.M., 267-301. Müller, Wolfgang C., 2008: Warum Große Koalitionen? Antworten aus koalitionstheoretischer Sicht, in: ZSE 6 (3), 499-523.

Müller, Wolfgang C./Bergman, Torbjörn/Strom, Kaare, 2008: Coalition Theory and Cabinet Governance: An Introduction, in: Kaare Strom/Wolfgang C. Müller/Torbjörn Bergman (Hrsg.), Cabinets and Coalition Bargaining, Oxford, 1-50.

Murswieck, Axel, 2008: Von Schröder zu Merkel - eine Frage des (Regierungs-) Stils? Zu den Machtressourcen der Bundeskanzlerin in einer Großen Koalition, in: Jens Tenscher/Helge Batt (Hrsg.), 100 Tage Schonfrist, Wiesbaden, 199-214.

Neu, Viola, 2009: Die Linke: eine Volkspartei?, in: Volker Kronenberg/Tilman Mayer (Hrsg.), Volksparteien: Erfolgsmodell für die Zukunft?, Freiburg, 190-227. 
Koalitionsbildungen und Koalitionsstrategien im neuen Fünfparteiensystem der BRD

Neugebauer, Gero/Stöss, Richard, 2008: Die Partei DIE LINKE. Nach der Gründung in des Kaisers neuen Kleidern? Eine politische Bedarfsgemeinschaft als neue Partei im deutschen Parteiensystem, in: Oskar Niedermayer (Hrsg.), Die Parteien nach der Bundestagswahl 2005, Wiesbaden, 151-199.

Niclauß, Karlheinz, 2004: Kanzlerdemokratie. Regierungsführung von Konrad Adenauer bis Gerhard Schröder, Paderborn.

Niedermayer, Oskar, 2007: Die Entwicklung des bundesdeutschen Parteiensystems, in: Frank Decker/Viola Neu (Hrsg.), Handbuch der deutschen Parteien, Bonn, 114-135.

Niedermayer, Oskar, 2008: Das fluide Fünfparteiensystem nach der Bundestagswahl 2005, in: ders. (Hrsg.), Die Parteien nach der Bundestagswahl 2005, Wiesbaden, 9-35.

Niedermayer, Oskar, 2009: Die Wahl zum Europäischen Parlament vom 7. Juni 2009 in Deutschland: SPD-Debakel im Vorfeld der Bundestagswahl, in: ZParl 40 (4), 711-731.

Nohlen, Dieter, 2009: Wahlrecht und Parteiensystem. Zur Theorie und Empirie der Wahlsysteme, Opladen (6. Aufl.).

Nolte, Detlef, 1988: Ist die Koalitionstheorie am Ende? Eine Bilanz nach 25 Jahren Koalitionsforschung, in: Zeitschrift für Politik 29 (2), 230-251.

Oberreuter, Heinrich, 2008: Stoibers Sturz. Ein Beispiel für die Selbstgefährdung politischer Macht, in: ZParl 39 (1), 112-118.

Pappi, Franz Urban, 2009: Regierungsbildung im deutschen Fünfparteiensystem, in: PVS 50 (2), 187-202.

Pappi, Franz Urban/Becker, Axel/Herzog, Alexander, 2005: Regierungsbildung in Mehrebenensystemen: Zur Erklärung der Koalitionsbildung in den deutschen Bundesländern, in: PVS 46 (3), 432-458.

Pappi, Franz Urban/Schmitt, Ralf/Linhart, Eric, 2008: Die Ministeriumsverteilung in den deutschen Landesregierungen seit dem Zweiten Weltkrieg, in: ZParl 39 (2), 323-342.

Platzeck, Matthias, 2009: Versöhnung ernst nehmen. Warum unser Land endlich inneren Frieden braucht, in: Der Spiegel, Nr. 45, 02.11.09, $72-73$.

Raschke, Joachim: 1993: Die Grünen. Wie sie wurden, was sie sind, Köln.

Raschke, Joachim, 2001: Die Zukunft der Grünen. „So kann man nicht regieren“, Frankfurt a.M.

Reif, Karlheinz/Schmitt, Hermann, 1980: Nine Second-Order National Elections: A Conceptual Framework for the Analysis of European Election Results, in: EJPR 8 (1), 3-44. 
Renzsch, Wolfgang/Schieren, Stefan, 1997: Große Koalition oder Minderheitsregierung: Sachsen-Anhalt als Zukunftsmodell des parlamentarischen Regierungssystems in den neuen Bundesländern?, in: ZParl 28 (3), 391-407.

Riker, William H., 1962: The Theory of Political Coalitions, New Haven, Conn. Rudzio, Wolfgang, 2002: Koalitionen in Deutschland: Flexibilität informellen Regierens, in: Sabine Kropp/Suzanne S. Schüttemeyer/Roland Sturm (Hrsg.), Koalitionen in West- und Osteuropa, Opladen, 43-67.

Rüttgers, Jürgen, 2009: Die Union ist die einzige Volkspartei, in: Die Politische Meinung, Nr. 481 (Dezember), 39-44.

Saalfeld, Thomas, 2006: Parteiensystem und Kabinettsstabilität in Westeuropa 1945-1999, in: Oskar Niedermayer (Hrsg.), Die Parteiensysteme Westeuropas, Wiesbaden, 477-506.

Saalfeld, Thomas, 2007: Parteien und Wahlen, Baden-Baden.

Saalfeld, Thomas, 2010a: Die Stabilität von Koalitionsregierungen im europäischen Vergleich: Empirische Befunde und institutionelle Erklärungsansätze, in: Klemens H. Schreck/Markus Söldner (Hrsg.), Analyse demokratischer Regierungssysteme, Wiesbaden, 499-523.

Saalfeld, Thomas, 2010b: Regierungsbildung 2009: Merkel II und ein höchst unvollständiger Koalitionsvertrag, in: ZParl 41 (1), 181-206.

Sartori, Giovanni, 1976: Parties and Party Systems. A Framework for Analysis, Cambridge, Mass.

Schindler, Peter, 1999: Datenhandbuch zur Geschichte des Deutschen Bundestages 1949 bis 1999. Bd. 1, Baden-Baden.

Schmitt, Karl, 1995: Die Landtagswahlen 1994 im Osten Deutschlands. Früchte des Föderalismus: Personalisierung und Regionalisierung, in: ZParl 26 (2), 261-295.

Schmitt-Beck, Rüdiger/Faas, Thorsten, 2009a: Die hessische Landtagswahl vom 27. Januar 2008: Wiederkehr der ,hessischen Verhältnisse“, in: ZParl 40 (1), 16-34.

Schmitt-Beck, Rüdiger/Faas, Thorsten, 2009b: Die hessische Landtagswahl vom 18. Januar 2009: der „ewige Koch“, in: ZParl 40 (2), 358-370.

Schröder, Richard, 2009: Versöhnung - mit wem? Warum die Linke nicht ausgegrenzt ist, in: Der Spiegel, Nr. 46, 09.11.09, 32-33.

Schroeder, Wolfgang (Hrsg.), 2008: Parteien und Parteiensystem in Hessen. Vom Vier- zum Fünfparteiensystem?, Wiesbaden.

Schüttemeyer, Suzanne S., 1998: Fraktionen im Deutschen Bundestag. Empirische Befunde und theoretische Folgerungen, Opladen. 
Koalitionsbildungen und Koalitionsstrategien im neuen Fünfparteiensystem der BRD

Schüttemeyer, Suzanne S., 1999: Koalitionsbildungen im Bund: Sache der Parteien?, in: Roland Sturm/Sabine Kropp (Hrsg.), Hinter den Kulissen von Regierungsbündnissen, Baden-Baden, 81-95.

Schwan, Gesine, 2009: In der Falle des Totalitarismus, in: Die Zeit, 25.06.09, 13.

Schwennicke, Christoph, 2009: Merkel und die FDP - Die schwarze Witwe, Spiegel online, 20.10.09, http://www.spiegel.de/politik/deutschland/0,1518,656141,00.html (Stand 16.12.10).

SPD Nordrhein-Westfalen, 2010: Pressemitteilung vom 21.01.10.

Steffani, Winfried, 1997a: Die Republik der Landesfürsten, in: ders., Gewaltenteilung und Parteien im Wandel, Opladen, 56-88.

Steffani, Winfried, 1997b: Semipräsidentialismus?, in: ders., Gewaltenteilung und Parteien im Wandel, Opladen, 89-124.

Steffani, Winfried, 1998: Wer trägt die Verantwortung? Wider die wissenschaftliche und politische Verharmlosung des „Magdeburger Modells“, in: ZParl 29 (1), 189-190.

Strohmeier, Gerd, 2009: Quo vadis CSU? Die bayerische Landtagswahl 2008 und ihre Folgen, in: Volker Kronenberg/Tilman Mayer (Hrsg.), Volksparteien: Erfolgsmodell für die Zukunft?, Freiburg, 143-161.

Strom, Kaare/Müller, Wolfgang C./Bergman, Torbjörn (Hrsg.), Cabinets and Coalition Bargaining: The Democratic Life Cycle in Western Europe, Oxford.

Sturm, Daniel Friedrich, 2009: Wohin geht die SPD?, München.

Sturm, Roland, 2006: Übergang oder Aufbruch? Die Perspektiven des neuen Regierungsbündnisses, in: Eckhard Jesse/Roland Sturm (Hrsg.), Bilanz der Bundestagswahl 2005, Wiesbaden, 323-341.

Tenscher, Jens, 2008: Große Koalition - kleine Wahlkämpfe? Die Parteienkampagnen zu den Landtagswahlen 2006 im Vergleich, in: Jens Tenscher/Helge Batt (Hrsg.), 100 Tage Schonfrist, Wiesbaden, 23-26.

Thaysen, Uwe, 2006a: Regierungsbildung 2005: Merkel, Merkel I, Merkel II?, in: ZParl 37 (3), 582-610.

Thaysen, Uwe, 2006b: Regierungsbildung in der Bundesrepublik Deutschland: Daten zum Start der Regierung Merkel 2005/2006, in: ZParl 37 (3), 470480.

Tils, Ralf/Saretzki, Thomas, 2008: Die niedersächsische Landtagswahl vom 27. Januar 2008: Popularität, Wahlstrategie und Oppositionsschwäche sichern Ministerpräsident Christian Wulff die schwarz-gelbe Mehrheit, in: ZParl 39 (2), 282-298. 
Völkl, Kerstin u.a. (Hrsg.), 2008: Wähler und Landtagswahlen in der Bundesrepublik Deutschland, Baden-Baden.

Vorländer, Hans, 2004: Die Schattenpartei. Mit Erfolg aus dem Scheinwerferlicht verschwunden: Die FDP, in: Hans Zehetmair (Hrsg.), Das deutsche Parteiensystem, Wiesbaden, 159-171.

Vorländer, Hans, 2008: Partei der Paradoxien. Die FDP nach der Bundestagswahl 2005, in: Oskar Niedermayer (Hrsg.), Die Parteien nach der Bundestagswahl 2005, Wiesbaden, 135-150.

Walter, Franz, 2009: Im Herbst der Volksparteien? Eine kleine Geschichte von Aufstieg und Rückgang politischer Massenintegration, Bielefeld.

Ware, Alan, 1996: Political Parties and Party Systems, Oxford.

Wehner, Markus, 2010: Oslo lässt grüßen, in: FAS, 24.01.10, 4.

Wengst, Udo, 1985: Auftakt zur Ära Adenauer. Koalitionsverhandlungen und Regierungsbildung 1949, Düsseldorf.

Werz, Nikolaus/Schoon, Steffen, 2007: Die mecklenburg-vorpommersche Landtagswahl vom 17. September 2006: Ein halber Regierungswechsel und das Ende des Dreiparteiensystems, in: ZParl 38 (1), 67-83.

Wyssuwa, Matthias, 2009: Stolpes Werk und Platzecks Beitrag, FAZ.net, 28.09.09, http://www.faz.net, (Stand 16.12.10).

Zastrow, Volker, 2009: Die Vier. Eine Intrige, Berlin.

Korrespondenzanschrift:

Dr. Patrick Horst

Universität Passau

Lehrstuhl für Politikwissenschaft (Prof. Dr. Gellner)

Dr.-Hans-Kapfinger-Straße 14

94032 Passau

E-Mail: patrick.horst@uni-passau.de 
Koalitionsbildungen und Koalitionsstrategien im neuen Fünfparteiensystem der BRD

\section{Anhang}

Tabelle A1

Regierungen und Regierungskoalitionen in Bund und Ländern 1946 bis 2010

\begin{tabular}{|c|c|c|c|c|}
\hline Wahl & $\begin{array}{l}\text { Termin } \\
\text { Wahl / } \\
\text { Reg.bildung } \\
\end{array}$ & Regierungsparteien & $\begin{array}{l}\text { BK, MP, } \\
\text { BM }\end{array}$ & $\begin{array}{l}\text { Koali- } \\
\text { tionstyp }\end{array}$ \\
\hline Bremen & 13.10 .1946 & SPD, BDV, KPD & Kaisen & ÜK \\
\hline Hamburg & 13.10 .1946 & SPD, FDP, KPD & Brauer & ÜK \\
\hline Berlin & 20.10 .1946 & SPD, CDU, LPD, SED & Ostrowski & ÜK \\
\hline Württemberg-Baden & 24.11 .1946 & DVP, CDU, SPD, KPD & Maier & ÜK \\
\hline Bayern & 01.12 .1946 & CSU, SPD, WAV & Ehard & ÜK \\
\hline Hessen & 01.12 .1946 & SPD, CDU & Stock & MMK \\
\hline Niedersachsen & 20.04 .1947 & $\begin{array}{l}\text { SPD, CDU, DP, FDP, Z, } \\
\text { KPD }\end{array}$ & Kopf & ÜK \\
\hline Nordrhein-Westfalen & 20.04 .1947 & CDU, SPD, Z, KPD & Arnold & ÜK \\
\hline Schleswig-Holstein & 20.04 .1947 & SPD & Lüdemann & ER \\
\hline Baden & 18.05 .1947 & BCSV/CDU, SP/SPD & Wohlleb & ÜK \\
\hline Rheinland-Pfalz & 18.05 .1947 & CDU, SPD, FDP, KPD & Altmeier & ÜK \\
\hline Württemberg-Hz. & 18.05 .1947 & CDU, SPD, DVP & Bock & ÜK \\
\hline Berlin & Juni 1947 & $S P D, C D U, L P D, S E D$ & Reuter & $\ddot{U} K$ \\
\hline Bayern & 24.06 .1947 & $C S U, S P D$ & Ehard & $\ddot{U} K$ \\
\hline Bayern & 21.09 .1947 & CSU & Ehard & $E R$ \\
\hline Saarland & 05.10 .1947 & CVP, SPS, Parteilose & Hoffmann & ÜK \\
\hline Bremen & 12.10 .1947 & SPD, BDV/FDP & Kaisen & MMK \\
\hline Baden & Februar 1948 & CDU & Wohlleb & ER \\
\hline Nordrhein-Westfalen & 07.02 .1948 & $C D U, S P D, Z$ & Arnold & $\ddot{U} K$ \\
\hline Niedersachsen & $\begin{array}{l}\text { Februar } \\
1948\end{array}$ & $S P D, C D U, D P, F D P, Z$ & Kopf & $\ddot{U} K$ \\
\hline Rheinland-Pfalz & 29.04 .1948 & $C D U, S P D$ & Altmeier & $M M K$ \\
\hline Niedersachsen & Juni 1948 & $S P D, C D U, Z$ & Kopf & $\ddot{U} K$ \\
\hline Württemberg-Baden & Juli 1948 & $D V P, C D U, S P D$ & Maier & $\ddot{U} K$ \\
\hline Hamburg & 28.07 .1948 & $S P D, F D P$ & Brauer & $\ddot{U} K$ \\
\hline Württemberg-Hz. & August 1948 & $C D U, S P D, D V P$ & Müller & $\ddot{U} K$ \\
\hline Berlin & 05.12 .1948 & SPD, CDU, LPD & Reuter & ÜK \\
\hline Bund & 14.08 .1949 & CDU, CSU, FDP, DP & Adenauer & MMK \\
\hline
\end{tabular}


Patrick Horst

\begin{tabular}{|c|c|c|c|c|}
\hline Schleswig-Holstein & 29.08 .1949 & $S P D$ & Diekmann & $E R$ \\
\hline Württemberg-Hz. & Sept. 1949 & $C D U, S P D$ & Müller & $\ddot{U} K$ \\
\hline Rheinland-Pfalz & Oktober 1949 & $C D U^{*}$ & Altmeier & $M R$ \\
\hline Hamburg & 16.10 .1949 & SPD & Brauer & ER \\
\hline Rheinland-Pfalz & Dez. 1949 & $C D U, S P D$ & Altmeier & $M M K$ \\
\hline Nordrhein-Westfalen & 18.06 .1950 & $\mathrm{CDU}^{*}$ & Arnold & $\mathrm{MR}$ \\
\hline Schleswig-Holstein & 09.07 .1950 & $\begin{array}{l}\text { CDU, GB/BHE, DP, } \\
\text { FDP }\end{array}$ & Bartram & ÜK \\
\hline Nordrhein-Westfalen & 15.09.1950 & $C D U, Z$ & Arnold & $K M K$ \\
\hline Niedersachsen & 18.09 .1950 & $S P D, Z^{*}$ & Kopf & $M K$ \\
\hline Hessen & 19.11 .1950 & SPD & Zinn & ER \\
\hline Württemberg-Baden & 19.11 .1950 & FDP/DVP, SPD & Maier & KMK \\
\hline Bayern & 26.11 .1950 & CSU, SPD, BHE & Ehard & ÜK \\
\hline Berlin & 03.12 .1950 & SPD, CDU, FDP & Reuter & ÜK \\
\hline Saarland & April 1951 & CVP & Hoffmann & $E R$ \\
\hline Rheinland-Pfalz & 29.04 .1951 & CDU, FDP & Altmeier & KMK \\
\hline Niedersachsen & 06.05 .1951 & SPD, GB/BHE, Z & Kopf & ÜK \\
\hline Schleswig-Holstein & 25.06 .1951 & $C D U, F D P^{*}$ & Lübke & $M K$ \\
\hline Schleswig-Holstein & 28.07 .1951 & $\begin{array}{l}C D U, G B / B H E, D P, \\
F D P\end{array}$ & Lübke & $\ddot{U} K$ \\
\hline Bremen & 07.10 .1951 & SPD, CDU, FDP & Kaisen & ÜK \\
\hline Schleswig-Holstein & 04.01 .1952 & $C D U, G B / B H E, D P$ & Lübke & $M M K$ \\
\hline Baden-Württemberg & 09.03 .1952 & FDP/DVP, SPD, BHE & Maier & ÜK \\
\hline Saarland & 30.11 .1952 & $C V P, S P S$ & Hoffmann & $\ddot{U} K$ \\
\hline Schleswig-Holstein & Januar 1953 & $C D U, G B / B H E^{*}$ & Lübke & $M K$ \\
\hline Bund & 06.09 .1953 & $\begin{array}{l}\text { CDU, CSU, FDP, DP, } \\
\text { GB/BHE }\end{array}$ & Adenauer & ÜK \\
\hline Baden-Württemberg & 07.10 .1953 & $\begin{array}{l}C D U, S P D, F D P / D V P, \\
G B / B H E\end{array}$ & Müller & $\ddot{U} K$ \\
\hline Hamburg & 01.11 .1953 & CDU, FDP, DP & Sieveking & KMK \\
\hline Berlin & 12.11 .1953 & $C D U, F D P$ & Schreiber & $K M K$ \\
\hline Niedersachsen & 01.12 .1953 & $S P D, G B / B H E$ & Kopf & $M M K$ \\
\hline Nordrhein-Westfalen & 27.06.1954 & CDU, FDP, Z & Arnold & ÜK \\
\hline Saarland & 17.07.1954 & CVP & Hoffmann & $E R$ \\
\hline Schleswig-Holstein & 12.09 .1954 & CDU, GB/BHE, FDP & Hassel & ÜK \\
\hline Bayern & 28.11 .1954 & SPD, BP, GB/BHE, FDP & Hoegner & ÜK \\
\hline
\end{tabular}


Koalitionsbildungen und Koalitionsstrategien im neuen Fünfparteiensystem der BRD

\begin{tabular}{|c|c|c|c|c|}
\hline Hessen & 28.11 .1954 & SPD, GB/BHE & Zinn & KMK \\
\hline Berlin & 05.12 .1954 & SPD, CDU & Suhr & ÜK \\
\hline Niedersachsen & 24.04 .1955 & $\begin{array}{l}\text { DP, CDU, GB/BHE, } \\
\text { FDP }\end{array}$ & Hellwege & MMK \\
\hline Rheinland-Pfalz & 15.05 .1955 & CDU, FDP & Altmeier & ÜK \\
\hline Bund & 23.07 .1955 & $C D U, C S U, F D P, D P$ & Adenauer & $\ddot{U} K$ \\
\hline Bremen & 09.10 .1955 & SPD, CDU, FDP & Kaisen & ÜK \\
\hline Saarland & 29.10 .1955 & Parteilose & Welsch & - \\
\hline Saarland & 18.12 .1955 & $\begin{array}{l}\text { CDU, DPS, SPD, } \\
\text { Parteilose }\end{array}$ & Ney & ÜK \\
\hline Bund & 25.02 .1956 & $C D U, C S U, D P$ & Adenauer & $\ddot{U} K$ \\
\hline Nordrhein-Westfalen & 28.02 .1956 & $S P D, F D P, Z$ & Steinhoff & $\ddot{U} K$ \\
\hline Baden-Württemberg & 04.03 .1956 & $\begin{array}{l}\text { CDU, SPD, FDP, GB/ } \\
\text { BHE }\end{array}$ & Müller & ÜK \\
\hline Bund & 21.03 .1956 & $\begin{array}{l}C D U, C S U, D P, D A / \\
F V P\end{array}$ & Adenauer & $\ddot{U} K$ \\
\hline Saarland & Dez. 1956 & $C D U, S P D^{*}$ & Ney & $M K$ \\
\hline Saarland & Juni 1957 & $C D U, D P S, S P D$ & Reinert & $\ddot{U} K$ \\
\hline Bund & 15.09.1957 & CDU, CSU, DP & Adenauer & ÜK \\
\hline Berlin & 03.10 .1957 & $S P D, C D U$ & Brandt & $\ddot{U} K$ \\
\hline Bayern & 16.10 .1957 & $C S U, G B / B H E, F D P$ & Seidel & $M M K$ \\
\hline Hamburg & 10.11 .1957 & SPD, FDP & Brauer & ÜK \\
\hline Niedersachsen & 19.11.1957 & $D P, C D U, S P D$ & Hellwege & $\ddot{U} K$ \\
\hline Nordrhein-Westfalen & 06.07 .1958 & $\mathrm{CDU}$ & Meyers & ER \\
\hline Schleswig-Holstein & 28.09 .1958 & CDU, FDP & Hassel & MMK \\
\hline Bayern & 23.11 .1958 & CSU, GB/BHE, FDP & Seidel & ÜK \\
\hline Hessen & 23.11 .1958 & SPD, GB/BHE & Zinn & KMK \\
\hline Berlin & 07.12 .1958 & SPD, CDU & Brandt & ÜK \\
\hline Baden-Württemberg & 17.12 .1958 & $\begin{array}{l}C D U, S P D, F D P, G B / \\
B H E\end{array}$ & Kiesinger & $\ddot{U} K$ \\
\hline
\end{tabular}


Patrick Horst

\begin{tabular}{|c|c|c|c|c|}
\hline Saarland & $\begin{array}{l}\text { Februar } \\
1959\end{array}$ & $C D U, S P D, C V P$ & Reinert & $\ddot{U} K$ \\
\hline Saarland & April 1959 & $C D U, S P D^{*}$ & Röder & $M K$ \\
\hline Niedersachsen & 19.04 .1959 & $\mathrm{SPD}, \mathrm{GB} / \mathrm{BHE}, \mathrm{FDP}$ & Kopf & MMK \\
\hline Rheinland-Pfalz & 19.04.1959 & CDU, FDP & Altmeier & ÜK \\
\hline Bremen & 11.10 .1959 & SPD, FDP & Kaisen & ÜK \\
\hline Bayern & 26.01 .1960 & $C S U, G B / B H E, F D P$ & Ehard & $\ddot{U} K$ \\
\hline Baden-Württemberg & 15.05 .1960 & CDU, FDP, GB/BHE & Kiesinger & ÜK \\
\hline Bund & 01.07 .1960 & $C D U, C S U$ & Adenauer & $E R$ \\
\hline Saarland & 04.12 .1960 & CDU, FDP/DPS & Röder & KMK \\
\hline Hamburg & 01.01 .1961 & $S P D, F D P$ & Nevermann & $\ddot{U} K$ \\
\hline Bund & 17.09.1961 & CDU, CSU, FDP & Adenauer & ММК \\
\hline Hamburg & 12.11.1961 & SPD, FDP & Nevermann & ÜK \\
\hline Niedersachsen & Dez. 1961 & $S P D, G B / B H E, F D P$ & Diederichs & $M M K$ \\
\hline Nordrhein-Westfalen & 08.07 .1962 & CDU, FDP & Meyers & KMK \\
\hline Schleswig-Holstein & 23.09 .1962 & CDU* & Hassel & MR \\
\hline Hessen & 11.11 .1962 & $\mathrm{SPD}, \mathrm{GDP} / \mathrm{BHE}$ & Zinn & ÜK \\
\hline Bund & 19.11.1962 & $C D U, C S U^{*}$ & Adenauer & $M R$ \\
\hline Bayern & 25.11 .1962 & $\mathrm{CSU}$ & Goppel & ER \\
\hline Bund & 11.12 .1962 & $C D U, C S U, F D P$ & Adenauer & MMK \\
\hline Schleswig-Holstein & 07.01 .1963 & $C D U, F D P$ & Lemke & $M M K$ \\
\hline Berlin & 17.02 .1963 & SPD, FDP & Brandt & ÜK \\
\hline Rheinland-Pfalz & 31.03 .1963 & CDU, FDP & Altmeier & KMK \\
\hline Niedersachsen & 19.05 .1963 & SPD, FDP & Diederichs & KMK \\
\hline Bremen & 29.09 .1963 & SPD, FDP & Kaisen & ÜK \\
\hline Bund & 17.10 .1963 & $C D U, C S U, F D P$ & Erhard & MMK \\
\hline Baden-Württemberg & 26.04 .1964 & CDU, FDP & Kiesinger & KMK \\
\hline Niedersachsen & 19.05.1965 & $S P D, C D U$ & Diederichs & $M M K$ \\
\hline
\end{tabular}


Koalitionsbildungen und Koalitionsstrategien im neuen Fünfparteiensystem der BRD

\begin{tabular}{|l|l|l|l|l|}
\hline Hamburg & 09.06 .1965 & SPD, FDP & Weichmann & ÜK \\
\hline Saarland & 27.06 .1965 & CDU, FDP/DPS & Röder & KMK \\
\hline Bremen & 20.07 .1965 & SPD, FDP & Dehnkamp & ÜK \\
\hline & & & & \\
\hline Bund & $\mathbf{1 9 . 0 9 . 1 9 6 5}$ & CDU, CSU, FDP & Erhard & MMK \\
\hline & & & & \\
\hline Hamburg & 27.03 .1966 & SPD & Weichmann & ER \\
\hline Nordrhein-Westfalen & 10.07 .1966 & CDU, FDP & Meyers & KMK \\
\hline & & & & \\
\hline Bund & $\mathbf{2 8 . 1 0 . 1 9 6 6}$ & CDU, CSU & Erhard & MR \\
\hline & & & & \\
\hline Hessen & 06.11 .1966 & SPD & Zinn & ER \\
\hline Bayern & 20.11 .1966 & CSU & Goppel & ER \\
\hline & & & & \\
\hline Bund & $\mathbf{0 1 . 1 2 . 1 9 6 6}$ & CDU, CSU, SPD & Kiesinger & MMK \\
\hline & & & & \\
\hline Nordrhein-Westfalen & 08.12 .1966 & SPD, FDP & Kühn & KMK \\
\hline Berlin & 14.12 .1966 & SPD, FDP & Albertz & ÜK \\
\hline Baden-Württemberg & 16.12 .1966 & CDU, SPD & Filbinger & MMK \\
\hline Berlin & 12.03 .1967 & SPD, FDP & Albertz & ÜK \\
\hline Schleswig-Holstein & 23.04 .1967 & CDU, FDP & Lemke & KMK \\
\hline Rheinland-Pfalz & 23.04 .1967 & CDU, FDP & Altmeier & MMK \\
\hline Niedersachsen & 04.06 .1967 & SPD, CDU & Diederichs & MMK \\
\hline Bremen & 01.10 .1967 & SPD, FDP & Koschnick & MMK \\
\hline Berlin & 19.10 .1967 & SPD, FDP & Schütz & ÜK \\
\hline Baden-Württemberg & 28.04 .1968 & CDU, SPD & Filbinger & MMK \\
\hline Rheinland-Pfalz & Mai 1969 & CDU, FDP & Kohl & MMK \\
\hline Bund & & & & \\
\hline & $\mathbf{2 8 . 0 9 . 1 9 6 9}$ & SPD, FDP & Brandt & KMK \\
\hline Hessen & Oktober 1969 & SPD & Osswald & ER \\
\hline Hamburg & 22.03 .1970 & SPD, FDP & Weichmann & ÜK \\
\hline Niedersachsen & 14.06 .1970 & SPD & Kubel & ER \\
\hline Nordrhein-Westfalen & 14.06 .1970 & SPD, FDP & Kühn & KMK \\
\hline Saarland & 14.06 .1970 & CDU & Röder & ER \\
\hline Hessen & 08.11 .1970 & SPD, FDP & Osswald & KMK \\
\hline Bayern & 22.11 .1970 & CSU & Goppel & ER \\
\hline Berlin & 14.03 .1971 & SPD & Schütz & ER \\
\hline & & & & \\
\hline
\end{tabular}


Patrick Horst

\begin{tabular}{|c|c|c|c|c|}
\hline Rheinland-Pfalz & 21.03 .1971 & $\mathrm{CDU}$ & Kohl & ER \\
\hline Schleswig-Holstein & 25.04 .1971 & $\mathrm{CDU}$ & Stoltenberg & ER \\
\hline Hamburg & 09.06 .1971 & $S P D, F D P$ & Schulz & $\ddot{U} K$ \\
\hline Bremen & Juni 1971 & $S P D^{*}$ & Koschnick & $M R$ \\
\hline Bremen & 10.10 .1971 & SPD & Koschnick & ER \\
\hline Baden-Württemberg & 23.04 .1972 & CDU & Filbinger & ER \\
\hline Bund & 19.11.1972 & SPD, FDP & Brandt & МMK \\
\hline Hamburg & 03.03 .1974 & SPD, FDP & Schulz & KMK \\
\hline Bund & 16.05.1974 & $S P D, F D P$ & Schmidt & MMK \\
\hline Niedersachsen & 09.06 .1974 & SPD, FDP & Kubel & KMK \\
\hline Bayern & 27.10 .1974 & CSU & Goppel & ER \\
\hline Hessen & 27.10 .1974 & SPD, FDP & Osswald & KMK \\
\hline Hamburg & 12.11.1974 & $S P D, F D P$ & Klose & $K M K$ \\
\hline Berlin & 02.03 .1975 & SPD, FDP & Schütz & KMK \\
\hline Rheinland-Pfalz & 09.03 .1975 & CDU & Kohl & ER \\
\hline Schleswig-Holstein & 13.04 .1975 & CDU & Stoltenberg & ER \\
\hline Nordrhein-Westfalen & 04.05 .1975 & SPD, FDP & Kühn & KMK \\
\hline Saarland & 04.05 .1975 & CDU* & Röder & MR \\
\hline Bremen & 28.09 .1975 & SPD & Koschnick & ER \\
\hline Niedersachsen & 06.02 .1976 & $C D U^{*}$ & Albrecht & $M R$ \\
\hline Baden-Württemberg & 04.04 .1976 & $\mathrm{CDU}$ & Filbinger & ER \\
\hline Hessen & 20.10 .1976 & $S P D, F D P$ & Börner & $K M K$ \\
\hline Bund & 03.10.1976 & SPD, FDP & Schmidt & KMK \\
\hline Rheinland-Pfalz & Dez. 1976 & $C D U$ & Vogel & $E R$ \\
\hline Niedersachsen & 19.01.1977 & $C D U, F D P$ & Albrecht & $K M K$ \\
\hline Saarland & 01.03 .1977 & $C D U, F D P$ & Röder & $K M K$ \\
\hline Berlin & 12.05 .1977 & $S P D, F D P$ & Stobbe & $K M K$ \\
\hline Hamburg & 04.06 .1978 & SPD & Klose & ER \\
\hline Niedersachsen & 04.06 .1978 & $\mathrm{CDU}$ & Albrecht & ER \\
\hline Baden-Württemberg & 30.08 .1978 & $C D U$ & Späth & $E R$ \\
\hline Nordrhein-Westfalen & Sept. 1978 & $S P D, F D P$ & Rau & $K M K$ \\
\hline Hessen & 08.10 .1978 & SPD, FDP & Börner & KMK \\
\hline
\end{tabular}


Koalitionsbildungen und Koalitionsstrategien im neuen Fünfparteiensystem der BRD

\begin{tabular}{|l|l|l|l|l|}
\hline Bayern & 15.10 .1978 & CSU & Strauß & ER \\
\hline Berlin & 18.03 .1979 & SPD, FDP & Stobbe & KMK \\
\hline Rheinland-Pfalz & 18.03 .1979 & CDU & Vogel & ER \\
\hline Schleswig-Holstein & 29.04 .1979 & CDU & Stoltenberg & ER \\
\hline Saarland & Juli 1979 & CDU, FDP & Zeyer & KMK \\
\hline Bremen & 07.10 .1979 & SPD & Koschnick & ER \\
\hline Baden-Württemberg & 16.03 .1980 & CDU & Späth & ER \\
\hline Saarland & 27.04 .1980 & CDU, FDP & Zeyer & KMK \\
\hline Nordrhein-Westfalen & 11.05 .1980 & SPD & Rau & ER \\
\hline & & & & \\
\hline Bund & $\mathbf{0 5 . 1 0 . 1 9 8 0}$ & SPD, FDP & Schmidt & KMK \\
\hline & & & & \\
\hline Berlin & 23.01 .1981 & SPD, FDP & Vogel & KMK \\
\hline Berlin & 10.05 .1981 & CDU* & Weizsäcker & MR \\
\hline Hamburg & 24.06 .1981 & SPD & Dohnanyi & ER \\
\hline Niedersachsen & 21.03 .1982 & CDU & Albrecht & ER \\
\hline Hamburg & 06.06 .1982 & SPD* & Dohnanyi & MR \\
\hline & & & & \\
\hline Bund & $\mathbf{1 7 . 0 9 . 1 9 8 2}$ & SPD* & Schmidt & MR \\
\hline & & & & \\
\hline Hessen & 26.09 .1982 & SPD* & Börner & MR \\
\hline & & & & \\
\hline Bund & $\mathbf{0 1 . 1 0 . 1 9 8 2}$ & CDU, CSU, FDP & Kohl & KMK \\
\hline & & & & \\
\hline Bayern & 10.10 .1982 & CSU & Strauß & ER \\
\hline Schleswig-Holstein & 14.10 .1982 & CDU & Barschel & ER \\
\hline Hamburg & 19.12 .1982 & SPD & Dohnanyi & ER \\
\hline Rheinland-Pfalz & 06.03 .1983 & CDU & Vogel & ER \\
\hline & & & Karschel & ER \\
\hline Bund & $\mathbf{0 6 . 0 3 . 1 9 8 3}$ & CDU, CSU, FDP & Koizäcker & KMK \\
\hline & & & Börner & MR \\
\hline Schleswig-Holstein & 13.03 .1983 & CDU & Diepgen & KMK \\
\hline Berlin & 17.03 .1983 & CDU, FDP & Späth & ER \\
\hline Bremen & 25.09 .1983 & SPD & Diepgen & KMK \\
\hline Hessen & 25.09 .1983 & SPD* & & \\
\hline Berlin & 09.02 .1984 & CDU, FDP & \\
\hline Baden-Württemberg & 25.03 .1984 & CDU & & \\
\hline Berlin & 10.03 .1985 & CDU, FDP & & \\
\hline & & & & \\
\hline
\end{tabular}


Patrick Horst

\begin{tabular}{|c|c|c|c|c|}
\hline Saarland & 10.03 .1985 & SPD & Lafontaine & ER \\
\hline Nordrhein-Westfalen & 12.05 .1985 & SPD & Rau & ER \\
\hline Bremen & 18.09 .1985 & $S P D$ & Wedemeier & $E R$ \\
\hline Hessen & 12.12 .1985 & SPD, Grüne & Börner & $K M K$ \\
\hline Niedersachsen & 15.06 .1986 & CDU, FDP & Albrecht & KMK \\
\hline Bayern & 12.10 .1986 & $\mathrm{CSU}$ & Strauß & ER \\
\hline Hamburg & 09.11 .1986 & SPD* & Dohnanyi & MR \\
\hline Bund & 25.01.1987 & CDU, CSU, FDP & Kohl & MMK \\
\hline Hessen & 10.02.1987 & $S P D^{*}$ & Börner & $M R$ \\
\hline Hessen & 05.04 .1987 & CDU, FDP & Wallmann & KMK \\
\hline Hamburg & 17.05 .1987 & SPD, FDP & Dohnanyi & KMK \\
\hline Rheinland-Pfalz & 17.05 .1987 & CDU, FDP & Vogel & MMK \\
\hline Bremen & 13.09.1987 & SPD & Wedemeier & ER \\
\hline Schleswig-Holstein & 13.09 .1987 & CDU* & Schwarz & MR \\
\hline Baden-Württemberg & 20.03 .1988 & $\mathrm{CDU}$ & Späth & ER \\
\hline Schleswig-Holstein & 08.05.1988 & SPD & Engholm & ER \\
\hline Hamburg & 08.06 .1988 & $S P D, F D P$ & Voscherau & $K M K$ \\
\hline Bayern & 19.10 .1988 & $C S U$ & Streibl & $E R$ \\
\hline Rheinland-Pfalz & 08.12 .1988 & $C D U, F D P$ & Wagner & $M M K$ \\
\hline Berlin & 29.01 .1989 & SPD, AL & Momper & MMK \\
\hline Saarland & 28.01 .1990 & SPD & Lafontaine & ER \\
\hline Niedersachsen & 13.05 .1990 & SPD, Grüne & Schröder & KMK \\
\hline Nordrhein-Westfalen & 13.05 .1990 & SPD & Rau & ER \\
\hline Bund & 03.10 .1990 & $C D U, C S U, F D P, D S U$ & Kohl & $\ddot{U} K$ \\
\hline Bayern & 14.10 .1990 & $\mathrm{CSU}$ & Streibl & ER \\
\hline Brandenburg & 14.10 .1990 & SPD, FDP, B 90 & Stolpe & KMK \\
\hline Meckl.-Vorpommern & 14.10 .1990 & CDU, FDP & Gomolka & KMK \\
\hline Sachsen & 14.10 .1990 & CDU & Biedenkopf & ER \\
\hline Sachsen-Anhalt & 14.10.1990 & CDU, FDP & Gies & MMK \\
\hline Thüringen & 14.10 .1990 & CDU, FDP & Duchac & MMK \\
\hline Berlin & 15.11 .1990 & $S P D^{*}$ & Momper & $M R$ \\
\hline Berlin & 02.12 .1990 & CDU, SPD & Diepgen & MMK \\
\hline Bund & 02.12.1990 & CDU, CSU, FDP & Kohl & МMK \\
\hline
\end{tabular}


Koalitionsbildungen und Koalitionsstrategien im neuen Fünfparteiensystem der BRD

\begin{tabular}{|c|c|c|c|c|}
\hline Hessen & 20.01 .1991 & SPD, Grüne & Eichel & KMK \\
\hline Baden-Württemberg & 22.01 .1991 & $C D U$ & Teufel & $E R$ \\
\hline Rheinland-Pfalz & 21.04.1991 & SPD, FDP & Scharping & KMK \\
\hline Hamburg & 02.06 .1991 & SPD & Voscherau & ER \\
\hline Sachsen-Anhalt & 04.07 .1991 & $C D U, F D P$ & Münch & $M M K$ \\
\hline Bremen & 20.09 .1991 & SPD, FDP, Grüne & Wedemeier & ÜK \\
\hline Thüringen & 05.02 .1992 & $C D U, F D P$ & Vogel & $M M K$ \\
\hline Meckl.-Vorpommern & 19.03.1992 & $C D U, F D P$ & Seite & $K M K$ \\
\hline Baden-Württemberg & 05.04.1992 & CDU, SPD & Teufel & MMK \\
\hline Schleswig-Holstein & 05.04 .1992 & SPD & Engholm & ER \\
\hline Schleswig-Holstein & 19.05 .1993 & $S P D$ & Simonis & $E R$ \\
\hline Bayern & 28.05 .1993 & $C S U$ & Stoiber & $E R$ \\
\hline Hamburg & 19.09 .1993 & SPD, Statt & Voscherau & KMK \\
\hline Sachsen-Anhalt & 02.12 .1993 & $C D U, F D P$ & Bergner & $M M K$ \\
\hline Brandenburg & März 1994 & $S P D, F D P^{*}$ & Stolpe & $M K$ \\
\hline Niedersachsen & 13.03 .1994 & SPD & Schröder & ER \\
\hline Sachsen-Anhalt & 26.06 .1994 & SPD, Grüne* & Höppner & MK \\
\hline Brandenburg & 11.09 .1994 & SPD & Stolpe & ER \\
\hline Sachsen & 11.09 .1994 & $\mathrm{CDU}$ & Biedenkopf & ER \\
\hline Bayern & 25.09 .1994 & $\mathrm{CSU}$ & Stoiber & ER \\
\hline Meckl.-Vorpommern & 16.10 .1994 & CDU, SPD & Seite & MMK \\
\hline Saarland & 16.10 .1994 & SPD & Lafontaine & ER \\
\hline Thüringen & 16.10 .1994 & CDU, SPD & Vogel & MMK \\
\hline Bund & 16.10.1994 & CDU, CSU, FDP & Kohl & KMK \\
\hline Rheinland-Pfalz & 26.10 .1994 & $S P D, F D P$ & Beck & $K M K$ \\
\hline Bremen & 24.02 .1995 & $S P D^{*}$ & Wedemeier & $M R$ \\
\hline Hessen & 19.02 .1995 & SPD, Grüne & Eichel & KMK \\
\hline Bremen & 14.05 .1995 & SPD, CDU & Scherf & MMK \\
\hline Nordrhein-Westfalen & 14.05 .1995 & SPD, Grüne & Rau & KMK \\
\hline Berlin & 22.10 .1995 & CDU, SPD & Diepgen & MMK \\
\hline Baden-Württemberg & 24.03 .1996 & CDU, FDP & Teufel & KMK \\
\hline Rheinland-Pfalz & 24.03 .1996 & SPD, FDP & Beck & KMK \\
\hline Schleswig-Holstein & 24.03 .1996 & SPD, Grüne & Simonis & KMK \\
\hline Hamburg & 21.09 .1997 & SPD, Grüne & Runde & KMK \\
\hline Niedersachsen & 01.03 .1998 & SPD & Schröder & ER \\
\hline Sachsen-Anhalt & 26.04 .1998 & SPD* & Höppner & MR \\
\hline
\end{tabular}


Patrick Horst

\begin{tabular}{|c|c|c|c|c|}
\hline Nordrhein-Westfalen & 27.05 .1998 & SPD, Grüne & Clement & $K M K$ \\
\hline Bayern & 13.09 .1998 & CSU & Stoiber & ER \\
\hline Meckl.-Vorpommern & 27.09 .1998 & SPD, PDS & Ringstorff & KMK \\
\hline Bund & 27.09.1998 & SPD, Grüne & Schröder & MMK \\
\hline Saarland & 28.10 .1998 & $S P D$ & Klimmt & $E R$ \\
\hline Niedersachsen & 28.10 .1998 & $S P D$ & Glogowski & $E R$ \\
\hline Hessen & 07.02 .1999 & CDU, FDP & Koch & KMK \\
\hline Bremen & 06.06 .1999 & SPD, CDU & Scherf & MMK \\
\hline Brandenburg & 05.09 .1999 & SPD, CDU & Stolpe & MMK \\
\hline Saarland & 05.09 .1999 & $\mathrm{CDU}$ & Müller & ER \\
\hline Thüringen & 12.09 .1999 & $\mathrm{CDU}$ & Vogel & ER \\
\hline Sachsen & 19.09.1999 & $\mathrm{CDU}$ & Biedenkopf & ER \\
\hline Berlin & 10.10 .1999 & CDU, SPD & Diepgen & MMK \\
\hline Niedersachsen & 15.12.1999 & $S P D$ & Gabriel & $E R$ \\
\hline Schleswig-Holstein & 27.02 .2000 & SPD, Grüne & Simonis & KMK \\
\hline Nordrhein-Westfalen & 14.05 .2000 & SPD, Grüne & Clement & KMK \\
\hline Baden-Württemberg & 25.03 .2001 & CDU, FDP & Teufel & KMK \\
\hline Rheinland-Pfalz & 25.03 .2001 & SPD, FDP & Beck & MMK \\
\hline Berlin & 16.06.2001 & SPD, Grüne* & Wowereit & $M K$ \\
\hline Hamburg & 23.09 .2001 & CDU, Schill, FDP & Beust & KMK \\
\hline Berlin & 21.10 .2001 & SPD, PDS & Wowereit & MMK \\
\hline Sachsen & 18.04 .2002 & $C D U$ & Milbradt & $E R$ \\
\hline Sachsen-Anhalt & 21.04 .2002 & CDU, FDP & Böhmer & KMK \\
\hline Brandenburg & 26.06 .2002 & $S P D, C D U$ & Platzeck & $M M K$ \\
\hline Meckl.-Vorpommern & 22.09.2002 & SPD, PDS & Ringstorff & KMK \\
\hline Bund & 22.09.2002 & SPD, Grüne & Schröder & MMK \\
\hline Nordrhein-Westfalen & 06.11 .2002 & SPD, Grüne & Steinbrück & $K M K$ \\
\hline Niedersachsen & 02.02 .2003 & CDU, FDP & Wulff & MMK \\
\hline Hessen & 02.02 .2003 & $\mathrm{CDU}$ & Koch & ER \\
\hline Bremen & 25.05 .2003 & SPD, CDU & Scherf & MMK \\
\hline Thüringen & 06.06 .2003 & $C D U$ & Althaus & $E R$ \\
\hline Bayern & 21.09 .2003 & CSU & Stoiber & ER \\
\hline Hamburg & 09.12 .2003 & $C D U, F D P^{*}$ & Beust & $M K$ \\
\hline Hamburg & 29.02 .2004 & CDU & Beust & ER \\
\hline
\end{tabular}


Koalitionsbildungen und Koalitionsstrategien im neuen Fünfparteiensystem der BRD

\begin{tabular}{|c|c|c|c|c|}
\hline Thüringen & 13.06 .2004 & $\mathrm{CDU}$ & Althaus & ER \\
\hline Saarland & 05.09 .2004 & CDU & Müller & ER \\
\hline Brandenburg & 19.09.2004 & SPD, CDU & Platzeck & KMK \\
\hline Sachsen & 19.09.2004 & CDU, SPD & Milbradt & KMK \\
\hline Schleswig-Holstein & 20.02.2005 & CDU, SPD & Carstensen & MMK \\
\hline Baden-Württemberg & 21.04 .2005 & $C D U, F D P$ & Oettinger & $K M K$ \\
\hline Nordrhein-Westfalen & 22.05 .2005 & CDU, FDP & Rüttgers & KMK \\
\hline Bund & 18.09 .2005 & CDU, CSU, SPD & Merkel & MMK \\
\hline Bremen & 08.11 .2005 & $S P D, C D U$ & Böhrnsen & $M M K$ \\
\hline Baden-Württemberg & 26.03 .2006 & CDU, FDP & Oettinger & KMK \\
\hline Rheinland-Pfalz & 26.03 .2006 & SPD & Beck & ER \\
\hline Sachsen-Anhalt & 26.03.2006 & CDU, SPD & Böhmer & KMK \\
\hline Meckl.-Vorpommern & 17.09 .2006 & SPD, CDU & Ringstorff & MMK \\
\hline Berlin & 17.09 .2006 & SPD, PDS & Wowereit & KMK \\
\hline Bremen & 13.05 .2007 & SPD, Grüne & Böhrnsen & MMK \\
\hline Bayern & 09.10 .2007 & CSU & Beckstein & $E R$ \\
\hline Niedersachsen & 27.01 .2008 & CDU, FDP & Wulff & MMK \\
\hline Hessen & 27.01 .2008 & CDU* & Koch & MR \\
\hline Hamburg & 24.02.2008 & CDU, Grüne & Beust & MMK \\
\hline Sachsen & 28.05 .2008 & $C D U, S P D$ & Tillich & $K M K$ \\
\hline Bayern & 28.09 .2008 & CSU, FDP & Seehofer & KMK \\
\hline Meckl.-Vorpommern & 06.10 .2008 & $S P D, C D U$ & Sellering & $M M K$ \\
\hline Hessen & 18.01 .2009 & CDU, FDP & Koch & MMK \\
\hline Schleswig-Holstein & 20.07.2009 & $C D U^{*}$ & Carstensen & $M R$ \\
\hline Saarland & 30.08 .2009 & CDU, FDP, Grüne & Müller & KMK \\
\hline Sachsen & 30.08 .2009 & CDU, FDP & Tillich & MMK \\
\hline Thüringen & 30.08 .2009 & CDU, SPD & $\begin{array}{l}\text { Lieber- } \\
\text { knecht }\end{array}$ & KMK \\
\hline Brandenburg & 27.09.2009 & SPD, Linke & Platzeck & MMK \\
\hline Schleswig-Holstein & 27.09 .2009 & CDU, FDP & Carstensen & KMK \\
\hline Bund & 27.09.2009 & CDU, CSU, FDP & Merkel & MMK \\
\hline Baden-Württemberg & 10.02 .2010 & $C D U, F D P$ & Mappus & $K M K$ \\
\hline Nordrhein-Westfalen & 09.05 .2010 & SPD, Grüne* & Kraft & MK \\
\hline Niedersachsen & 01.07 .2010 & $C D U, F D P$ & McAllister & $M M K$ \\
\hline
\end{tabular}




\begin{tabular}{|l|l|l|l|l|}
\hline Hamburg & 25.08 .2010 & $C D U$, Grüne & Ahlhaus & $M M K$ \\
\hline Hessen & 31.08 .2010 & $C D U, F D P$ & Bouffier & $M M K$ \\
\hline Hamburg & 29.11 .2010 & $C D U^{*}$ & Ahlhaus & $M K$ \\
\hline
\end{tabular}

* Parlamentarisches Patt oder Minderheitsregierung.

Legende: $\mathrm{MR}=$ Minderheitsregierung, $\mathrm{ER}=$ Einparteiregierung $($ mit parlamentarischer Mehrheit), $\mathrm{MK}=$ Minderheitskoalition, MMK = Minimale Mehrheitskoalition (minimal winning), $\mathrm{KMK}=$ Kleinste Mehrheitskoalition (minimum winning), ÜK = Übergroße Koalition (oversize). Kursiv gesetzt sind Koalitionswechsel innerhalb der Wahlperiode des jeweiligen Parlaments. Hier ließ sich der Zeitpunkt der Koalitionsbildung nicht immer exakt bestimmen. Zur Bestimmung von Anfang und Ende eines Kabinetts wurde die in der international vergleichenden Koalitionsforschung übliche Definition verwandt. Ein Kabinett endet demzufolge dann, wenn eines der drei folgenden Ereignisse eintritt: Änderung der parteipolitischen Zusammensetzung des Kabinetts, neuer Regierungschef, Parlamentswahl (Saalfeld 2007: 205).

Quellen: Schindler 1999: 1122-1132, 1439-1462; Jun/Haas/Niedermayer (Hrsg.) 2008: passim; Bundeswahlleiter 2009: 95-127; Dokumentation der Bundestags- und Landtagswahlen sowie der anschließenden Regierungsbildung in der ZParl. 


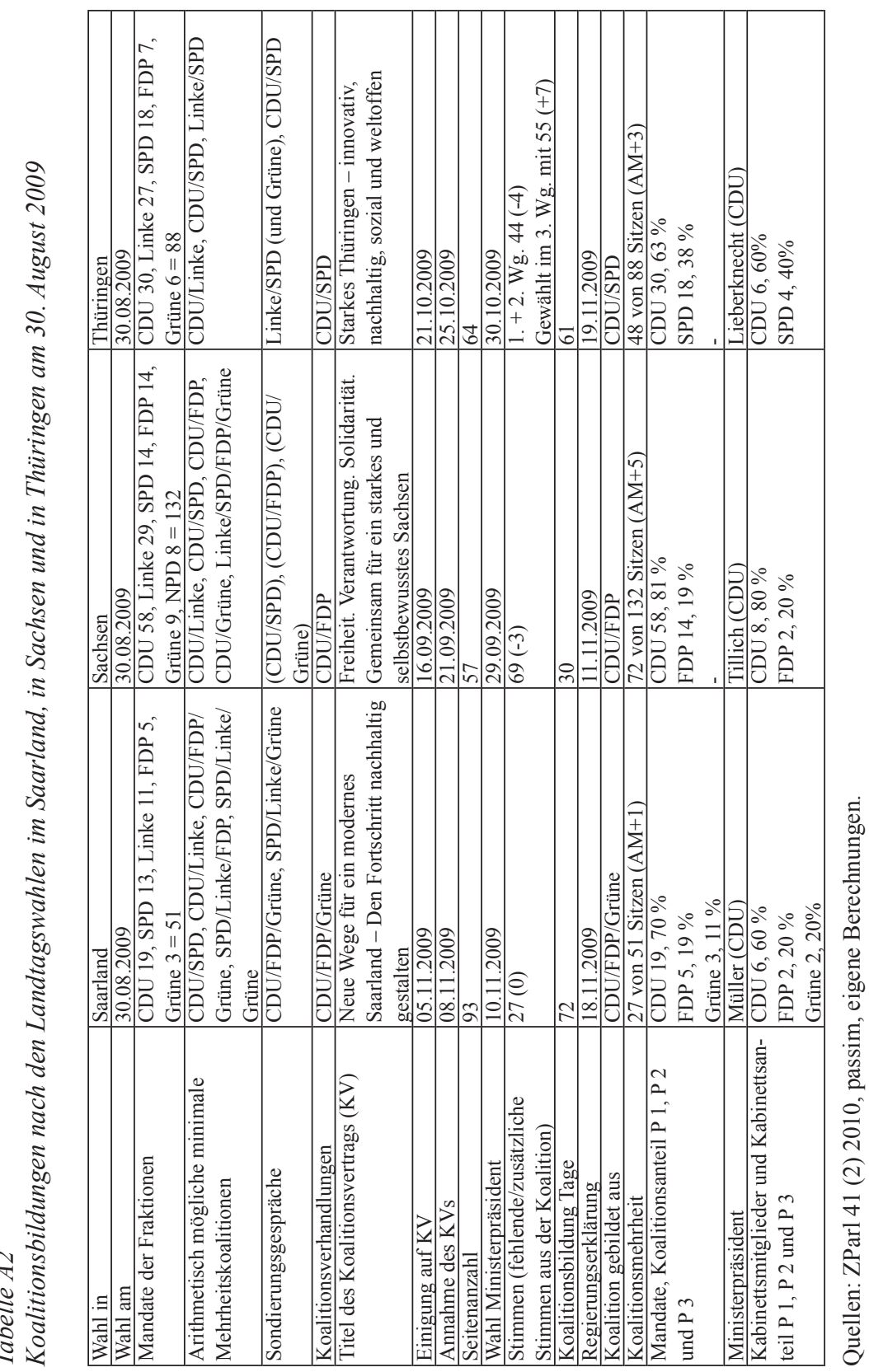




\section{Patrick Horst}

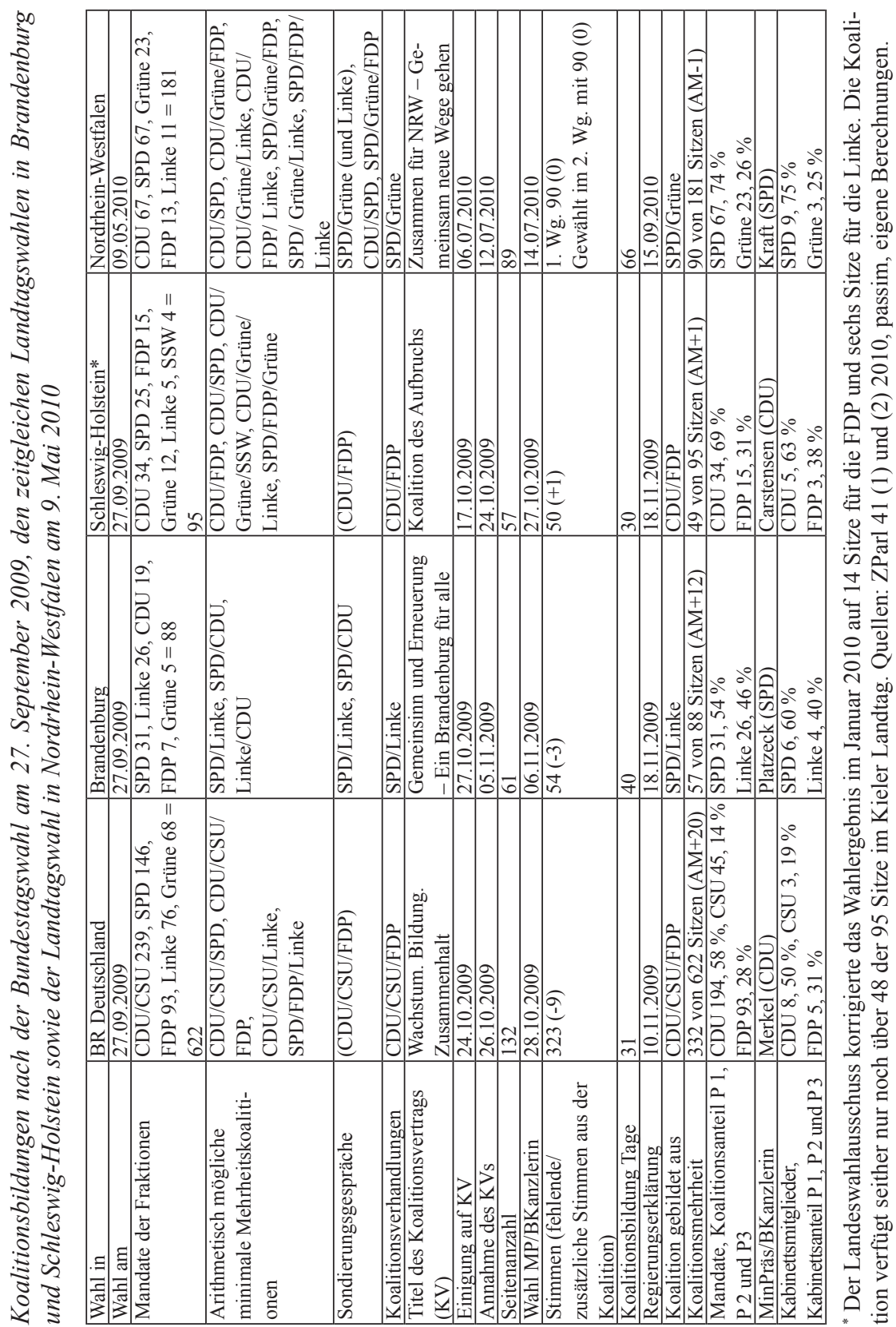

